\title{
Laboratory simulations of rainfall-induced landslide reactivation mechanisms following the 2016 Kaikoura Earthquake
}

\author{
By \\ Joshua Adam Lee
}

\begin{abstract}
A thesis
submitted to Victoria University of Wellington

in partial fulfilment of requirements for the degree of

Master of Science in Physical Geography
\end{abstract}

School of Geography, Environment and Earth Sciences

Victoria University of Wellington 


\section{Abstract}

Increases in rainfall-induced landsliding following large earthquake are well documented but the time frames over which this heightened hazard persists in the landscape remains poorly understood. Whilst it is well known that the presence of failed and partially slopes after earthquakes significantly reduces the rainfall thresholds required to activate slope movement, their failure susceptibility during specific storms and how this changes through time remains poorly studied. To improve knowledge in this field requires well-documented slope failures following earthquakes and a detailed understanding of their potential failure mechanisms when pore pressures are elevated in the slope. The $2016 \mathrm{Mw} 7.8 \mathrm{Kaik}^{-}$oura earthquake provides a unique opportunity to study how rainfall events following the earthquake may impact the timing and mechanisms of landslide reactivation.

This study conducted a suite of specialist triaxial cell experiments, designed to replicate varying rainfall scenarios on remoulded samples collected from two sites where numerous earthquake-induced landslides were recorded in similar Late Cretaceous to Neogene sediments with similar physical properties (the Leader Dam Landslides (LDL) and the Limestone Hill landslide (LHL)). In each experiment rainfall events were simulated using a series of different pore pressure scenarios (increases and decreases in mean effective stress) at representative field stress conditions whilst monitoring material deformation behaviour.

The results demonstrate that both the deformation behaviour and pore pressure required to generate failure were influenced by the previous changes in pore pressure. Samples subjected to stepped increases in pore pressure were subject to greater prefailure deformation (dilation) and subsequently failed at lower pore pressures (higher mean effective stress) when compared to samples subjected to linear increases in pore pressure. In addition, increases in the rate of pore pressure also increased the amount of pre-failure deformation allowing failure to occur when pore pressures were lower. In contrast a sample subjected to both increases and decreases in pore pressure underwent pre-failure densification and subsequently required a larger increase in pore pressure to fail. The results demonstrate that landslide reactivation is influenced by a number of factors including the amount and rate of previous changes in pore pressure and the slope drainage history.

The results provide new insights into why landslide susceptibility may remain elevated for prolonged periods of time (e.g. decades) in the landscape as well as why the rainfallthresholds for site specific failures during storms may be difficult to predict. 


\section{Acknowledgements}

First and foremost I would like to thank both my supervisors Jon Carey and Kevin Norton for helping me through the completion of my thesis. Your dedication and interest in science has helped me produce the work to the standard it is today. The approachable and easy-going nature of you both made the Masters experience an enjoyable one, from our breakfast meetings and going for mountain bike rides in lunch breaks.

Thanks to all the staff at GNS science and VUW who have helped out with my laboratory work and landslide mapping in the last year including Barbara Lyndsell, Brenda Rosser, Jane Chewings and Zane Bruce. Your input was been crucial to helping me produce the backbones of my thesis.

I want to thank my office mates in the JB Libary, especially Sam, Emily, Brenton, Theo, Stuart, it made coming into uni each day more bearable, especially with the office antics on Friday afternoons.

A massive thanks to my family, especially my parents and my sister for the unconditional support from the start of my university journey to finishing my Masters. I can't forget my Nana and Poppa who have been there right with me sending numerous care packages full of yummy baking.

Last but not least, Brittany, thank you. 


\section{Contents}

Abstract $\quad$ iii

\begin{tabular}{|l|l}
\hline Acknowledgments & v
\end{tabular}

List of Figures xi

List of Tables $\quad$ XV

1 Introduction 1

1.1 Global landslide hazard and an agent of geomorphological change . . . 1

1.2 New Zealand's landslide hazard and an agent of geomorphological change 2

1.3 Study aims and objectives . . . . . . . . . . . . . . . . . 4

1.4 Thesis structure $\ldots \ldots \ldots$. . . . . . . . . . . . . . . . . . . . . . . 4

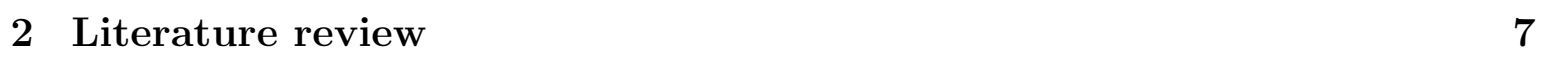

2.1 Slope stability and landslide fundamentals . . . . . . . . . . . . . 7

$2.1 .1 \quad$ Slope stability . . . . . . . . . . . . . . . . . 7

$2.1 .2 \quad$ Landslide types and failure mechanisms. . . . . . . . . . . . . . 10

2.2 Rainfall and earthquakes as failure mechanisms . . . . . . . . . . . . . 14

$2.2 .1 \quad$ Pore pressure . . . . . . . . . . . . . . . . . . . . . . 14

2.2 .2 Earthquakes . . . . . . . . . . . . . . . . . . . . . 15

2.3 Hillslope preconditioning to failure . . . . . . . . . . . . . . 16

2.4 Theoretical models and laboratory testing of rainfall-induced landslides 19

2.4 .1 Slider block friction model . . . . . . . . . . . . . . . . . . . 20

2.4 .2 Dilatancy and pore pressure feedback model . . . . . . . . . . . 21

2.4 .3 Progressive failure model . . . . . . . . . . . . . . . . . . . . 23

$2.4 .4 \quad$ Shear zone liquefaction . . . . . . . . . . . . . . . . . . . . 28

2.5 Literature review conclusions _ . . . . . . . . . . . . . . . . . . . . 30

\begin{tabular}{lll}
\hline 3 & Kaikōura and its setting & 33
\end{tabular} 


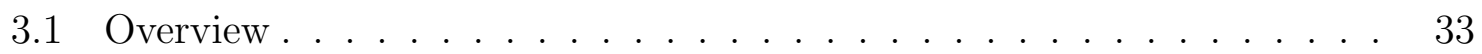

3.2 Study location and landslide mapping . . . . . . . . . . . . . . . . . . 40

$3.2 .1 \quad$ Limestone Hills Landslide . . . . . . . . . . . . . . . . . . . . . 41

3.2 .2 Leader Dam Landslide . . . . . . . . . . . . . . . . . . . . . . . 45

\begin{tabular}{lll}
\hline & Methods & 47
\end{tabular}

4.1 Sample collection $\ldots \ldots \ldots$. . . . . . . . . . . . . . . . . . . . . . . . . 47

4.2 Physical properties $\ldots \ldots \ldots$. . . . . . . . . . . . . . . . . 47

$4.2 .1 \quad$ Particle size . . . . . . . . . . . . . . . . . . . . . . . . . . . . . . 48

4.2 .2 Calcium carbonate content . . . . . . . . . . . . . . . . 48

4.2 .3 Moisture content . . . . . . . . . . . . . . . . . . . . 49

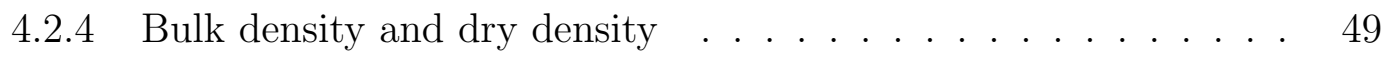

4.2 .5 Atterberg limits . . . . . . . . . . . . . . . . . . . 49

4.3 Triaxial cell testing . . . . . . . . . . . . . . . . . . . . 52

4.3 .1 Sample preparation and set up . . . . . . . . . . . 52

$4.3 .2 \quad$ Sample saturation and consolidation phases . . . . . . . . . 54

4.3.3 Conventional isotropically consolidated undrained (ICU) shearing experiments . . . . . . . . . . . . . . . . . . 55

4.3 .4 Pore pressure reinflation (PPR) testing . . . . . . . . . . . 55

$\begin{array}{lll}5 & \text { Results } & 59\end{array}$

5.1 Physical Properties . . . . . . . . . . . . . . . . . . . . 59

5.2 Triaxial cell testing . . . . . . . . . . . . . . . . . 61

5.2 .1 Consolidation behaviour . . . . . . . . . . . . . 61

5.2 .2 ICU shear strength characteristics . . . . . . . . . . . . 63

$5.2 .3 \quad$ Pore Pressure Reinflation (PPR) Testing . . . . . . . . . . . . 63

$\begin{array}{lll}6 & \text { Discussion } & 75\end{array}$

6.1 Can laboratory experiments explain the behaviour of failed landslide material?. . . . . . . . . . . . . . . . . . . 75

6.2 Given similarity between materials, is the behaviour similar? . . . . . . 77

6.3 Do changes in the pattern of pore pressure increase influence landslide behaviour?. . . . . . . . . . . . . . . . . 79

$6.4 \quad$ Is there a rate effect observed within pore pressure and displacement? . $\quad 81$

6.5 Do fluctuating pore pressures influence landslide failure behaviour? . . 83

6.6 Conceptual landslide model . . . . . . . . . . . . . . . . . 85

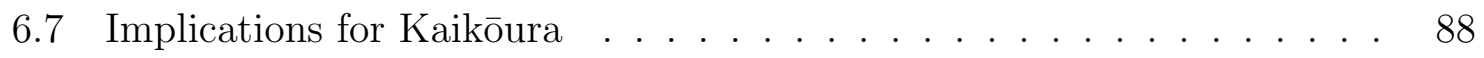

6.7 .1 Limitations and recommendations for future research . . . . . . 89 
\begin{tabular}{lll}
\hline 7 Conclusions & 91
\end{tabular}

\begin{tabular}{ll}
\hline A Appendix & 103
\end{tabular} 


\section{List of Figures}

1.1 Widespread landsliding from Cyclone Bola, March 1988, east coast, - North Island, New Zealand . . . . . . . . . . . . . . . . . . . . 3

2.1 Different stresses acting on a hillslope relating to the factor of safety equation. . . . . . . . . . . . . . . . . . 8

2.2 Key components of the Mohr-Coulomb failure criterion for stress condi- . . . . . . . . . . . . . . . . . 10

2.3 Diagram demonstrating the effect of pore pressures on soil particles. . . 15

2.4 Conceptual diagram demonstrating the effect of increasing pore pres\begin{tabular}{|c|}
\hline sures shifting the Mohr circle towards the failure envelope to an unstable \\
\hline
\end{tabular} state for failure. . . . . . . . . . . . . . . . . . . . . 15

2.5 Graphs demonstrating velocity strengthening and weakening by Helm-

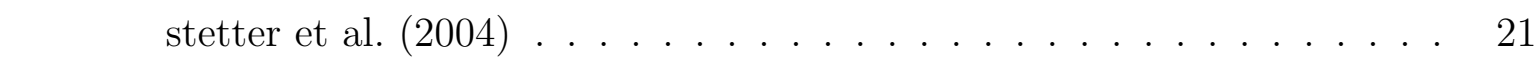

2.6 Sliding block model used for the dilatancy model described by Iverson

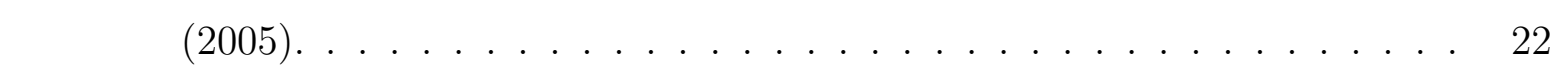

$2.7 \quad$ Inverse velocity vs time (1/v-t) trends by Petley et al. (2002) . . . . . . 24

2.8 Stages of movement for rainfall-induced landslides by Ng and Petley (2009) 24

2.9 Strain rate vs time plot for sample TC21 demonstrating failure under

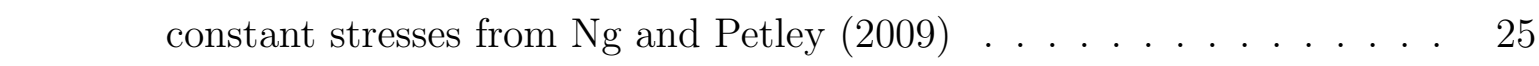

2.10 Conceptual model of the relationship between displacement rate and mean effective stress in a landslide in response to changes in pore pres-

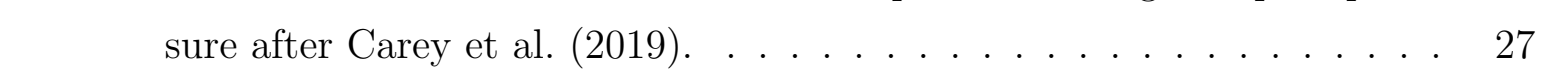

2.11 Graphs demonstrating displacement behaviour vs pore pressure for the \begin{tabular}{|c|}
\hline Utiku landslide complex in a) laboratory testing from Carey et al. (2019) \\
\hline
\end{tabular}

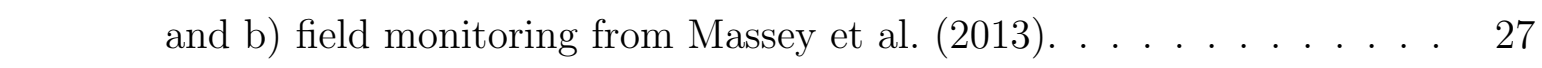

2.12 Graphs demonstrating $1 /$ velocity vs time and 1 /displacment rate vs time

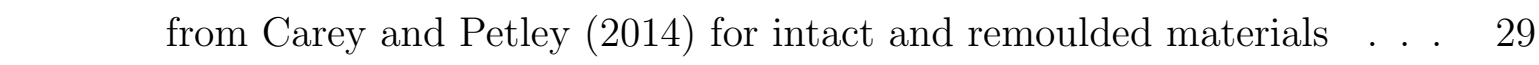

2.13 Schematic diagrams demonstrating a) conventional (mass) liquefaction

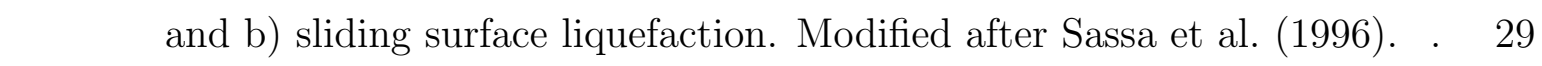


2.14 Results from undrained ring shear experiments from Wang et al. (2002) and Sassa et al. (1996) . . . . . . . . . . . . . . . . . 31

3.1 Associated faults with the 2016 Kaikōura earthquake and their relative displacements from GeoNet (2017). . . . . . . . . . . . . . . . . . 34

$3.2 \quad$ Kaikōura landslide inventory version 2.0, following the 2016 earthquake. Modified after Massey et al. (2020). . . . . . . . . . . . . . . . . . . . 35

$3.3 \quad$ Kaikōura earthquake landslide densities and logistical regression model results from Massey et al. (2020) _ . . . . . . . . . . . . . . . . 36

$3.4 \quad$ Landslides and rainfall contours for Cyclone Alison over the Kaikōura region from Rosser et al. (2020). . . . . . . . . . . . . . . . . . . . . . . 38

3.5 Landslide reactivation following Cyclone Gita (2018), north of Kaikōura 38

$3.6 \quad$ Overview map demonstrating the location of Limestone Hills Landslide (LHL) and Leader Dam Landslide (LDL) with context to New Zealand. 40

$3.7 \quad$ Simplified geology for the Kaikōura region and each study site, with the 2016 earthquake-induced landslide data set overlain . . . . . . . . . . 41

$3.8 \quad$ Aerial photograph of Limestone Hills Landslide . . . . . . . . . . . . . 42

3.9 Landslide mapping window slope statistics for LDL and LHL . . . . . . 42

3.10 Study window of spatially mapped landslides in the vicinity of LHL. . . 44

3.11 Aerial photograph of Leader Dam Landslide taken April 2017. . . . . . 45

3.12 Study window of spatially mapped landslides in the vicinity of LDL. . . $\quad 46$

4.1 Diagrams of plastic and liquid limit methodologies . . . . . . . . . . . . 50

4.2 Diagram demonstrating the key components of a triaxial cell and the associated equipment . . . . . . . . . . . . . . . 53

4.3 Schematic diagram of triaxial testing stages . . . . . . . . . . . . 56

$4.4 \quad$ Diagram representing PPR testing regimes against real time . . . . . 56

$5.1 \quad$ Passing percentage graph of particle size obtained from LDPSA results for LDL and LHL. . . . . . . . . . . . . . . . . . . . . . . 60

5.2 Casagrande plasticity chart for LHL and LDL samples . . . . . . . . . 60

5.3 Consolidation histories demonstrating axial strain vs time for all LDL and LHL tests . . . . . . . . . . . . . . . . . . . . . . . . . . . . 61

5.4 Stress path plots of deviator stress vs mean effective stress from ICU tests for both LDL and LHL . . . . . . . . . . . . . . . . . . . . . . 62

5.5 Mohr Circles constructed from ICU tests for both LDL and LHL . . . . 62

5.6 Deformation behavior of LDL and LHL during linear PPR $5 \mathrm{kPa} / \mathrm{h}$ tests 64

5.7 Linear $5 \mathrm{kPa} / \mathrm{h}$ test plots of inverse velocity (1/ Displacement rate) vs time with $\mathrm{R}^{2}$ values for both LDL and LHL . . . . . . . . . . . . . . . 64 
5.8 Split test plots for stepped $5 \mathrm{kPa} / \mathrm{h}$ tests demonstrating displacement rate and back pressure/pore pressure vs time for both LDL and LHL . 66

$5.9 \quad$ Stepped $5 \mathrm{kPa} / \mathrm{h}$ test plots of mean effective stress vs displacement rate and inverse velocity vs time for both LDL and LHL . . . . . . . . . . 67

5.10 Split test plots for stepped variable $\mathrm{kPa} / \mathrm{h}$ tests demonstrating displacement rate and back pressure/pore pressure vs time for both LDL and

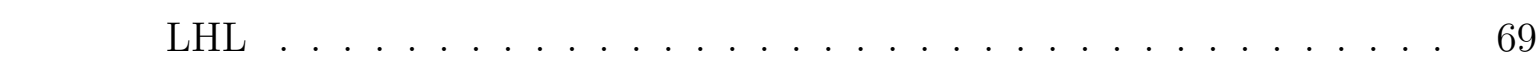

5.11 Stepped variable $\mathrm{kPa} / \mathrm{h}$ test plots for mean effective stress vs displace-

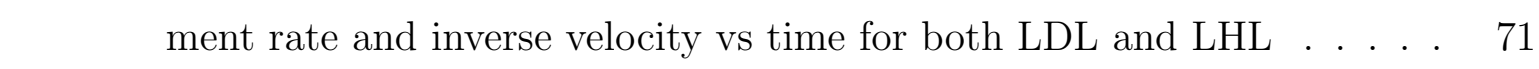

5.12 Fluctuating $5 \mathrm{kPa} / \mathrm{h}$ test summary plots for LDL . . . . . . . . . . . 73

6.1 Conceptual diagram demonstrated stages of sample behaviour for linear

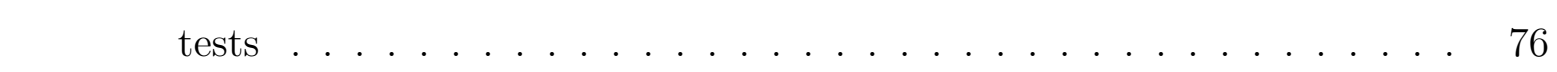

6.2 Comparison plots of sample volume vs time for all linear and stepped

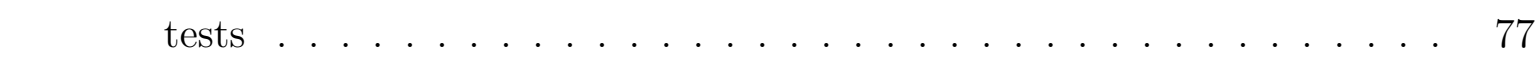

6.3 Comparison plots for linear $5 \mathrm{kPa} / \mathrm{h}$ tests of displacement rate vs mean

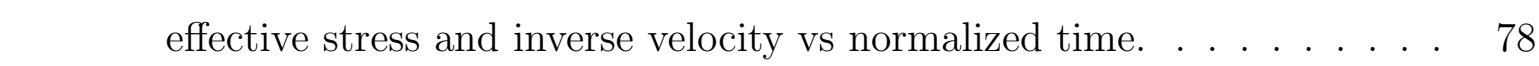

6.4 Comparison plots for stepped $5 \mathrm{kPa} / \mathrm{h}$ and stepped variable $\mathrm{kPa} / \mathrm{h}$ tests \begin{tabular}{|c|}
\hline of displacement rate vs mean effective stress and inverse velocity vs \\
\hline
\end{tabular}

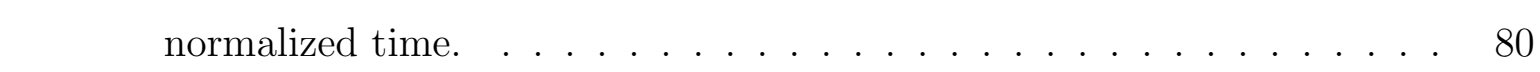

6.5 Plots demonstrating the rate effect associated with stepped variable tests. 82

6.6 Comparison plots for the LDL fluctuating $5 \mathrm{kPa} / \mathrm{h}$ test . . . . . . . . . 83

6.7 Summary plots for both LDL and LHL demonstrating displacement rate

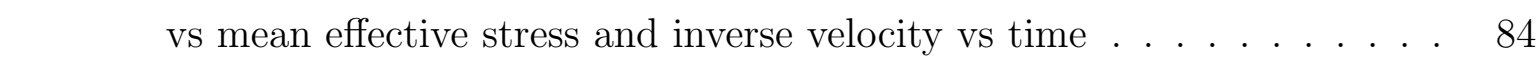

6.8 Conceptual landslide model demonstrating progressive deformation and

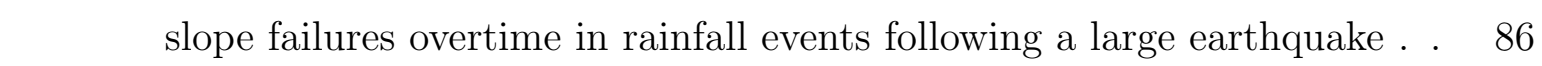

A.1 Limestone Hills Landslide (LHL) liquid and plastic limit raw laboratory

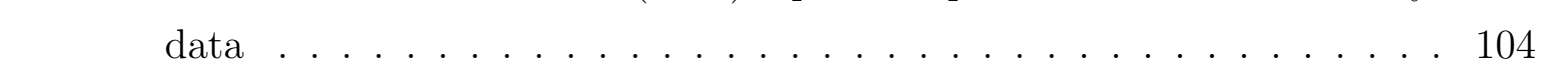

A.2 Leader Dam Landslide (LDL) liquid and plastic limit raw laboratory data105 A.3 Post test photograph of LDL PPR3 demonstrating sample barrelling. . 106 


\section{List of Tables}

$2.1 \quad$ Classification of factors contributing to mass movements in soils, after Selby (1982). . . . . . . . . . . . . . . . . . . 11

2.2 Summary of updated Varnes landslide classification after Hungr et al. (2014) . . . . . . . . . . . . . . . . . . . . 12

$2.3 \quad$ Landslide movement scale after Cruden and Varnes (1996). . . . . . . . 13

2.4 Summary of preconditioning, preparatory or triggering factors and examples of processes involved after McColl (2015) . . . . . . . . . . . . . 17

3.1 Summary of large earthquakes experienced in the Kaikōura region over the last 140 years. . . . . . . . . . . . . . . . . . . . . 33

3.2 Cyclones and their associated rainfall and return periods for Kaikōura in the last 45 years from Rosser et al. (2020) . . . . . . . . . . . . . . . 37

4.1 Summary of the ICU and PPR testing programme conducted in this study 55

$5.1 \quad$ Summary of physical properties for Limestone Hills Landslide (LHL) and Leader Dam Landslide (LDL) debris samples. . . . . . . . . . . . . 59

$5.2 \quad$ Coefficient fits for inverse velocity analysis for both LDL and LHL. . . 65

A.1 Table summarising initial test densities after producing a remoulded sample for each PPR test . . . . . . . . . . . . . . . . . . . . . 107 


\section{Chapter 1}

\section{Introduction}

\subsection{Global landslide hazard and an agent of geo- morphological change}

As a landscape evolves through time landslides represent one of the most important geomorphological processes in steep settings that contributes to its formation. In many environments landsliding is a critical process of hillslope erosion, supplying sediment to channel networks and sedimentary basins and in setting the fundamental structure of the landscape (Densmore \& Hovius, 2017). As they are, in many cases, a natural process, their unpredictable nature is a serious hazard resulting in loss of life and damage to infrastructure and property globally. For instance, they are responsible for 55,997 fatalities from 4862 catalogued distinct landslide events between 2004 and 2016 globally (Froude \& Petley, 2018), with $76 \%$ being triggered by rainfall. It is widely agreed that rainfall-induced landslides are labelled as one of the most devastating landslide types due to their rapid movement and long runout distances, potentially evolving into end members such as debris flows (Tiranti et al., 2018; Liao et al., 2012; Jakob et al., 2005). It is these factors that, combined with the unpredictable nature, pose a significant hazard to society.

Rainfall-induced landslides are a global hazard. For example, the 1966 and 1967 landslides of Rio de Janeiro and Serra das Araras Escarpment in Brazil, where Jones (1973) details widespread slides, avalanches and debris/mudflows, resulted in 1000 deaths in 
1966 and 1700 in 1967 respectively. In 2010, in Guanling Guizhou, China, 99 people were killed, and two villages buried by a rainfall-induced rockslide-debris flow (Yin, 2011). In certain cases, no deaths have been recorded, but huge economic losses have been the result, such as the 1983 Thistle debris slide in Utah, United States of America. Heavy rain and snowmelt resulted in a debris slide destroying major highways and railroads, flooding towns causing a total of approximately US\$600 million dollars in damage (Schuster \& Highland, 2001).

Complex interactions between the hazard and geomorphological change was highlighted following the $2008 \mathrm{Mw}$ 7.9 Wenchuan earthquake in Sichuan, China where heavy rainfall since the earthquake has resulted in increased susceptibility to debris flows, along with a drop in triggering threshold by 15-22\% (Tang et al., 2011). Ultimately following the earthquake on 24th September 2008, 72 debris flows were triggered killing 42 people in Beichuan County (Tang et al., 2009). Additionally, a total of 969 new landslides were triggered covering $6.9 \mathrm{~km}^{2}$ and the enlargement of 169 existing landslides covering $2.48 \mathrm{~km}^{2}$ (Tang et al., 2011). Debris flow activity has continued to occur and was still active in eight years later in 2016, causing severe damage to nearby villages and reconstruction sites from the earthquake and past debris flows (Fan et al., 2018).

\subsection{New Zealand's landslide hazard and an agent of geomorphological change}

Landslides in New Zealand, much like the rest of the world are most frequently caused by earthquakes or rainfall events (Rosser et al., 2017), with rainfall-induced landslides the most common form. For instance, rainfall-induced landsliding events take place between two to three times a year on average (Crozier, 2005, Page et al., 2000). These events can be single large events contributed to by rainfall and groundwater conditions such as the 1979 Abbotsford landslide in Dunedin New Zealand, where a 5 million $\mathrm{m}^{3}$ block slide caused a loss of 69 houses and an overall cost of damage totalling $\$ 10-13$ million (Hancox, 2008). Alternatively, they can be characterized as multiple occurrence regional landslide events (MORLE's) that have 100 's to 1000's of landslides within defined areas from 10's to 1000's of km² simultaneously (Crozier, 2018). For example, 1988 Cyclone Bola (Figure1.1), where 


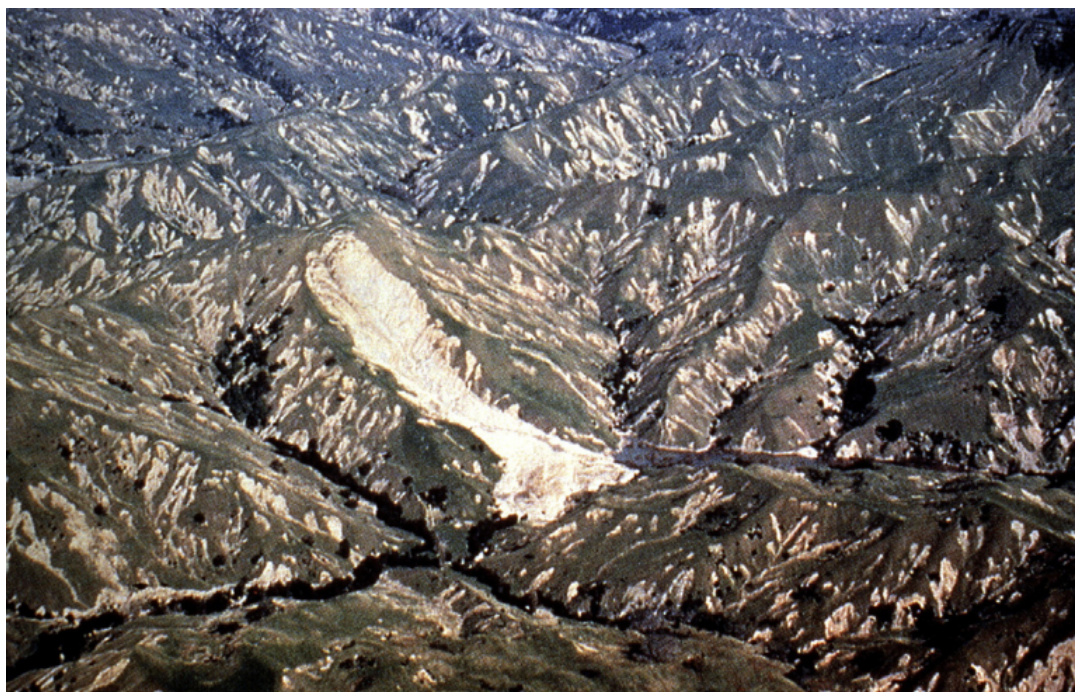

Figure 1.1: Widespread landsliding from Cyclone Bola, March 1988, east coast, North Island, New Zealand. Source: Noel Trustrum as cited in (Crozier, 2005).

rainfall intensities of $23 \mathrm{~mm} / \mathrm{hr}$ and a total of $917 \mathrm{~mm}$ in $72 \mathrm{hr}$ was received (Marden \& Rowan, 1993) and triggered widespread landsliding across the east coast of North Island New Zealand over an area of $8300 \mathrm{~km}^{2}$.

To help address the landslide problem in New Zealand, the New Zealand Landslide Database (NZLD) was developed by Rosser et al. (2017) compiling New Zealand's factual landslide data. This includes locations of landslides and investigations, types of movement, triggering events, volume and area data and damage consequences where available. All complied data helps aid and facilitate crucial landslide hazard and risk assessments as it provides factual evidence of previous landslides and can inform potential future areas at risk.

Whilst the New Zealand Landslide Database, and subsequent susceptibility mapping and investigations provide fundamental knowledge of where and how landslides may or may not occur spatially, there remains a lack of understanding around the heightened rainfall-induced landslide risk following large earthquakes. It is likely that New Zealand earthquakes could increase rainfall-induced landslide risk similar to Wenchuan (Tang et al., 2009), but to date limited research has been undertaken as very few major earthquakes have occurred with the suitable high-resolution spatial data to accurately assess landslide frequencies in the periods after major earthquakes. In addition, recent advances in laboratory testing can now be used to explore landslide susceptibility and failure mechanisms in different sediments following major 
earthquakes in response to elevated pore water pressures during rainstorms (Carey et al., 2019; Cosgrove, 2018; Carey \& Petley, 2014; Ng \& Petley, 2009). The 2016 Mw 7.8 Kaikōura earthquake provides a timely opportunity to assess rainfall-induced landslide susceptibility following a major earthquake in New Zealand and will aid in determining the largely unknown behavior of failed landslide debris.

\subsection{Study aims and objectives}

This study will undertake specialist laboratory experiments on landslide debris samples to replicate the stress conditions, and simulate their reactivation mechanisms. The key objectives are to:

1. Investigate how pore pressure scenarios influence the reactivation mechanism of failed debris using specialist laboratory equipment.

2. Infer from results how this may influence the location and timing of rainfall-induced landslides in Kaikōura, New Zealand and the potential hazard rainfall-induced landslide activity may pose.

Specifically the following research questions will be answered:

- How does stress/strain accumulation change through time with variable increases in pore pressure?

- How do failure/deformation mechanics change in response to perturbations in pore pressure?

Results will provide a new data set to improve our understanding of the rainfall induced landslide impacts following the Kaikōura earthquake, and will be relevant planning for prolonged hazards and other potential future large earthquakes in New Zealand.

\subsection{Thesis structure}

The following is an overview of chapters within this thesis which will help address the proposed research motivations:

Chapter 1 - Introduction (this chapter) provides an introduction and brief 
overview of landslides and the hazard they pose globally how they impact New Zealand. Study questions and objectives are outlined to set the intentions of this study.

Chapter 2 - Literature review details a comprehensive review of the current literature to give background for this study. The fundamentals of slope stability are covered, along with landslide types. Rainfall and earthquakes are looked in depth as failure mechanisms, along with slope preconditioning. Finally theoretical models and laboratory studies are examined and the gap which this research will fill is highlighted.

Chapter 3 - Kaikōura and its setting provides regional context of the Kaikōura, along with the tectonic and climatic history. Geomorphological mapping is undertaken for each study area to give an understanding of each study site sampled for this study.

Chapter 4 - Methods gives a comprehensive outline of the methodologies used to generate data for this thesis. These include sample collection, physical property analysis and triaxial cell methods.

Chapter 5 - Results presents the results and analysis conducted for each test completed using the triaxial cell. Tests are broken down and behavior is described in detail for each pore pressure test type.

Chapter 6 - Discussion discusses the implications of behavior observed within the results. Existing literature is used to bring findings into context. A new conceptual landslide model is proposed explaining why different slopes fail at different times under different rainfall events.

Chapter 7 - Conclusions concludes the research conducted for this thesis, highlighting the key results and how they build on knowledge around the prolonged rainfall-induced problem following large earthquakes for Kaikōura. 


\section{Chapter 2}

\section{Literature review}

\subsection{Slope stability and landslide fundamentals}

\subsubsection{Slope stability}

Landslides are defined as the movement of a mass of rock, earth and debris down a slope under the influence of gravity to find a more stable state (Highland, Bobrowsky, et al., 2008; Selby, 1982; Varnes, 1978). For failure to occur, driving forces (shear forces) must exceed resisting forces (shear resistance) within a hillslope (Figure 2.1). This balance of forces ultimately govern if a slope is stable or not and is expressed as the factor of safety (FOS) (Selby, 1982). When forces promoting stability and promoting instability are equal $\mathrm{F}=1$. When $\mathrm{F}<1$ the slope is in a state ready for failure and where $\mathrm{F}>1$, the slope is likely to be stable.

$$
\text { Factor of Safety }(\text { FOS })=\left(\frac{\text { sum of resisting forces }}{\text { sum of driving forces }}\right)=\left(\frac{\tau_{\mathrm{f}}}{\tau}\right)
$$

The major stresses acting in the FOS equation are illustrated in Figure 2.1. The driving force, known as shear stress $(\tau)$ is the down slope component (force per unit area) of the weight of the slope forming material (Bierman, 2014) that acts on a sliding or shear plane and can be written as:

$$
\tau=W \sin \beta
$$




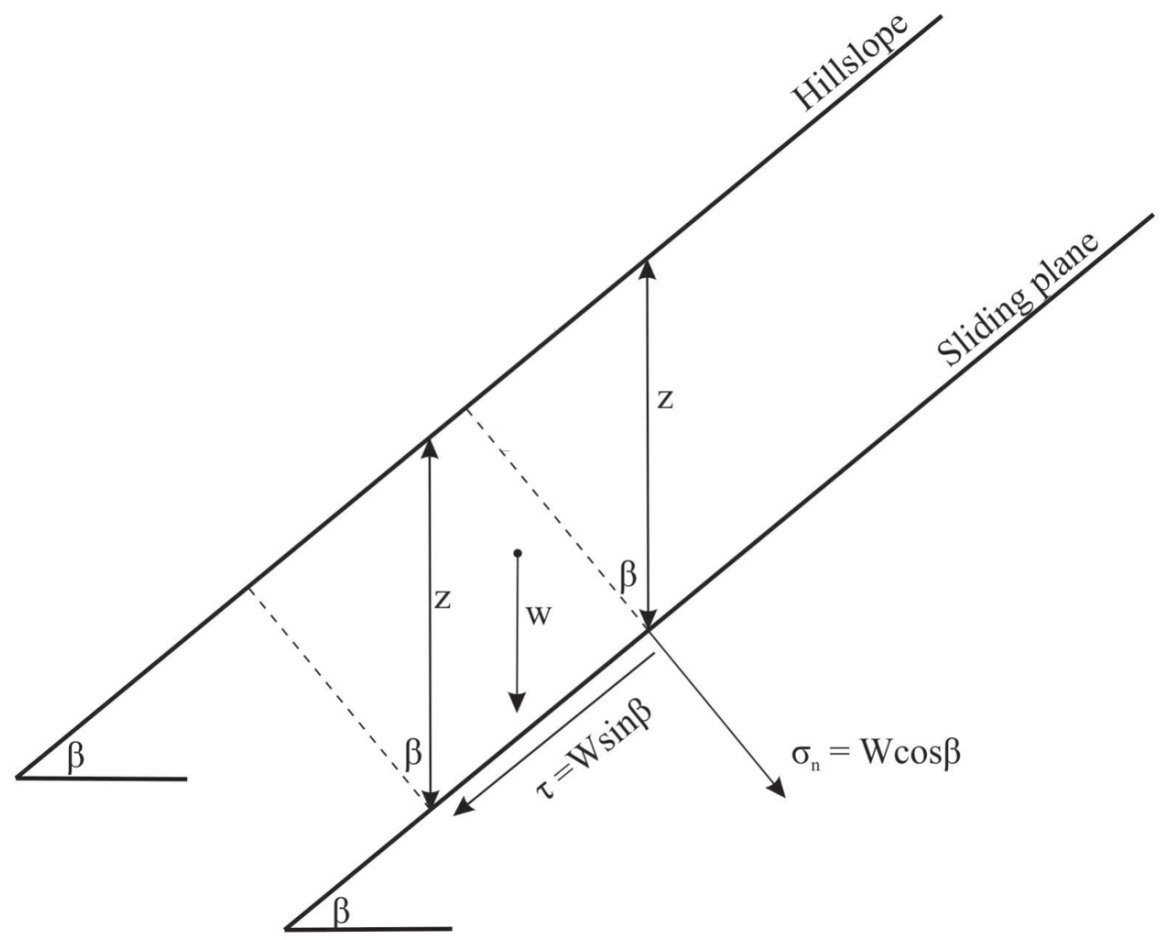

Figure 2.1: Different stresses acting on a hillslope relating to the factor of safety equation. Modified after (Selby, 1982 .

The resisting forces (shear strength $\tau_{\mathrm{f}}$ ), are defined as the materials unit weight perpendicular to the slope considered per unit area of the slope less buoyancy from water (Bierman, 2014), often referred to as the normal stress and can be written as:

$$
\sigma_{\mathrm{n}}=W \cos \beta
$$

Where $\tau=$ shear stress, $\sigma_{\mathrm{n}}=$ normal stress, $\mathrm{W}=\mathrm{m}$ (mass) $\times \mathrm{g}$ (gravity), $\beta=$ angle of the slope (Selby, 1982)

The shear strength of a soil can be defined in simple terms as the maximum shear stress a soil can withstand which is made up of three components; 1) angle of internal friction, 2) cohesion and 3) normal stress. In instances where shear stress is equal to or greater than shear strength, failure should occur (Craig, 2004). Shear stress can be expressed by the Mohr-Coulomb equation, a linear relationship between shear strength and normal stress:

$$
\tau_{\mathrm{f}}=C+\sigma_{\mathrm{f}} \tan \phi
$$

Where $\tau_{\mathrm{f}}$ is the shear stress of a soil at a point, $(\mathrm{C})$ is the cohesion, $\sigma_{\mathrm{n}}$ is the normal 
stress, at the same point and $\phi$ is the internal angle of friction. A important relationship exists between shear stress and the FOS equation, as shear stress is a driving force component therefore has influence on if failure may occur.

Research undertaken by Terzaghi (1925), demonstrated pore pressure can have an influence on the effective stress resulting in decreases in shear strength. Therefore, normal stress $\sigma_{\mathrm{n}}$ can be included in equation 2.4 and rewritten as:

$$
\tau_{\mathrm{f}}=C^{\prime}+\sigma^{\prime}{ }_{\mathrm{n}} \tan \phi^{\prime}
$$

Where $C^{\prime}$ is the apparent cohesion, $\sigma_{\mathrm{n}}^{\prime}$ is the effective normal stress (equal to $\sigma-\sigma_{\mathrm{n}}$ ), $\phi '$ is the internal angle of friction. The above equation is generally used for soils, however is applicable to porous and permeable rocks, as effective stresses can be influenced by pore pressures in these rocks (Selby, 1982).

The Mohr-Coulomb equation components are key to slope stability and each component contributes to the overall stability of a slope. Cohesion $\left(\mathrm{C}^{\prime}\right)$ is described as the bonding of soil particles together by water (capillary stresses) and other chemicals and through surface roughness causing interlocking at the microscopic level (Selby, 1982). Effective normal stress $\left(\sigma_{n}^{\prime}\right)$ is the result of the difference between the normal stress acting and pore pressure equal to the remaining normal stress (force) that is supported by a network of ridged grain to grain contacts (Bierman, 2014). The internal angle of friction is the angle measured between the normal force and resultant force at which shear failure occurs on a stress graph (Figure 2.1).

Failure thus can occur at any point in the soil where a critical combination of shear stress and effective normal stress develops from increasing pore pressure (Craig, 2004). The stress state can be presented visually through the use of a Mohr circle which is defined by the principle stresses at a point on a slope; $\left(\sigma^{\prime} 1\right)$ and $\left(\sigma^{\prime}{ }_{3}\right)$ (Figure 2.2. Graphically a straight line tangent to the principle stresses is drawn, representing equation 2.5 and defines the failure envelope. Any stress state that lies above the envelope is theoretically impossible to exist (Craig, 2004). It is important to recognise this is a simplification of stresses acting on a given slope, however this provides a practical and functional method to analyse these stresses in soil mechanics 


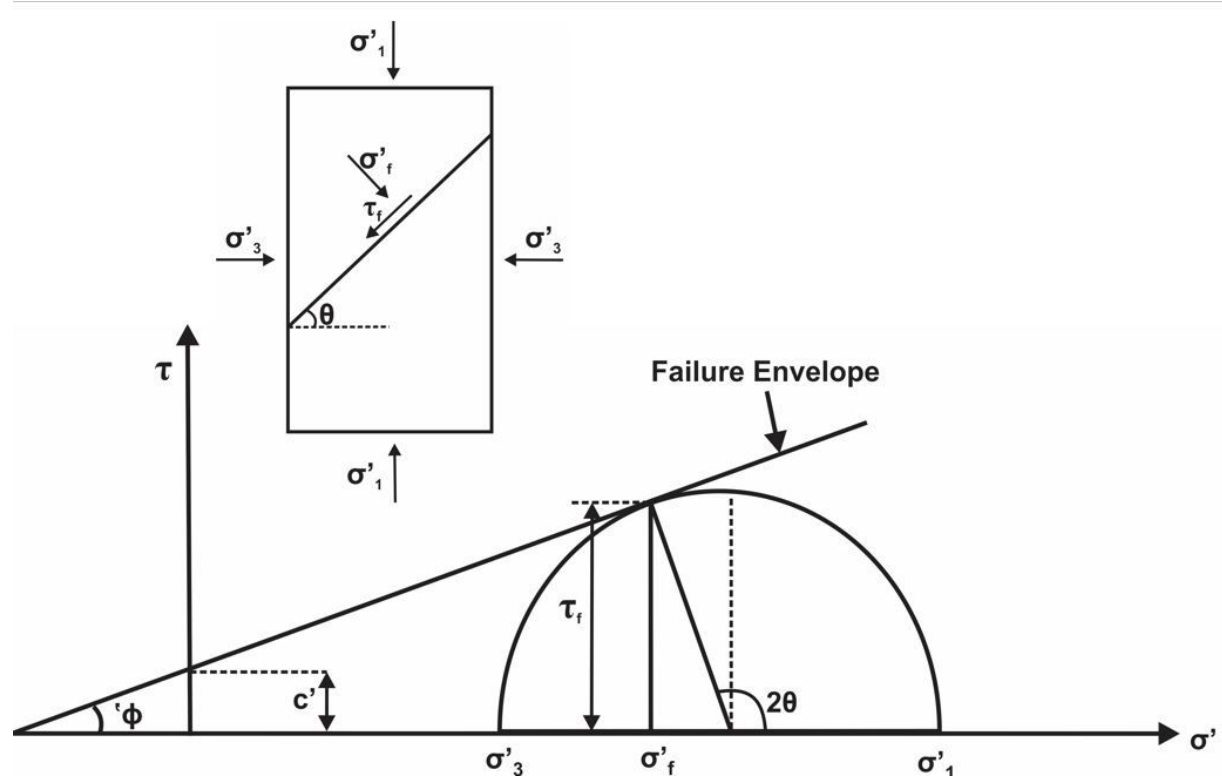

Figure 2.2: Key components of the Mohr-Coulomb failure criterion for stress conditions at failure. Where $\sigma^{\prime} 1$ and $\sigma_{3}^{\prime}=$ principal stresses, $\sigma_{\mathrm{f}}^{\prime}=$ effective normal stress at failure, $\tau_{\mathrm{f}}=$ shear strength, $\mathrm{c}^{\prime}=$ effective cohesion, $\phi^{\prime}=$ angle between major principal plane and plane of failure. Modified after Head et al. (1998)

and slope stability research.

\subsubsection{Landslide types and failure mechanisms}

Despite the understanding of the physics that govern slope instability, natural landslides remain problematic because landslides are complex as the "processes involved compromise a continuous series of events from cause to effect" Varnes 1978 . p. 26). Determining a single cause of a landslide is often difficult; it may be a combination of multiple processes that culminate in overall slope instability. Therefore, it is key to break down the initiation of process into the two main stresses that act on a slope:

1. Factors contribute to increased shear stresses

2. Factors that contribute to a reduction in shear strength

Efforts have been made by Varnes (1978) and Selby (1982), who have produced a spectrum of influencing factors, with the Selby (1982) classification summarised in (Table 2.1). Both classifications distinguish between factors contributing to high shear stress and factors contributing to low or reduced shear strength.

Due to the various factors contributing to the initiation of landslides, a variety of different types of landslides and movements exist. Efforts have been made to develop 
Table 2.1: Classification of factors contributing to mass movements in soils, after Selby (1982).

\begin{tabular}{|c|c|}
\hline $\begin{array}{l}\text { Factors contributing to high } \\
\text { shear stress }\end{array}$ & \\
\hline Types & Major Mechanism \\
\hline 1. Removal of lateral support & $\begin{array}{l}\text { (i) Stream, water, or glacial erosion } \\
\text { (ii) Subaerial weathering, wetting, drying and frost action } \\
\text { (iii) Slope steepness increased by mass movement } \\
\text { (iv) Quarries and pits, or removal of toe slopes by human activity }\end{array}$ \\
\hline 2. Overloading by & $\begin{array}{l}\text { (i) Weigh of rain, snow, talus } \\
\text { (ii) Fills, waste piles, structures }\end{array}$ \\
\hline 3. Transitory stress & $\begin{array}{l}\text { (i) Earthquakes - ground motions and tilt } \\
\text { (ii) Vibrations from human activity - blasting, traffic, machinery }\end{array}$ \\
\hline 4. Removal of underlying support & $\begin{array}{l}\text { (i) Undercutting by running water } \\
\text { (ii) Subaerial weathering, wetting, drying and frost action } \\
\text { (iii) Subterranean erosion (culviation of fines or solution of salts), } \\
\text { squeezing out of underlying plastic soils } \\
\text { (iv) Mining activities, creation of lakes, reservoirs }\end{array}$ \\
\hline 5. Lateral pressure & $\begin{array}{l}\text { (i) Water in intersitces } \\
\text { (ii) Freezing of water } \\
\text { (iii) Swelling by hydration of clays } \\
\text { (iv) Mobilization of residual stress }\end{array}$ \\
\hline 6. Increase of slope angle & $\begin{array}{l}\text { (i) Regional tectonic tilting } \\
\text { (ii) Volcanic processes }\end{array}$ \\
\hline $\begin{array}{l}\text { Factors contributing to low shear } \\
\text { strength }\end{array}$ & \\
\hline 1. Composition and texture & $\begin{array}{l}\text { (i) Weak materials such as volcanic tuff and sedimentary clays } \\
\text { (ii) Loosely packed materials } \\
\text { (iii) Smooth grain shape } \\
\text { (iv) Uniform grain size }\end{array}$ \\
\hline 2. Physico-chemical reactions & $\begin{array}{l}\text { (i) Cation (base) exchange } \\
\text { (ii) Hydration of clay } \\
\text { (iii) Drying of clays } \\
\text { (iv) Solution of cements }\end{array}$ \\
\hline 3. Effects of pore water & $\begin{array}{l}\text { (i) Buoyancy effects } \\
\text { (ii) Reduction of capillary tension } \\
\text { (iii) Viscous drag of moving water on soul grains, piping }\end{array}$ \\
\hline 4. Changes in structure & $\begin{array}{l}\text { (i) Spontaneous liquefaction } \\
\text { (ii) Progressive creep with reorientation of clays } \\
\text { (iii) Reactivation of earlier shear planes }\end{array}$ \\
\hline 5. Vegetation & $\begin{array}{l}\text { (i) Removal of trees } \\
\text { (a) reducing normal loads } \\
\text { (b) removing apparent cohesion of tree roots } \\
\text { (c) raising of water tables } \\
\text { (d) increased soil cracking }\end{array}$ \\
\hline 6 Relict structures & $\begin{array}{l}\text { (i) Joints and other panes of weakness } \\
\text { (ii) Beds of plastic and impermeable soils }\end{array}$ \\
\hline
\end{tabular}


Table 2.2: Summary of updated Varnes landslide classification after Hungr et al. (2014). Note that “*” corresponds to movement types that reach extremely rapid velocities $\left(5 \times 10^{3} \mathrm{~mm} / \mathrm{second}\right)$ as defined by Cruden and Varnes (1996).

\begin{tabular}{ccc}
\hline Type of Movement & Rock & Soil \\
\hline Fall & 1. Rock/ice fall & 2. Boulder/debris/silt fall* \\
\hline Topple & 3. Rock block topple* & 5. Gravel/sand/silt topple* \\
& 4. Rock flexural topple & \\
\hline Slide & 6.Rock rotational slide & 11. Clay/silt rotational slide \\
& 7. Rock planar slide* & 12. Clay/silt planar slide \\
& 8. Rock wedge slide* & 13. Gravel/silt debris slide* \\
& 9. Rock compound slide & 14. Clay/silt compound slide \\
10. Rock irregular slide* & \\
\hline 15. Rock slope spread & 16. Sand/silt liquefaction spread* \\
& & 17. Sensitive clay spread* \\
\hline Fpread & 18. Rock/ice avalanche** & 19. Sand/silt/debris dry flow \\
& & 20. Sand/silt/debris flowside* \\
& & 21. Sensitive clay flowslide* \\
& & 22. Debris flow* \\
& & 23. Mud flow* \\
& & 24. Debris flood \\
& & 25. Debris avalanche* \\
& & 26. Earthflow \\
& & 27. Peat flow \\
\hline Slope deformation & 28. Mountain slope deformation & 30. Soil slope deformation \\
& 29. Rock slope deformation & 31. Soil creep \\
& & 32. Solifluction \\
\hline
\end{tabular}

classifications and simplify the wide range of landslide types e.g. (Hungr et al., 2014; Cruden \& Varnes, 1996; Varnes, 1978; Nemcok, 1972; Varnes, 1958). The most commonly accepted and used classification system was proposed by Varnes (1978) which is structured by the type of material and type of movement. Hungr et al. (2014) has since updated and refined this classification to 32 types of landslides each with its own formal definition, which provides compatibility with already accepted geotechnical, geomorphological and geological terminology of soils and rocks.

Major material type categories consist of rock and soil to cover the basic types and can be further sub-divided into the following sub categories: "peat, soil, mud, clay, silt, sand, rock, boulder, debris, ice". This covers a wide range of material that is commonly associated with landslides. Much like the type of material, the kinematic movement of material can be differentiated into a spectrum of movements which includes "falls, topple, slides, spreads, flows and slope deformation". By combining the material type and movement type different landslide types can be summarised in (Table 2.2).

Falls can be described as a mass that is detached from a slope or cliff where little or no shear displacement occurs, and moves by falling, bouncing and rolling (Cruden \& Varnes, 1996). Toppling is a similar movement and is identified as the forward rotation of a unit or mass out of the slope around an axis or point below the centre of 
Table 2.3: Landslide movement scale after Cruden and Varnes 1996).

\begin{tabular}{cccc}
\hline Velocity class & Description & Velocity $(\mathbf{m m} / \mathbf{s e c o n d})$ & Typical velocity \\
\hline 7 & Extremely Rapid & greater than $5 \times 10^{3}$ & greater than $5 \mathrm{~m} / \mathrm{sec}$ \\
6 & Very Rapid & up to $5 \times 10^{3}$ & up to $5 \mathrm{~m} / \mathrm{sec}$ \\
5 & Rapid & up to $5 \times 10^{1}$ & up to $3 \mathrm{~m} / \mathrm{min}$ \\
4 & Moderate & up to $5 \times 10^{-1}$ & up to $1.9 \mathrm{~m} / \mathrm{hr}$ \\
3 & Slow & up to $5 \times 10^{-3}$ & up to $13 \mathrm{~m} / \mathrm{month}$ \\
2 & Very Slow & up to $5 \times 10^{-5}$ & up to up to $1.6 \mathrm{~m} /$ year \\
1 & Extremely Slow & up to $5 \times 10^{-7}$ & up to $16 \mathrm{~mm} /$ year \\
\hline
\end{tabular}

gravity of the mass displaced (Cruden \& Varnes, 1996). Slides are characterised by the downward movement of a mass on or above a narrow defined shear plane or rupture surface (Selby, 1982; Varnes, 1978). Slides can be differentiated further into rotational and translational (planar), where the major distinction between the two is rotational slides move across a surface that is curved and concave about an axis parallel to the ground surface and transverse across the slide. Spreads or lateral spreads generally occur on shallow or flat terrain and involve the lateral extension of cohesive soil or rock due to lateral movement of softer underlying material.

Subsidence into underlying material is often associated with this landslide type. Flows can be thought of as analogous to viscous fluids, where material moves downslope like a fluid with no well-defined internal shear planes. Flows can range from fast or slow velocities and can be wet or dry. Slope deformation is a movement type included by Hungr et al. (2014) which involves the deformation of a slope at different scales, ranging from mountains, to rocks and soil. It also includes soil creep and solifluction terms/movements for completeness.

The classification by (Varnes, 1978) has further defined complex landslides as a category whereby any landslide that consist of two movement types can fall into for example, rock slide debris avalanche. Hungr et al. (2014) has not included complex landslides as a separate category as they state "every landslide is complex to a degree" pg 167, therefore such category can prove to be not useful. Despite this, Hungr et al. (2014) suggests that composite terminology should be decided by the user of the classification.

Different landslide types due to their formation and movement type will move at different velocities downslope. Therefore a further important classification is the rate of movement to provide additional information that can be related to the magnitude of damage from a landslide. Varnes (1958) initially proposed a classification for the 
rate of movement based on the velocity class, description, velocity and the typical velocity for boundaries between velocity classes. Nemcok (1972) additionally proposed a division of four similar velocity ranges. Cruden and Varnes (1996), has refined (Varnes, 1958) classification further to include SI units which range from $\mathrm{m} / \mathrm{sec}$ to $\mathrm{mm} /$ year (Table 2.3).

\subsection{Rainfall and earthquakes as failure mechanisms}

\subsubsection{Pore pressure}

The saturation of slopes by water is one of the key causes of landsliding as discussed in section 1.1 and 1.2. The infiltration of water into a slope has several ways it can influence stability. In dry soil, the absence of water results in atmospheric pressures; the soil fabric is supported by particle contacts and voids within the soil are filled with air (Figure 2.3). Pore pressures are therefore zero. In partially saturated soils, surface tension is created from water between particles and pore pressure is negative as particles are effectively under suction (Figure 2.3). Fully saturated soils behave differently, as the lack of surface tension results in a loss of apparent cohesion in the soil. This is contributed by the transfer of normal stress from overburden to soil, resulting in a buoyancy effect where pore pressures are positive and particles pushing each other apart. This loss of cohesion ultimately leads to failure as a reduction of effective normal stress and shear strength in the soil occurs (Selby, 1982).

Rainfall saturating these slopes has spatial and temporal variability, however the way it is received in terms of duration and intensity is an important factor for rainfall-induced landslide activity. Minimum rainfall amounts (thresholds) exist whereby landslides are not likely to initiate under, rainfall amounts greater than this threshold is likely to result in landslide initiation (Crosta \& Frattini, 2001; Caine, 1980). Rainfall triggering thresholds are a simple way to express the impact increasing pore pressures have across a large scale e.g. regional thresholds (Glade et al., 2000; Glade, 1998). However the stresses e.g. effective stresses cannot be visualised as part of these thresholds and thus require to be graphically observed on a 

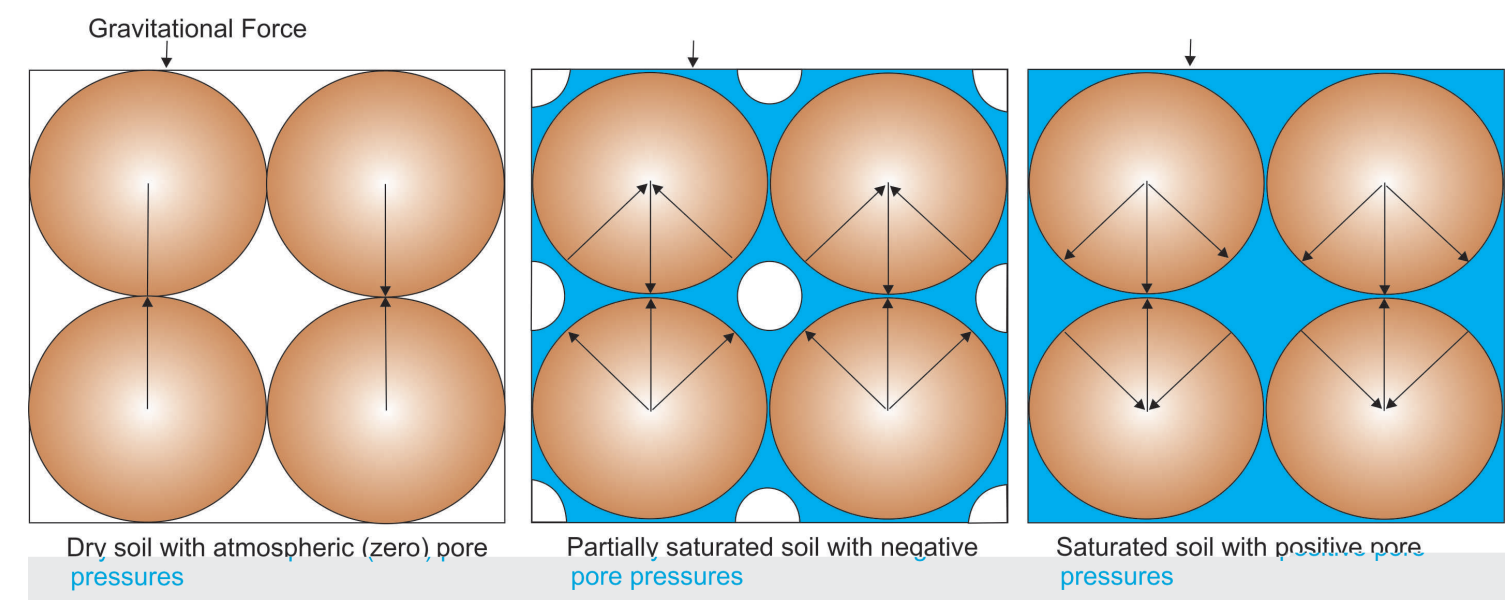

Figure 2.3: Diagram demonstrating the effect of different pore pressures on soil particles. Modified after Selby $(1982)$.

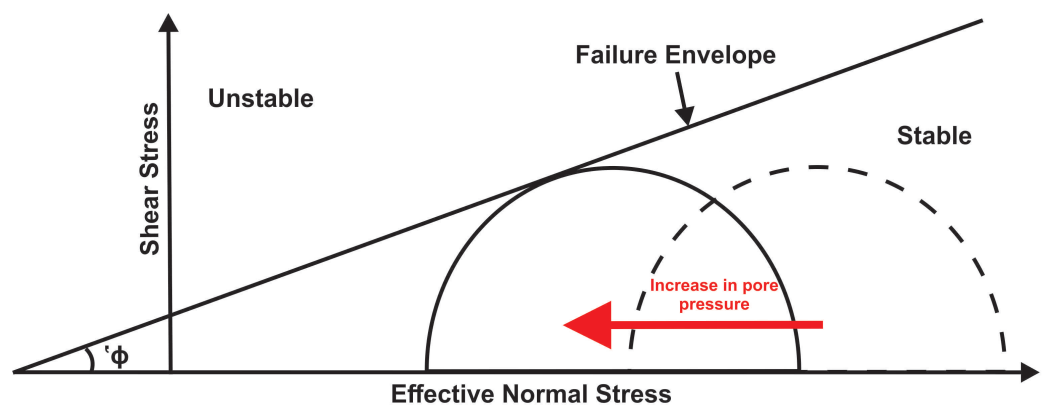

Figure 2.4: Conceptual diagram demonstrating the effect of increasing pore pressures shifting the Mohr circle towards the failure envelope to an unstable state for failure.

Mohr circle (Figure 2.4) along with equation 2.5. Whereby the original principle stresses plotted shift to the left as a result of an increase in pore pressure, shifting the soil to an unstable state. Terzaghi (1936) concluded that the differences between the normal stress transmitted on inter-particle contacts and the stress supported by pore pressure is equal to the effective normal stress.

\subsubsection{Earthquakes}

Earthquakes are well-documented events which cause widespread damage including triggering landslides, as a result of seismic energy release causing extreme ground shaking. Earthquake-induced landslides have been shown to concentrate around the areas of highest seismic intensity or Peak Ground Acceleration (PGA) and Peak Ground Velocity (PGV) (Parker et al., 2015; Nakamura et al., 2014; Chen et al., 2012; Gorum et al., 2011; Khazai \& Sitar, 2004) which can be explained by the highest ground shaking occurring at these localities. Spatial distributions of landslides have been also found to correlate with the proximity to faults; where 
landslides often follow fault traces and clustering decreases perpendicular to faults e.g. Wenchuan earthquake (Xu et al., 2011) Chi-Chi (Khazai \& Sitar, 2004) and Kaikōura earthquakes (Massey et al., 2020; Massey et al., 2018). At a hillslope scale, convex slopes and their associated moderate to steep slopes angles are most common where landslides are triggered in earthquake events (Massey et al., 2018; Gorum et al., 2011; Khazai \& Sitar, 2004), nowever, site effects in the form of topographic amplification have a strong influence on landslide location. Meunier et al. (2008) demonstrate that various earthquakes from different localities including California, Chi-Chi, Taiwan and Papua New Guinea show seismic amplification occurring near ridge crests matching the spatial pattern of these landslides. It is important to acknowledge that each factor individually e.g. ground motion, hillslope gradient and geology cannot explain the whole landslide distribution and occurrence, but it is a combination of these factors that control the distribution (Massey et al., 2020; Massey, et al., 2018; Parker et al., 2015; Chen et al., 2012). While it is clear that lanusliues can be triggered by earthquakes and rainfall, a set of more complex factors, can precondition slopes for failure.

\subsection{Hillslope preconditioning to failure}

Hillslope pre-conditioning is the term to describe factors that influence the stability of a hillslope and "conditions" them for failure by triggering events. Pre-conditioning factors can be divided into two categories; intrinsic attributes (e.g. strength, geology, topography) at that site and extrinsic factors (e.g. earthquakes and heavy rainfall), whereby both factors contribute to the occurrence of landslides. An important distinction is that preconditioning factors are factors that influence the inherent strength of a given slope and over human time scales are deemed to be temporally unchanging (McColl, 2015). A range of preconditioning factors has been summarised by McColl (2015) in (Table 2.4). It is important to note overlap occurs between preconditioning factors and preparatory factors. For example, a site may be subject to high weathering rates, therefore the slope material is weathered; however, this site is also predisposed to the process of weathering which is causing a reduction in inherent strength. 

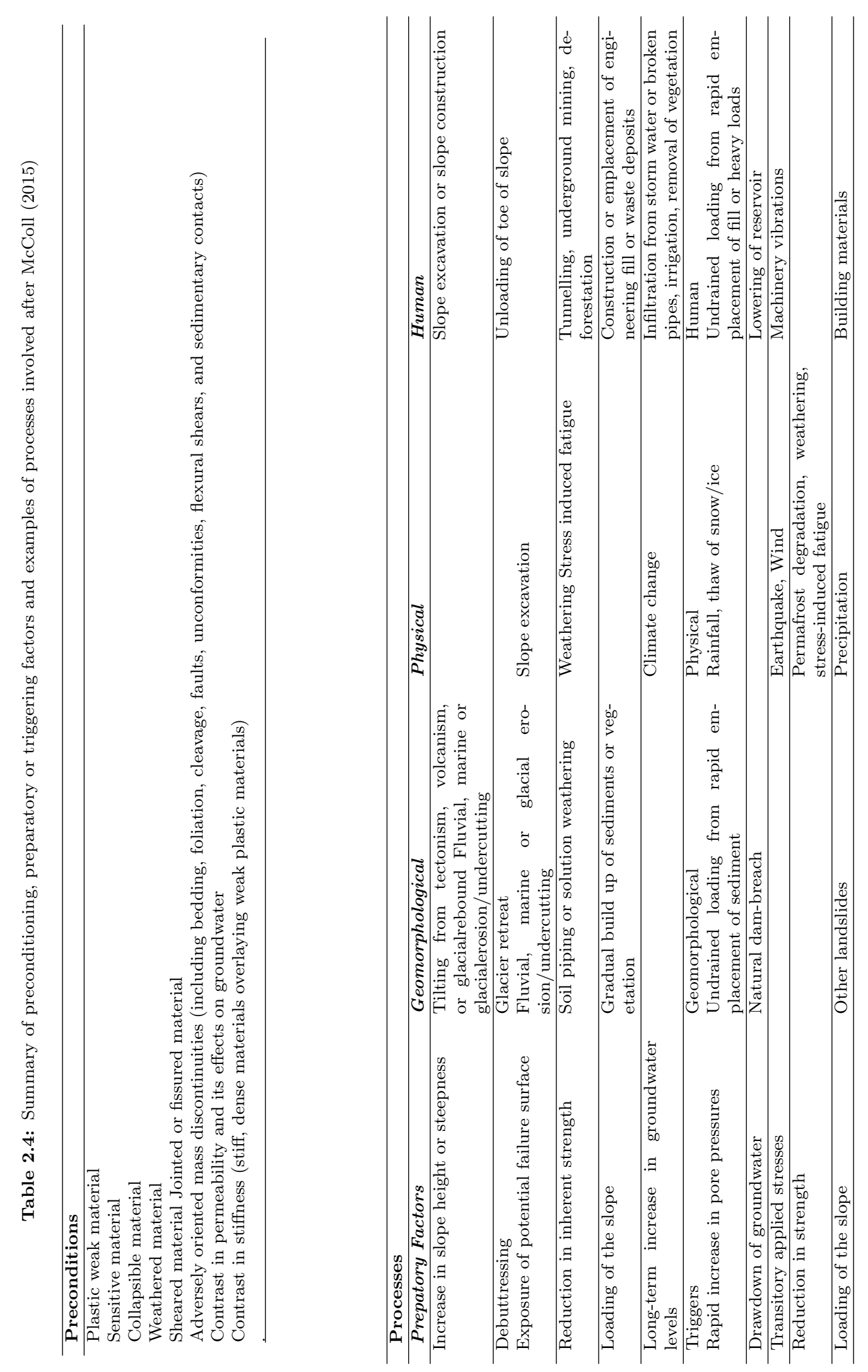
Ultimately preconditioning and preparatory factors are not the factors that trigger a landslide but are the factors that help contribute and condition the slope to be in a state for a trigger to cause failure.

Distinctions between factors have been made, but the influence of earthquakes as a preconditioning factor has ambiguity as varying influences over different time scales exist. Parker et al. (2015) undertook analysis on the spatial distributions of landslides triggered from the 1929 Buller (Murchison) and 1968 Inangahua earthquakes in northwest South Island of New Zealand. Their results demonstrated hillslopes from the 1929 earthquake that did not fail were subject to progressive brittle accumulation and subsequently failed in the following 1968 earthquake. This suggests damage persists in hillslopes that do not fail during or post-earthquake and have only been weakened for failure in the next triggering event. Following the 2011 Christchurch earthquake risk assessments by Massey, Della Pasqua, et al. (2014) and Massey, Taig, et al. (2014) found the strength of rock masses forming slopes in the Richmond Hill and Redhill localities were significantly reduced through earthquake-induced fractures and movement. These results agree with Parker et al. (2015) as slopes are now weakened and further ground movements and chemical and physical properties and wetting/drying will continue to weaken the slope until the next triggering events.

Contrary to this, Brain et al. (2017) conducted tests using a dynamic back-pressured shearbox to simulate earthquake ground shaking on ductile hillslope material. They conclude that ground-shaking events before the main aftershock that do not cause landslide strain accumulation, can result in increases in bulk density and inter-particle friction. Ultimately this suggests seismic events can cause co-seismic shear strength increases and can potentially reduce hillslope susceptibility in future seismic events.

Elevated landsliding due to rainfall events following large earthquakes highlights another prominent preconditioning factor observed in China and Taiwan. Following the 2008 Wenchuan earthquake, Tang et al. (2011) identified within four months 969 new landslides and 169 existing landslides that were enlarged, combined with a decrease in the accumulated rainfall triggering threshold by $15-22 \%$. This was explained by the widespread destabilized of landslide debris from the earthquake, increasing susceptibility to failure. Similar results were observed by Hovius et al. 
(2011) who demonstrated mass wasting in the form of landslides had increased more than five times above the background rate following the 1999 Chi-Chi earthquake. Along with a decrease in maximum effective cumulative precipitation for the rainfall threshold of 50\% (Shieh et al., 2009). Both examples demonstrate rainfall events following large earthquakes are an alternative process by which increased landsliding occurs. Earthquakes set up conditions for rainfall-induced landsliding but are not the dominant cause as the landslides do not rely on the next earthquake, instead the next major rainfall event.

It is clear there is uncertainty in the influence that earthquakes have on hillslopes in different tectonic settings; whether the influences cause hillslope weakening or strengthening or is a combination of the earthquakes and other external factors. As such, it is difficult to determine the exact causes of failure in natural hillslopes. All factors must be considered to determine the likelihood of landslide initiation and distribution. Laboratory testing provides a unique approach whereby the stress conditions within and landslide shear surface can be simulated and deformation response can be used to infer slope movement patterns and failure mechanisms.

\subsection{Theoretical models and laboratory testing of rainfall-induced landslides}

The forces acting on a landslide during deformation are complex to replicate, but are achievable through theoretical models and laboratory testing. A wide range of work has been conducted to advance the understanding of how landslides behave, i.e. (Carey et al., 2019; Cosgrove, 2018; Carey \& Petley, 2014; Ng \& Petley, 2009; Iverson, 2005; Helmstetter et al., 2004; Petley et al., 2002; Wang et al., 2002; Wang \& Sassa, 2002; Sassa et al., 2000; Sassa et al., 1996). The following models and behaviours will be discussed with supporting laboratorical data:

- Slider block friction model

- Dilantancy and pore pressure feedback model

- Progressive failure model

- Shear zone liquefaction 


\subsubsection{Slider block friction model}

Helmstetter et al. (2004) developed a physical model based on the slider block model using state and velocity dependent friction laws established in laboratory environments. The model generalizes and accounts for Voight (1988a) and Voight (1988b) observations that catastrophic landslide acceleration displacements preceding failure are empirically found to to follow a time to failure power law, corresponding to a finite singularity of the velocity (approaching roughly 0/stable) (Helmstetter et al., 2004). The model accounts for observations by Voight (1988a) where movement is dependent on the ratio B/A for two parameters 1) rate and state friction law and 2) initial frictional state of the sliding surfaces produced by a reduced parameter $\mathrm{X}_{\mathrm{i}}$. Essentially, when $\mathrm{B}<\mathrm{A}$ friction increases with slip velocity, therefore resisting the increasing velocity and produces a stable state. Alternatively, when $\mathrm{B}>\mathrm{A}$ friction does not increase with increasing velocity and an unstable state is reached.

Helmstetter et al. (2004) demonstrates that upon the initial states and variables, four possible regimes can be characterised (Figure 2.5):

1. velocity weakening and acceleration

2. velocity strengthening and constant/stable acceleration

3. velocity weakening and deceleration

4. velocity strengthening and deceleration

The model was used to undertake quantitative analysis on two landslides, Vaiot (Italy) and La Clapi'ere (France) by completing inversions of a slider block model on displacement data sets. Both landslides demonstrated good fit to observations where the Vaiot landslide identified with the unstable velocity weakening regime, while the La Clapie're landslide for an accelerating phase between 1982- 1987 gave B/A $<1$, corresponding to the stable regime. It is important to note the friction model used on real data assumes properties of the material are part of the key parameters set and initial conditions outlined.

Helmstetter et al. (2004) additionally suggests that accelerating patterns are generated from crack nucleation and propagation proposed by Petley et al. (2002) can also be produced by friction, demonstrated by the power law in this study. However, it is not clear whether the frictional law should change for ductile material as the 

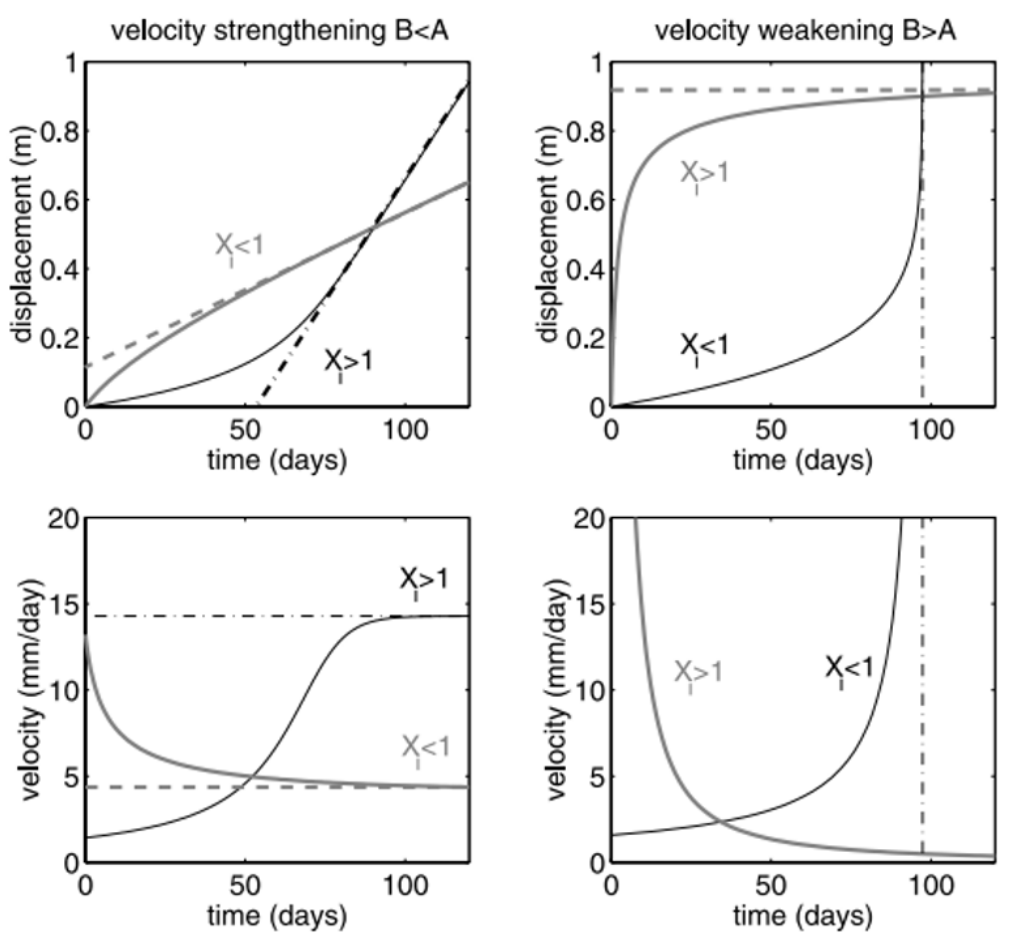

Figure 2.5: Graphs demonstrating displacement, velocity and state variable $\left(\mathrm{X}_{\mathrm{i}}\right)$ vs time for both velocity strengthening and weakening regimes by Helmstetter et al. (2004). Bold grey lines represent decreasing velocity and increasing state variables. Thin grey lines represent increasing velocities and decreasing state variables. Note: If $\mathrm{X}_{\mathrm{i}}>1$ sliding velocity increases and if $\mathrm{X}_{\mathrm{i}}<1$ sliding velocity decreases.

model by Helmstetter et al. (2004) requires the presence of an interface. Work by Petley et al. (2002) demonstrates the ability to determine between brittle and ductile deformation, this could be completed for the frictional model case by Helmstetter et al. (2004) if direct observations of the shear zone was available.

\subsubsection{Dilatancy and pore pressure feedback model}

Further to the work of Helmstetter et al. (2004), another model based around a sliding block was developed by Iverson (2005) incorporating the feedback between displacement and shear zone dilation/contraction that modulates basal pore pressure and sliding friction for a landslide. The model builds on the proposed consolidation model developed by Hutchinson (1986) whereby both model's translation (movement) is regulated by basal pore fluid pressure obeying a one-dimensional consolidation equation. Differently to Hutchinson (1986), Iverson (2005) based their model centrally around pore pressure feedback, which is absent in Hutchinson's model. The model developed can be thought of as a sliding block moving down a slope (Figure 2.6 whereby stress is defined by Newton's second law and basal Coulomb friction. 


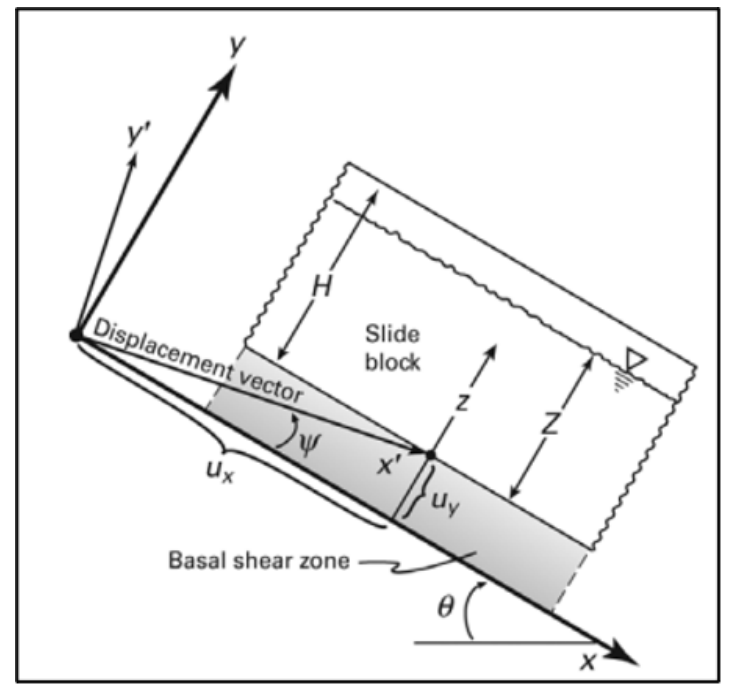

Figure 2.6: Sliding block model used for the dilatancy model described by Iverson 2005).

Feedback between the displacement, shear zone volume change and pore pressure is controlled by a dimensionless parameter $(\alpha)$ which more importantly is dependent on dilatancy angle $(\psi)$ and the timescales for the generation and dissipation of pore pressure (Figure 2.6). Two main conditions prevail:

If $\alpha<0$ (dilatancy angle is negative) positive pore pressure feedback takes place, the shear zone contracts, and runaway acceleration will likely occur.

If $\alpha>0$, (dilatancy angle is positive) negative pore pressure feedback takes place, the shear zone dilates, and slow steady displacement occurs by rainfall infiltration into the material.

For case two, $(\psi)$ is required not to decay largely and will stabilize to become increasingly large in dormant periods of landslide movement (shear zone dilation). Iverson (2005) result's agree with previous field observations e.g. Schulz et al. (2009) which demonstrate in a field experiment that changes in dilatancy is associated with decreases in pore pressures. Therefore, highlighting the important relationship between pore pressure and displacement as dilation can regulate pore pressure and movement while contraction causes increased landslide movement through building pore pressure. 


\subsubsection{Progressive failure model}

Whilst, important efforts have been made by (Iverson, 2005: Helmstetter et al., 2004), links between laboratory testing and models are needed, demonstrated by the progressive failure model by Petley et al. (2002). The progressive failure model proposes that in many cases landslide movement occurs along either a broad shear zone through ductile deformation or a discrete shear surface as a result of crack propagation. Petley et al. (2002), studied a series of accelerating landslides and found two distinct two movement styles when their inverse velocity $(1 / \mathrm{v})$ was plotted over time $(1 / \mathrm{v}-\mathrm{t}$ space). The first style of movement demonstrates a linear trend in $1 / \mathrm{v}$ against time, whereby inverse deformation rate has a negative gradient toward $1 / \mathrm{v}=$ 0 at which point velocity theoretically becomes infinitely large and a catastrophic failure occurs. Petley et al. (2002) argue this failure style occurs in cohesive materials as a result of brittle deformation as observed in monitoring data from the Selborune Cutting experiment (Figure 2.7). In these materials, failure propagates through the initial development of micro-cracks which eventually coalesce and nucleate to form a singular shear surface along which rapid failure can occur. A second movement style was also observed which was characterised by an asymptotic trend in $1 / \mathrm{v}-\mathrm{t}$ suggesting landslide movement trends towards a final steady-state rather than catastrophic failure (Figure 2.7).

It is important to recognise while this methodology can have a critical role in forecasting landslide movement and failure, the crack propagation is largely based on first time failures in cohesive materials. Therefore, cohesive materials are more likely to demonstrate brittle deformation behaviours through localised deformation. The distinction that ductile behaviour is characteristic of asymptotic patterns is important as this may be more realistic in non-cohesive remoulded materials, as previously failed materials in Kaikoura fall into this category.

Laboratories testing through the use of both triaxial cell and dynamic back-pressure shear box (DBPSB) experiments (Carey et al., 2019; Carey \& Petley, 2014, Ng \& Petley, 2009) have since supported observations of Petley et al. (2002). Ng and Petley (2009) undertook pore pressure reinflation (PPR) testing using a triaxial cell testing on cohesive material from a landslide at Tung Chung on Lantau Island, Hong Kong. 


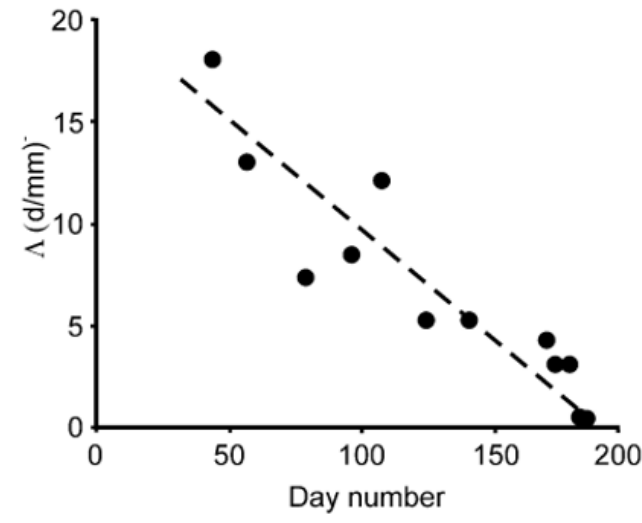

(a)

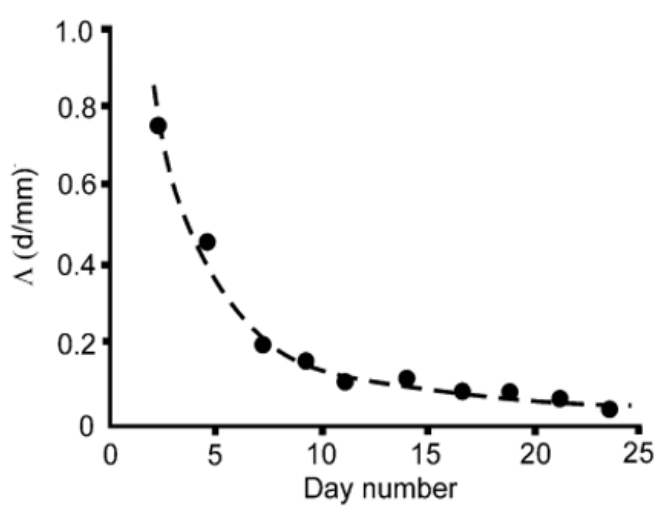

(b)

Figure 2.7: Inverse velocity vs time trends by Petley et al. (2002), identifying a) linear 1/v trend and b) asymptotic $1 / \mathrm{v}$ trend. Note: $\wedge=1 /$ velocity.

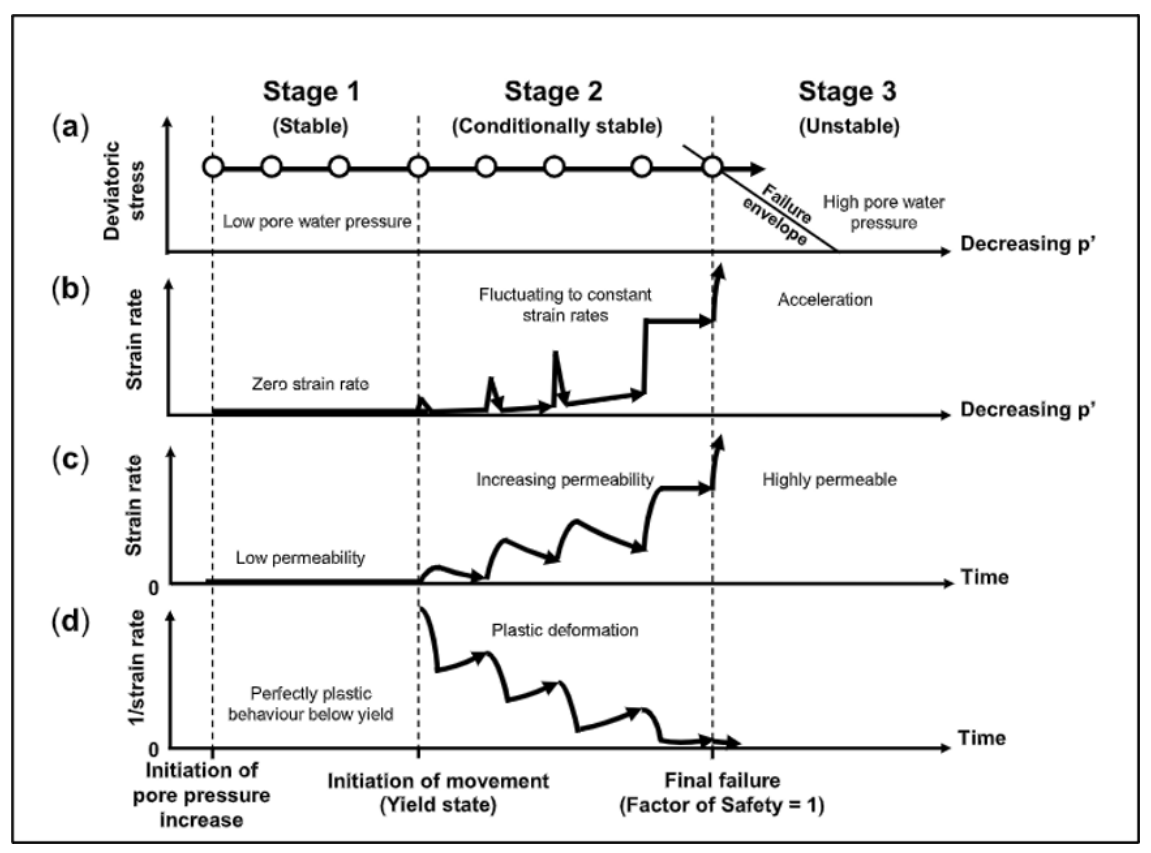

Figure 2.8: Schematic diagrams demonstrating three main stages of rainfall-induced landslide movements within residual soils after $\mathrm{Ng}$ and Petley (2009). Note circles in graph (a) represent instantaneous increases in pore pressure pressure. 
(a)

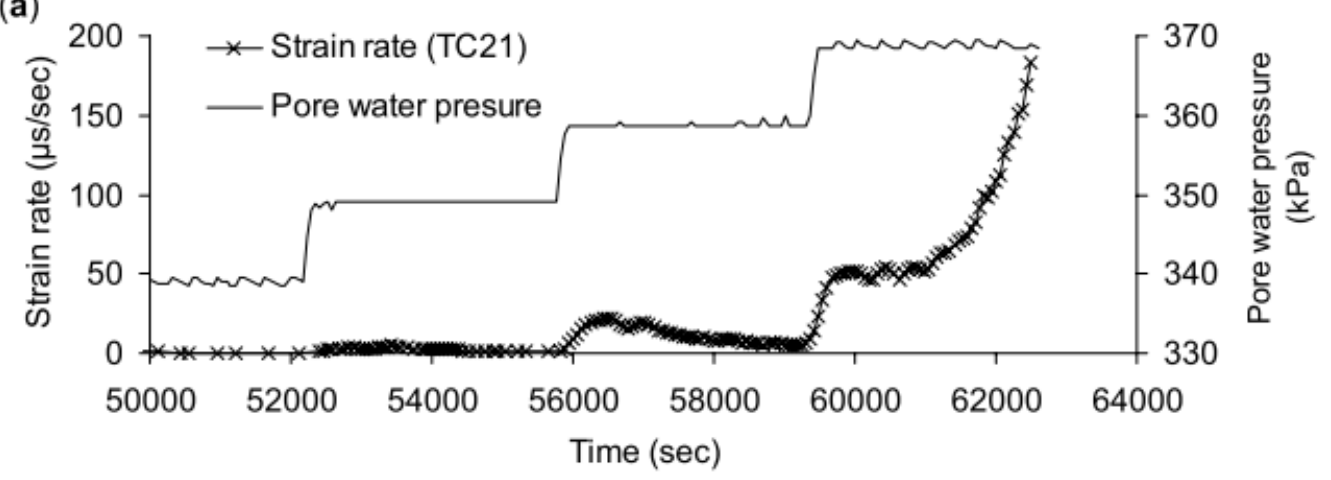

Figure 2.9: Strain rate and pore pressure vs time for sample TC21 after 50,000 seconds from Ng and Petley (2009).

Intact landslide samples were fully saturated, isotropically consolidated to predetermined effective stress states and then underwent a shearing phase. For the PPR phase samples were subject to linear and stepped increases in PWP at rates of $1,5,10 \mathrm{kPh}^{-1}-1$ with the addition of 15 and $50 \mathrm{kPh}^{-1}$ rates to analyse the relationship between displacement and pore pressure. Ng and Petley (2009) demonstrate development to failure has a close relationship with pore pressure and three key stages of movement exist (Figure 2.8):

1. Initial strain accumulation at low strain rates

2. The fluctuation of strain rates

3. Rapid acceleration to failure

A decrease in mean effective stress in stage one with stress is characterised by relatively low strain rates. Further non-linear pore pressure increase will cause pulsed movement in the landslide (stage two). This strain rate fluctuates within stage two in response to fluctuations in pore water pressure and therefore mean effective stress. Landslides can fluctuate between stage one and two until an event e.g. rainfall results in a large enough increase in pore pressure and thus acceleration to failure i.e stage three. While it is easy to categorise a landslide into stages of movement, $\mathrm{Ng}$ and Petley (2009) state the progression of movement is likely to be a continuum.

$\mathrm{Ng}$ and Petley (2009) propose that their results can explain the mechanism by which stick-slip movement e.g. (Allison \& Brunsden, 1990) occurs where rapid slip events (i.e stage 2) are associated with short pulses in movement due to a rapid pore pressure increase. Asymptotic 1/v patterns agree with (Petley et al., 2002), whereby progressive ductile deformation i.e stages two and three are characterised by 
movement in response to pore pressure behaviour. It is also emphasized that accelerated movement to failure can also take place under constant pore pressure (Figure 2.9). This suggests the movement is progressive and landslides can reach the required critical stresses for failure e.g. Factor of Safety $=1$, but internal deformation e.g. internal restructuring must occur to bring the material to failure, agreeing with Petley et al. (2002) who hypothesises final failure is associate with damage accumulation. Thus, demonstrating the time-dependent component of this process.

Carey et al. (2019) used a dynamic back-pressure shear box (DBPSB) to investigate the relationship of pore water pressure and displacement in the Utiku landslide complex (North Island, New Zealand). Samples were saturated to replicate field conditions, consolidated to 150 and $400 \mathrm{kPa}$ respectively and under drained conditions sheared at a rate of $0.001 \mathrm{~mm} / \mathrm{min}^{-1}$. To understand the displacement response, PPR testing was undertaken by increasing pore water pressures in linear and stepped patterns at constant normal and shear stresses. Results by Carey et al. (2019) demonstrated displacement rates during periods of elevated pore pressure are a function of both the instantaneous pore pressure (e.g. Mean effective stress at that time) at the shear surface and the transient stress state of pore pressure (the rate of change of normal effective stress) (Figure 2.10). This is important as a reduced critical mean effective stress must be reached first as pore pressure is generated for displacement to occur (Figure 2.11), from then the pore pressure and the rate of change of pore pressure controls displacement.

Results are consistent with both field monitoring data (Massey et al., 2013; Corominas et al., 2005) (Figure 2.11b) and laboratory testing (Petley et al., 2017; Ng \& Petley, 2009) in terms of a rate effect influence. Observed increases in pore pressure result in increased displacement, whereas in periods of lowering pore pressure, displacement rates correspondingly decrease, this is termed creep-rupture behaviour (Figures 2.10 and 2.11). This behaviour is stipulated to link to slip-stick movements observed in slow moving landslide systems e.g.(Ng \& Petley, 2009; Allison \& Brunsden, 1990), suggesting the coupling between landslide movement and pore pressure is important and the combination of monitoring records and laboratory testing can help replicate and understand these movements. The observation of a rate effect has implications for failure as Kaikōura could potentially be impacted (rates of 


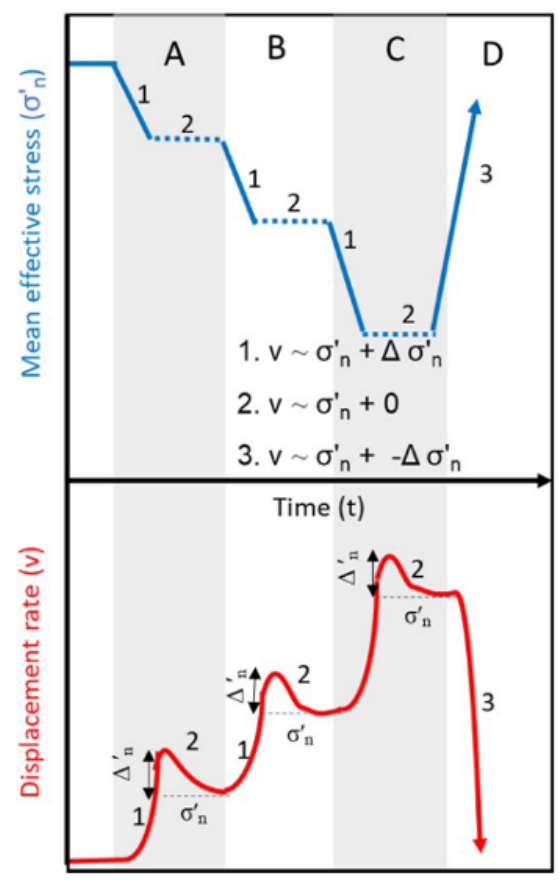

Figure 2.10: Conceptual model of the relationship between displacement rate and mean effective stress in a landslide in response to changes in pore pressure after Carey et al. (2019).

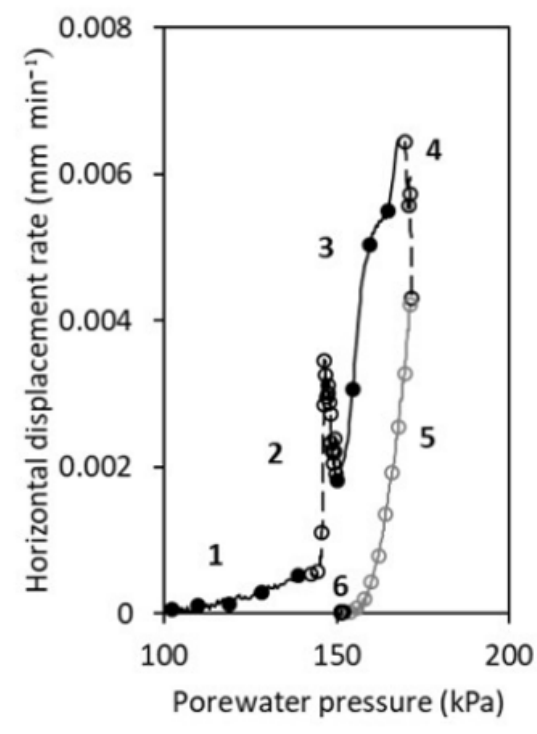

(a)

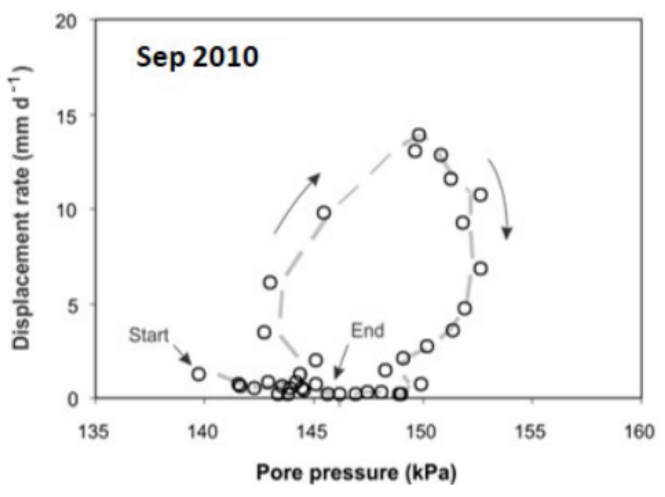

(b)

Figure 2.11: Graphs demonstrating displacement behaviour vs pore pressure for the Utiku landslide complex in a) laboratory testing from Carey et al. (2019) and b) field monitoring from Massey et al. (2013). 
deformation on weakened material) by the way rainfall is received.

Experiments by Carey and Petley (2014) investigated the mechanisms of progressive shear surface development using triaxial cell tests on Gault Clay samples from the Ventnor Undercliff landslide complex in the United Kingdom. Both intact and remoulded samples were subject to full saturation, isotropic consolidation to respective effective stresses and then undrained shear (ICU) and drained (ICD) shear at $0.001 \mathrm{~mm} / \mathrm{min}$. For the pore pressure reinflation $(\mathrm{PPR})$ stage ICD samples were subject to pore pressure increases of 5, 10 and $19 \mathrm{kPh} / \mathrm{hr}$ to replicate groundwater monitoring data. The authors demonstrated upon their PPR tests similar observations in the relationship between displacement and mean effective stress for different pore pressure increases, indicating strain generated by pore pressure increases is not only dependent on the effective normal stress but also the rate of change of mean effective stress, aligning with observations by (Carey et al., 2019; Ng \& Petley, 2009).

Intact Gault Clay samples underwent initial exponential displacement, yielding an asymptotic trend in $1 / \mathrm{v}$-t space (Figure 2.12), however as pore pressure is further increased, hyperbolic acceleration in displacement was observed yielding a linear trend in $1 / \mathrm{v}$-t space. Final acceleration to failure producing a linear trend in $1 / \mathrm{v}$ - $\mathrm{t}$ space initiating at $200 \mathrm{kPa}$, suggests crack propagation and strain localisation was dominant before this critical effective stress and rapid shear surface development once the critical stress was reached, which is consistent with (Kilburn \& Petley, 2003 ; Petley et al., 2002). However, an asymptotic $1 / \mathrm{v}$ trend was observed within remoulded samples suggesting the lack of shear surface development observed in intact samples, but instead more broad internal deformation. Ng and Petley (2009), also demonstrated an asymptotic trend in $1 / \mathrm{v}$ - $\mathrm{t}$ space, with cohesive samples in the intact form. This demonstrates ductile deformation can occur within both intact and remoulded samples.

\subsubsection{Shear zone liquefaction}

While the concept of progressive failure has proven to be critical in landslide studies; other important mechanisms operate at a shear surface level e.g. liquefaction (Sassa 


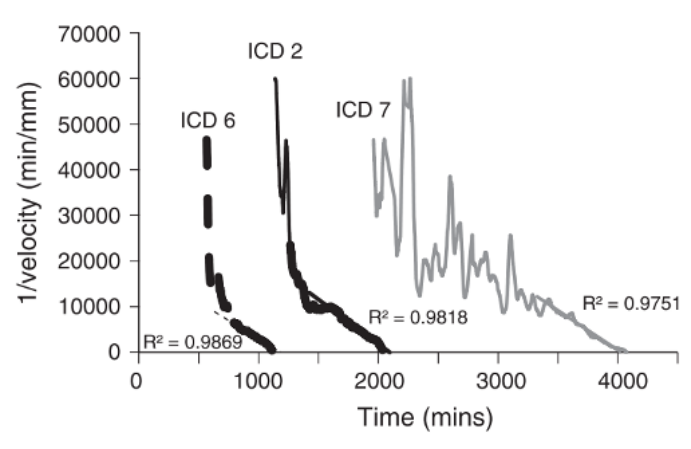

(a)

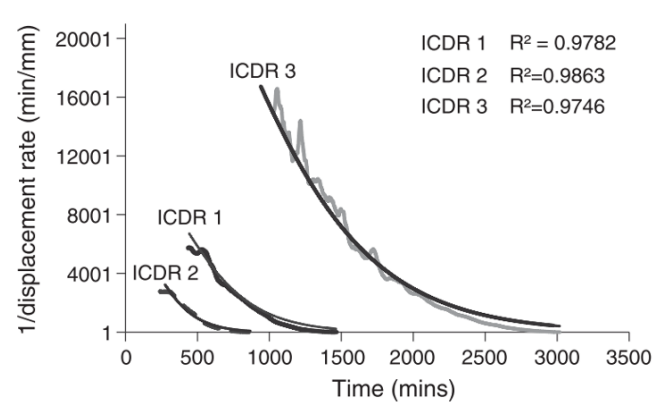

(b)

Figure 2.12: Graphs demonstrating 1 /velocity vs time and 1 /displacment rate vs time from Carey and Petley (2014) for a) intact gault clay b) remoulded gault clay.
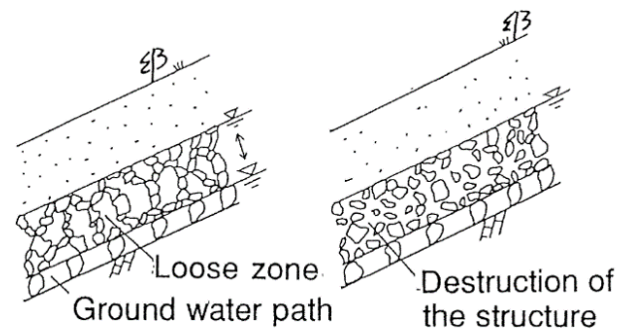

(a)

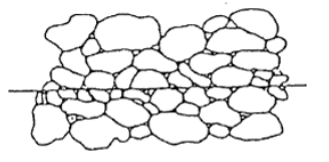

Before shear

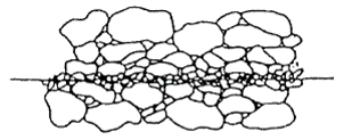

After shear

(b)

Figure 2.13: Schematic diagrams demonstrating a) conventional (mass) liquefaction and b) sliding surface liquefaction. Modified after Sassa et al. (1996).

et al., 1996) which has been demonstrated through ring shear tests by (Wang et al., 2007; Sassa et al., 2004; Wang et al., 2002; Wang \& Sassa, 2002).

Liquefaction in simple terms is the loss of strength and stiffness in saturated or partially saturated soil due to applied stress. This is commonly caused by dynamic shaking (earthquakes) where a collapse of the soil skeleton occurs due to excessive strain, followed by a loss of strength and increase in pore pressure under undrained conditions (Figure 2.13a) (Hungr, 2007). This is an important mechanism as debris flows are often associated with this phenomenon and cause widespread damage due to their long run-out distances and high travel velocity (Sassa et al., 2004, Wang \& Sassa, 2003; Iverson et al., 1997). Throughout the literature it has been widely recognized that sandy materials are predominantly subject to liquefaction, however additional research demonstrates grain size is an important factor as liquefaction can occur in other materials e.g. sandy gravels (Dawson et al., 1998) and different grades of material (Igwe et al., 2004).

The concept discussed above is a conventional liquefaction model, however, a second 
model exists proposed by Sassa et al. (1996) whereby liquefaction occurs on a sliding surface in granular material (sliding surface liquefaction) (Figure 2.13). Instead of the liquefaction process described by Hungr (2007), Sassa et al. (1996) demonstrate high pore pressures produced by textural changes and contraction due to grain crushing along the sliding surface as a result of large displacements. Since the proposition of this mechanism, subsequent ring shear experiments have been conducted e.g. (Sassa et al., 2004; Wang et al., 2002; Wang \& Sassa, 2002) with observations demonstrating this mechanism. In these experiments, undrained ring shear simulations all demonstrate upon shearing excess pore pressure is accompanied by a decrease in shear stress/shear resistance. Subsequent effective stress paths show a rapid drop in effective stress moving to values of near zero. This behaviour is attributed to shear zone contraction through grain crushing, allowing the build up of excess pore pressure and thus liquefaction. Stress path behaviour is consistent with the mechanism described by (Sassa et al., 1996). If such mechanisms are applicable to Kaikōura materials, it is likely that fluidised flows e.g. debris flows could be common through reactivation of weakened material.

While these studies show compelling evidence of shear zone liquefaction, it is important to recognise ring shear devices restrict volume changes, i.e. volume is constant. Volume changes at the shear zone are important as contraction through grain crushing is key for this type of liquefaction (Sassa et al., 1996), however, dilation is also important as it may influence the displacement behaviour e.g. (Iverson, 2005). This reminds us around the importance of the applicability of such tests to replicate specific landslides e.g. debris flows.

\subsection{Literature review conclusions}

Theoretical models and laboratory testing have been successfully combined to aid in the explanation of various mechanisms behind landslide behaviour. Numerous studies focus on single slopes and specific failure modes for such landslides. Timescales for these studies are relative short, except for (Carey \& Petley, 2014; Ng \& Petley, 2009) who demonstrate that long creep tests have a time dependent component. Therefore this highlights the need to investigate the landslide behaviour over long time scales, 


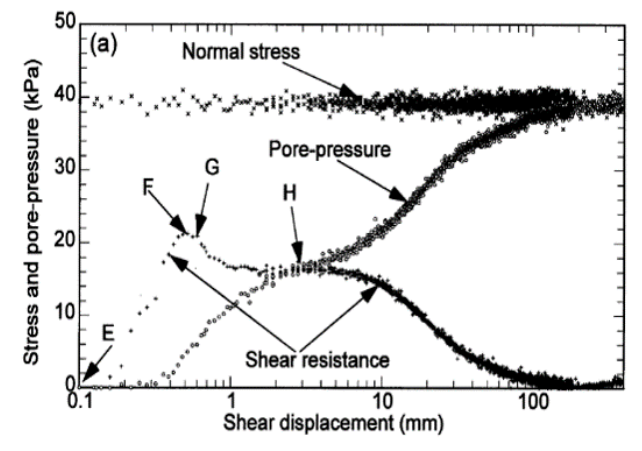

(a)

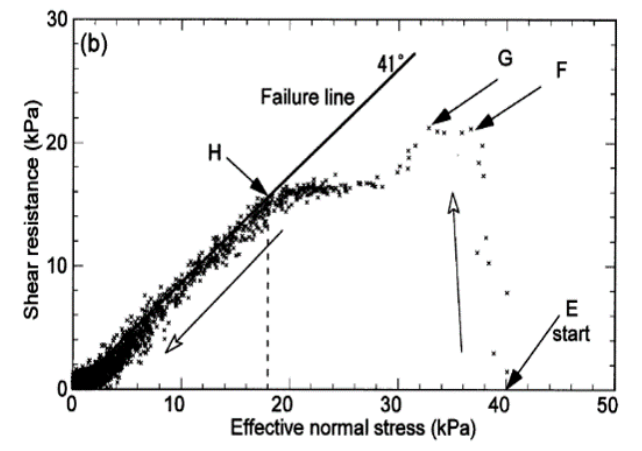

(b)

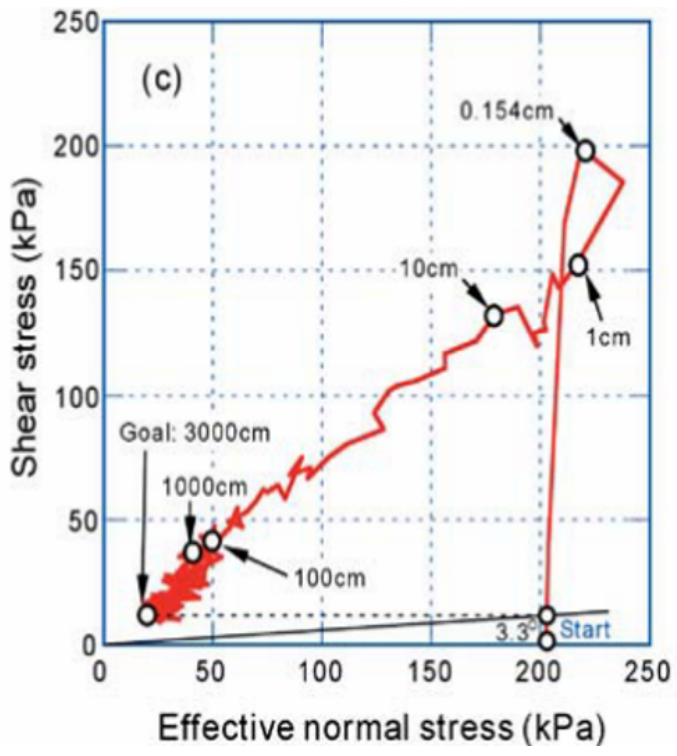

(d)

Figure 2.14: Results from undrained ring shear experiments after Wang et al. (2002) demonstrating a) stress and pore pressure vs shear displacement b) shear resistance vs effective normal stress and from Sassa et al. (1996) c) stress and pore pressure vs shear displacement d) shear resistance vs effective normal stress. 
as model timescales are different to that of natural timescales where such processes take place. The methodology by Ng and Petley (2009) has the closest approach to a method that can be utilized to simulate reactivated rainfall-induced landslides over long time scales. Undertaking testing on previously failed material from the 2016 Kaikōura earthquake, provides an opportunity to determine how these materials may behave in response to rainfall, providing a unique and unstudied data set that may inform the long term hazard associated with landscapes following large earthquakes, not only for Kaikōura, but applied internationally. 


\section{Chapter 3}

\section{Kaikōura and its setting}

\subsection{Overview}

The Kaikōura region is located on the east coast of the South Island New Zealand, approximately $180 \mathrm{~km}$ north of Christchurch. The area itself is part of the Marlborough Fault System (MFS), a $150 \mathrm{~km}$ wide belt of active dextral strike-slip faults (Little \& Jones, 1998). Four main faults make up the MFS and numerous smaller faults, with slip rates along these major faults increase with distance south, e.g. Wairau Fault 3-5mm/yr (Zachariasen et al., 2006) to $23.4 \mathrm{~mm} / \mathrm{yr}$ on the Hope Fault (Langridge et al., 2003). This zone accommodates $40 \mathrm{~mm} / \mathrm{yr}$ of plate motion (DeMets et al., 2010) between the Australian and Pacific plates at the Hikurangi subduction zone in the north and continental collision on the Alpine fault to the south-west. The manifestation of this is the mountainous topography of the Southern Alps to the south and Kaikōura Ranges (Rattenbury et al., 2006). Naturally, due to the tectonic setting, the region has experienced a number of large earthquakes summarised below in Table 3.1 .

Table 3.1: Summary of large earthquakes experienced in the Kaikōura region over the last 140 years.

\begin{tabular}{ccll}
\hline Year & Magnitude & Earthquake and/or Fault Rupture & Reference \\
\hline 1884 & Mw 7.5 & Awatere Fault & (Mason \& Little, 2006 \\
\hline 1855 & Mw 8+ & Waiarapa earthquake & (Grapes \& Downes, \\
\hline 1888 & Mw 7.0-7.3 & Amuri earthquake, Hope Fault River seg- & (Cowan, 1991) \\
\hline 2010 & Mw 7.1 & Darfield earthquake & (Quigley et al., 2012) \\
\hline 2013 & Mw 6.6 & Cook Strait and Lake Grassmere earthqukes & (Holden et al., 2013) \\
\hline
\end{tabular}




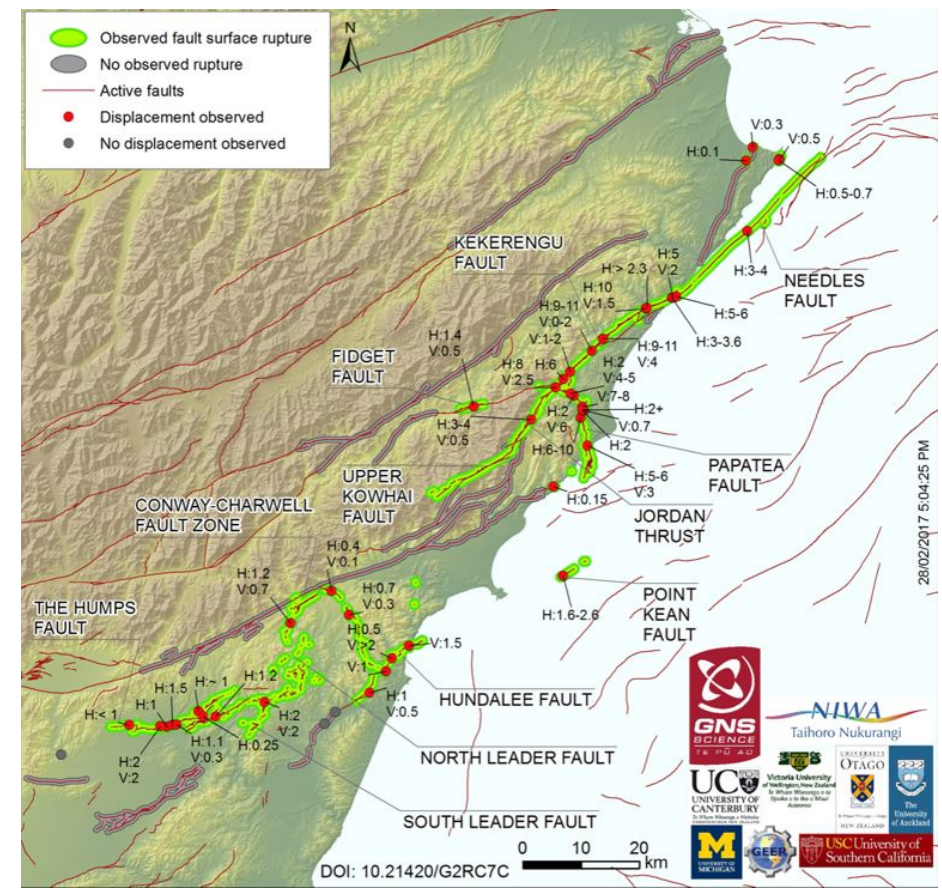

Figure 3.1: Associated faults with the 2016 Kaikōura earthquake and their relative displacements from GeoNet (2017).

The recent 2016 Mw 7.8 Kaikōura earthquake was of particular significance due to the complexity, and widespread damage caused. The epicentre was located $4 \mathrm{~km}$ south from the town of Waiau, North Canterbury, where the rupture propagated 170km north along mapped and unmapped faults before continuing offshore at the island's north-eastern extent (Figure 3.1) (Hamling et al., 2017; Kaiser et al., 2017). Surface ruptures were observed along at least 12 major faults (Figure 3.1), including substantial coastal uplift, widespread anelastic deformation, an 8-meter uplift of a fault-bounded block and possible slip along the southern Hikurangi subduction interface from geodetic observations (Hamling et al., 2017). Along with the extensive damage from ground shaking and fault ruptures, widespread landsliding prevailed. Initial detailed mapping and analysis was undertaken by (Massey et al., 2018) producing a landsl de inventory of 10,000 landslides, this has been superseded with an updated inventory, version 2.0 of $>29,000$ landslides (Massey et al., 2020) where most fell within a concentrated zone of $3600 \mathrm{~km}^{2}$ (Figure 3.2). Various landslide sty es were observed including:

- Debris avalanches and flows

- Planar, translation and rotational slides 


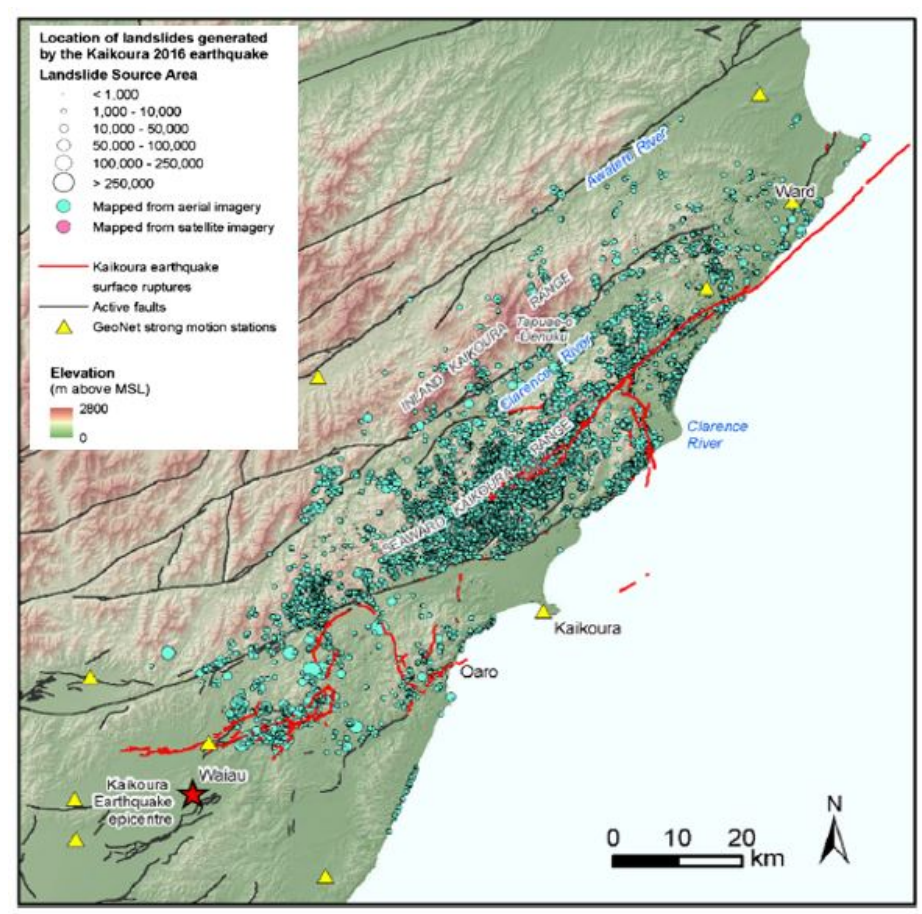

Figure 3.2: Kaikōura landslide inventory version 2.0, following the 2016 earthquake. Modified after Massey et al. (2020).

- Flow slides

- Deep seated slides and slumps

- Rockfalls and rock avalanches

- Topples

- Slope deformation

The mapped landslides were triggered across multiple geological materials including, 1) Quaternary sands, silts and gravels, 2) Neogene limestones, sandstones and siltstones, 3) Upper Cretaceous to Paleogene rocks, consisting of limestones, sandstones, silstones and minor volcanic rocks and 4) Lower Cretaceous Torlesse basement rocks, greywacke (sandstone and argillite) summarised by (Massey et al., 2018; Rattenbury et al., 2006). Each geological material largely reflected and controlled resultant landslide types that occurred (Massey et al., 2018) such that rockfalls tended to originate in strong, closely jointed Lower Cretaceous Torlesse, alternatively slides and flows typically occured in weaker massive Upper Cretaceous to Paleogene limestones, sandstones and siltstones. However, some variation is inevitable. Of all the geological materials, landslides were preferentially triggered within Neogene and Upper Cretaceous to Paleogene aged limestones, sandstones, siltstones, corresponding to landslide densities 


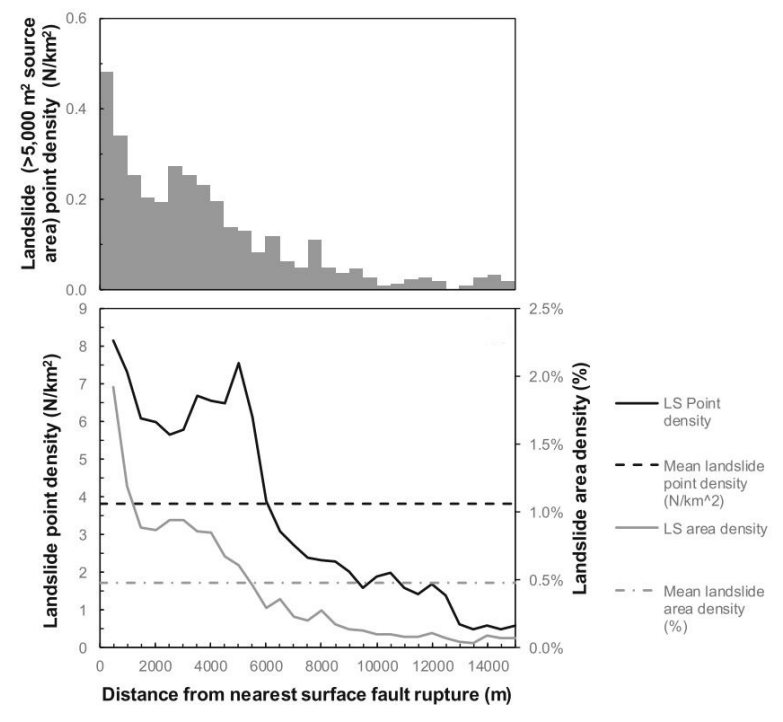

(a)

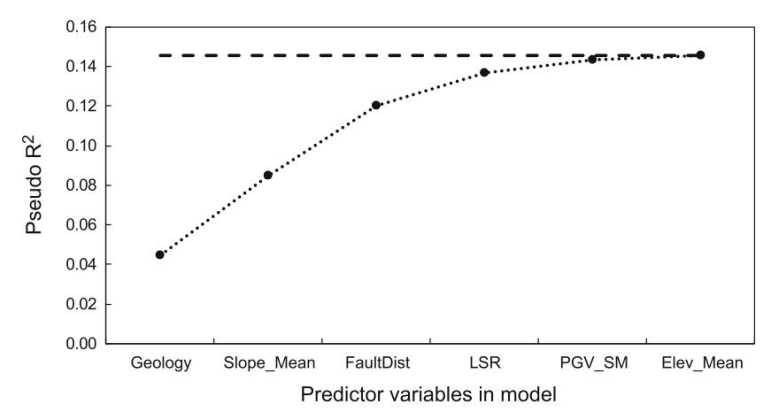

(b)

Figure 3.3: Kaikōura earthquake landslide distribution after Massey et al. (2020). a) Distance from nearest surface fault rupture demonstrating landslide densities. b) logistical regression model predictor variables and their fit.

of 5.5 and 4.6 landslides per km2 respectively (Massey et al., 2018). The largest landslide mapped from of the event, the Hapuku Landslide had approximately $20(+/-2)$ $\mathrm{Mm}^{3}$ of material and a run-out distance of $2.7 \mathrm{~km}$ occurred where a fault running through the source area ruptured, which is also reflected in other large landslides in the area.

The landslide distribution for the event demonstrates a key influence of fault surface ruptures as landslide densities decrease with distance away from a surface rupture, highlighted by densities three times as large within $5 \mathrm{~km}$ compared to within $14 \mathrm{~km}$ (Figure 3.3a) (Massey et al., 2020). In areas of higher local slope relief (LSR) larger landslides are triggered, with the reasoning that lower LSR slopes are less likely to initiate large landslides in response to amplified earthquake shaking. However, coastal slopes have landslide densities on an order of magnitude greater than inland slopes across the same slope angles and within similar materials suggesting local ground 
Table 3.2: Cyclones and their associated rainfall and return periods for Kaikōura in the last 45 years. Data from Rosser et al. (2020).

\begin{tabular}{ccl}
\hline Event & Date & Rainfall/Return Period \\
\hline Cyclone Allison & 11-12th March 1975 & $560 \mathrm{~mm}$ in $48 \mathrm{hrs}$. Max 40-70mm/hr \\
\hline Cyclone Debbie & 23 March to 7 April 2017 & $155 \mathrm{~mm}$ in 36 hrs. <1-2 years return period \\
\hline Cyclone Cook & 14th April 2017 & $86 \mathrm{~mm}$ in 19 hrs. Return period of $<1-2$ years. \\
\hline Cyclone Gita & 20th Feburary 2018 & $\begin{array}{l}269 \mathrm{~mm} \text { in 12 hours }=1 / 200 \text { year return period. } 301.5 \mathrm{~mm} \text { in 24 } \\
\text { hours }=1 / 150 \text { year return period. }\end{array}$ \\
\hline
\end{tabular}

shaking amplification may play a role in triggering landslides for these slopes.

Analysing all variables as a whole, geology has the largest relative contribution to the logistical regression model fit by (Massey et al., 2020, Massey et al., 2018) (larger than ih version 1.0), followed by mean slope and fault distance (Figure 3.3b). Results suggested individual contributing variables play a role but a combination of variables helped produce and explain the landslide distribution for Kaikōura

While these previous works have increased our understanding of how and where the earthquake-induced landslide distribution lies for the region, they do not take climate into account, which is essential to understand and consider due to its role in rainfall-induced landslides. The climate of the Kaikōura region is a product of the westerly weather systems and the mountainous topography to the west.

Temperatures typically decrease with distance from the coast, where median annual average temperatures range from $13^{\circ} \mathrm{C}$ at the coast and $4^{\circ} \mathrm{C}$ in the Kaikôura Ranges. On average, temperatures are higher in summer months compared to winter months. The prevailing westerly wind direction sets the spatial distribution of rainfall received for the region primarily influenced by the orographic effect from weather systems forced up and over the main divide from the Tasman Sea. Typically mean annual rainfall varies from $>2000 \mathrm{~mm}$ in the Kaikōura ranges to $\sim 700 \mathrm{~mm}$ at the Kaikōura coastline (Macara, 2016).

While mean annual rainfall is spatially variable explained by the topographic influence, extreme weather events generating high intensity and long duration rainfall can contribute to this in the form of ex-tropical cyclones (Table 3.2 with follow on effects. Kaikōura has experienced ex-tropical cyclones in the past with damaging results most notably the 10's of thousands of associated landslides. For instance, cyclone Alison in 1975 producing at least 19,000 landslides from rainfall of $580 \mathrm{~mm}$ in 48 hours, and a maximum of 40-70mm in one hour (Figure 3.4 (Rosser et al., 2020). 


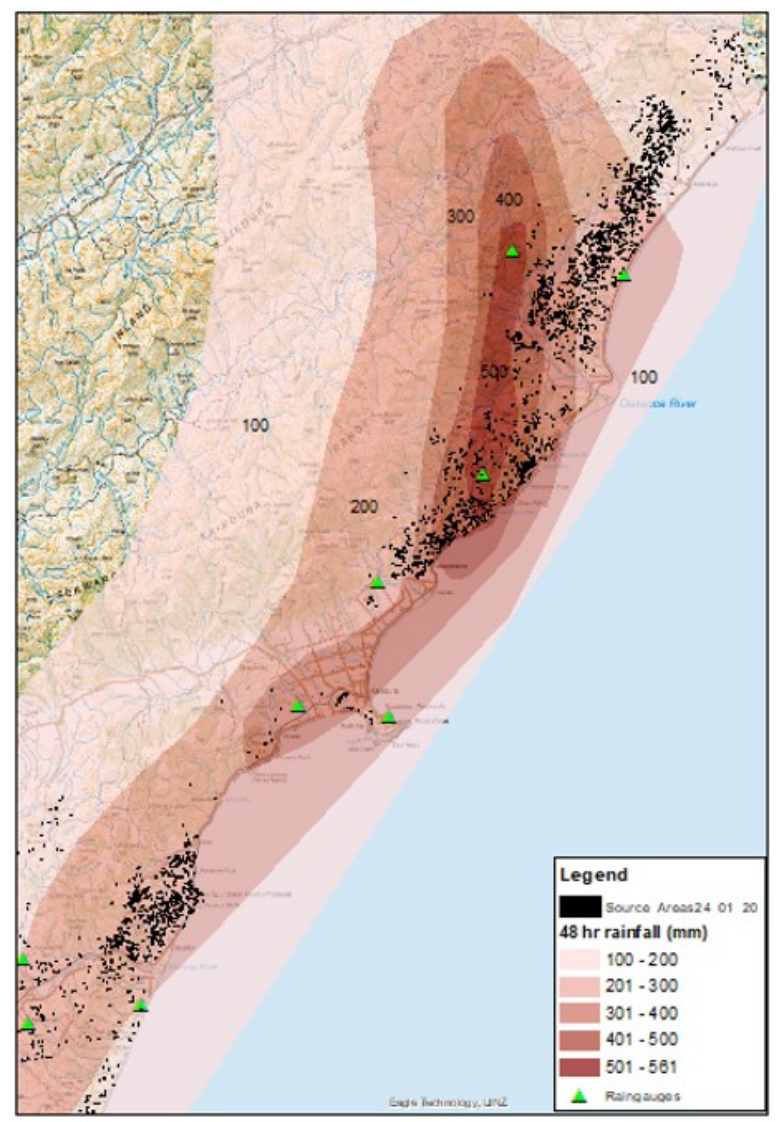

Figure 3.4: Landslides and rainfall contours for Cyclone Alison over the Kaikōura region from Rosser et al. 2020.
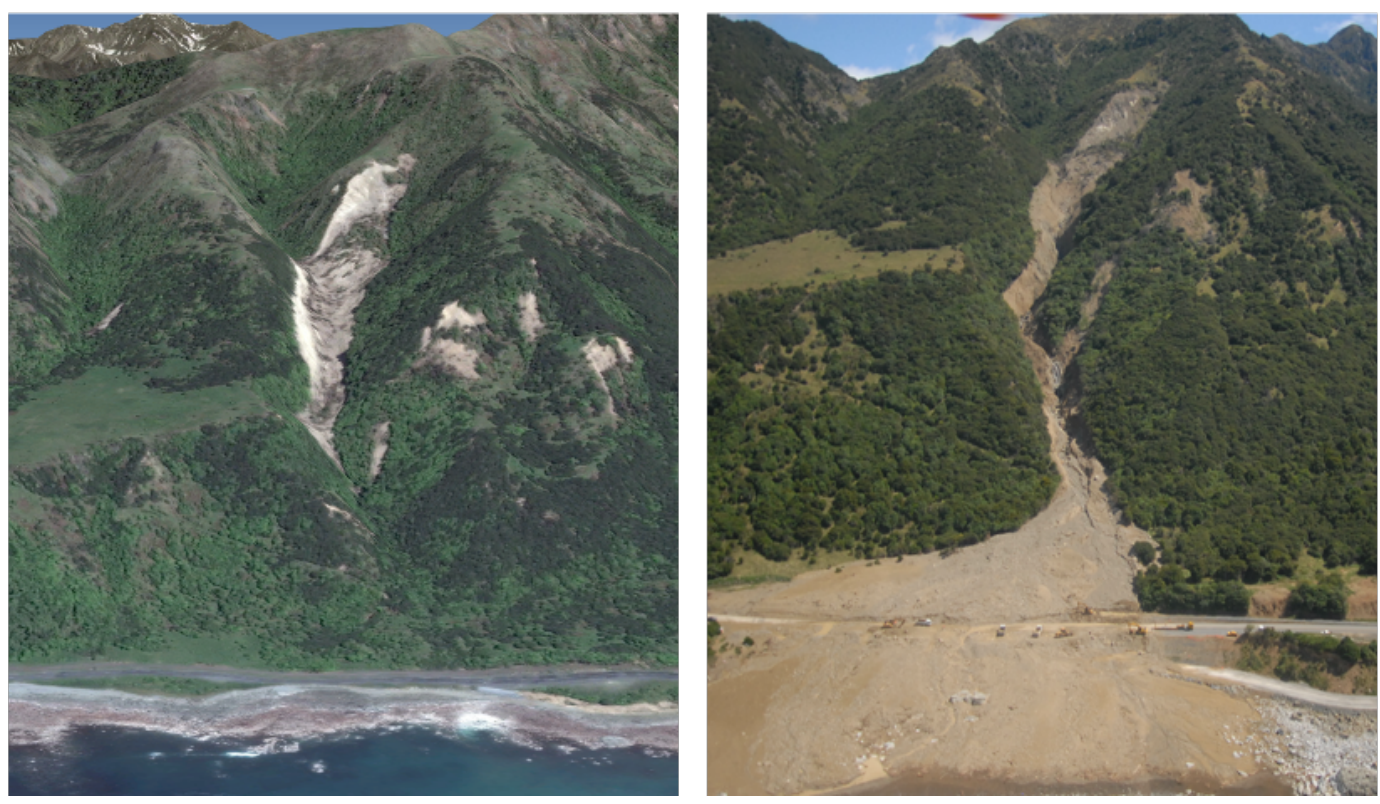

Figure 3.5: Landslide reactivation observed following Cyclone Gita 2018 on SH1 north of Kaikōura. Left, a earthquake induced landslide prior to Gita (2016). Right, landslide reactivation into a debris flow. Source: (Chris Massey, 2020)

Similar to Alison, more recently Cyclone Gita, Cook and Debbie show to trigger landslides under various rainfall amounts and annual return periods (Table 3.2).

Landslides produced in events similar to Cyclone Alison are often first time failures. 
However, now of concern is landslide reactivation through the remobilisation of earthquake-induced landslide deposits from rainfall, as the first evidence has been observed following cyclones Debbie, Cook and Gita (Table 3.2) and (Figure 3.5). Following large earthquakes internationally landslide triggering thresholds have been shown to drop compared to prior to the large earthquake, combined with elevated landsliding rates e.g. Chi-Chi 1999 Shieh et al. (2009) observed a decrease in maximum effective cumulative precipitation for the rainfall threshold of $50 \%$. Preliminary rainfall triggering threshold results for Kaikōura through spatial landslide mapping and analysis conducted by Rosser et al. (2020), demonstrate following the 2016 earthquake triggering thresholds have decreased from now $64 \mathrm{~mm} / \mathrm{hr}$ prior to the earthquake down to $9 \mathrm{~mm} / \mathrm{hr}$ post earthquake.

The reduction in triggering threshold observed was coupled with a significant increase in landsliding through the initiation of new landslides on weakened slopes, the reworking of landslide debris stored on the landscape and the reactivation of existing landslides. As evidence by Rosser et al. (2020) already demonstrates elevated landsliding rates in Kaikōura, this highlights the future potential for landslide reactivations through time from large rainfall events and poses questions about whether landslides will continue to occur for decadal timescales. 


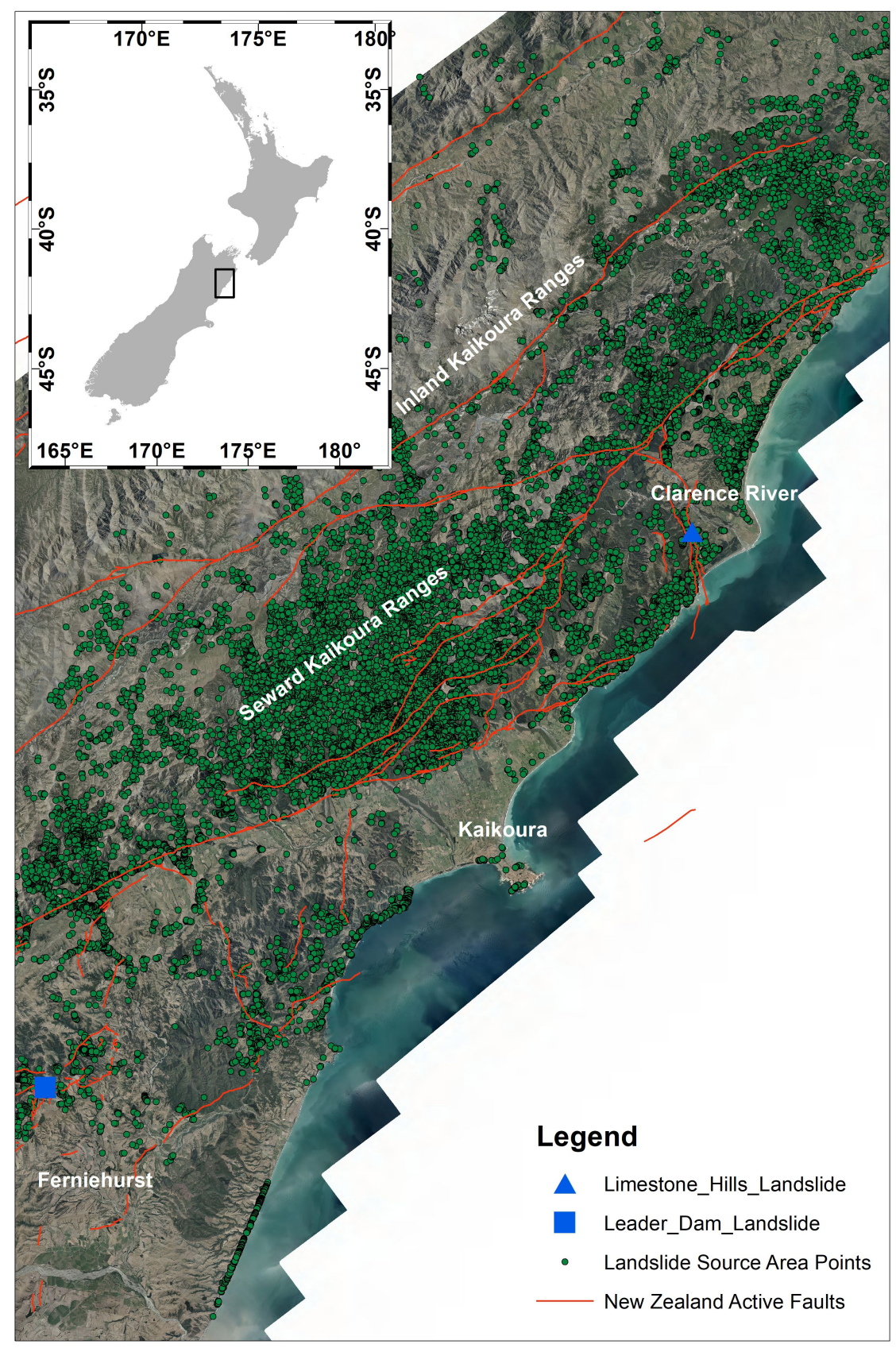

Figure 3.6: Overview map demonstrating the location of Limestone Hills Landslide (LHL) and Leader Dam Landslide (LDL) with context to New Zealand.

\subsection{Study location and landslide mapping}

For this study, we are concerned and interested in materials that failed on catchment slopes in the Kaikōura region, i.e. landslide deposits rather than specific landslides, for the reason these materials are susceptible to reactivation under rainfall events. Therefore, samples are required to be in the form of landslide debris from landslides that failed directly from the 2016 Kaikōura earthquake within Late Cretaceous to Neogene sediments (the most impacted units) as seen in Figure 3.7. Two 

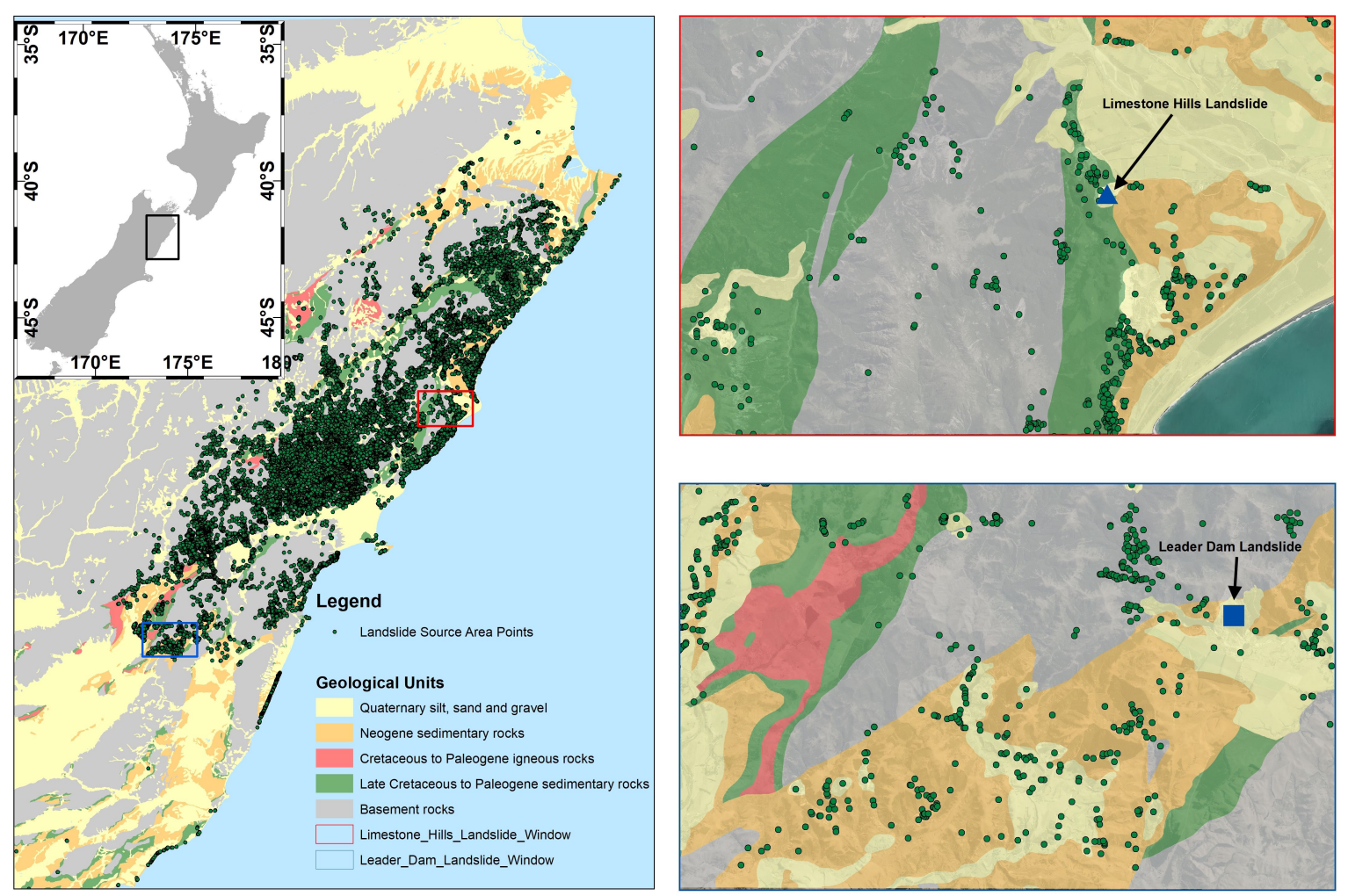

Figure 3.7: Simplified geology for the Kaikōura region and each study site, with the 2016 earthquake-induced landslide data set overlain. Geological data sourced from (QMAP) (Rattenbury \& Isaac, 2012)

representative samples locations were selected for this study, Limestone Hills Landslide (LHL) and Leader Dam Landslide (LDL) (Figures 3.6, 3.8 and 3.11)

To gain a sense of the sampled landslides in this study and landslides within the encompassing area, a study window has been selected for each. Detailed landslide mapping was undertaken on windows with areas of approximately $82 \mathrm{~km}^{2}$. Data used has been extracted from the version 2.0 Kaikōura landslide database complied by Massey et al. (2020) which was mapped following the methodology after Dellow et al. (2017).

\subsubsection{Limestone Hills Landslide}

Limestone Hills Landslide is located approximately $5.3 \mathrm{~km}$ inland from the Clarence River mouth. The landslide itself is a debris flow-slide, that failed within Oligocene siltstone along the Papatea fault rupture (Figures 3.8 and 3.10). Whilst geological mapping indicates LHL is part of Quaternary sediments (Figure 3.7), it failed within Oligocene siltstone (Late Cretaceous to Paleogene), following the 2016 earthquake the landslide has since been updated to Quaternary landslide deposit, within the 


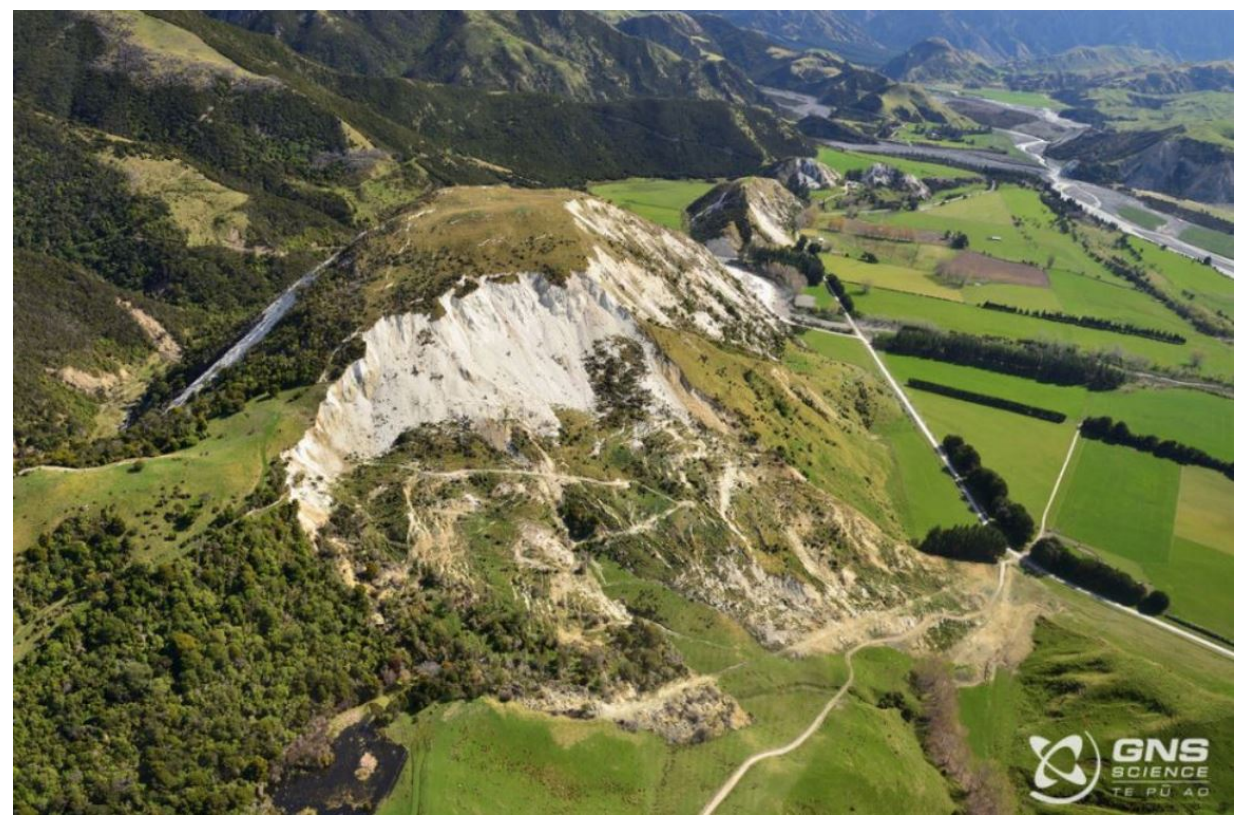

Figure 3.8: Aerial photograph of Limestone Hills Landslide. Source: (GNS Science, 2019)

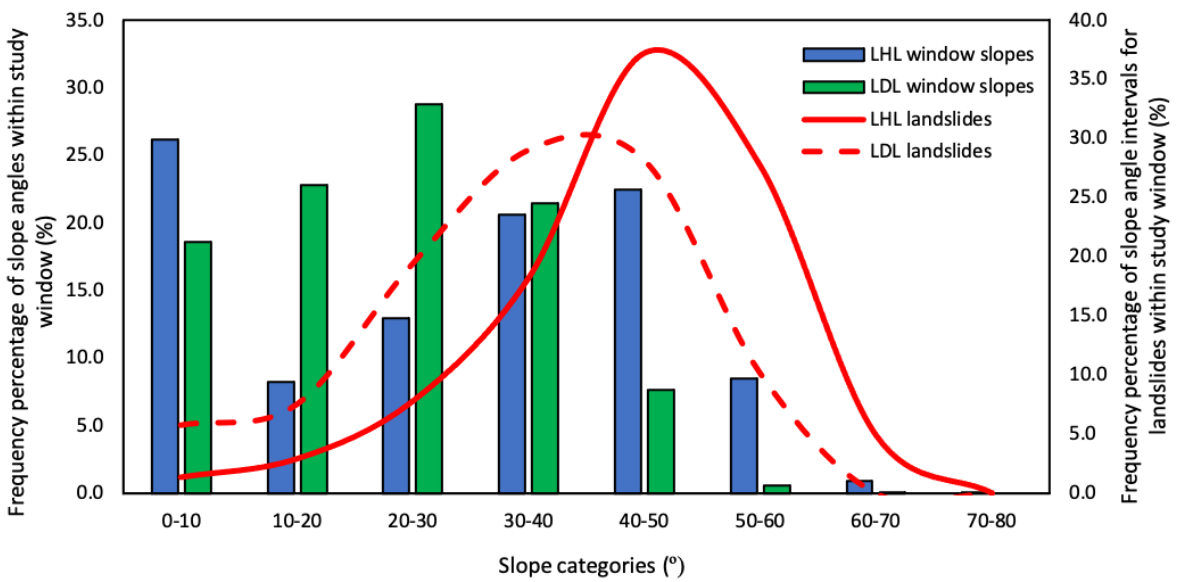

Figure 3.9: Frequency percentage graph demonstrating the percentage of each slope category, overlain with the percentage of landslides within each slope category for each mapping window. 
geological QMAP data. Landslides with the study window totalled $\mathrm{N}=451$, with $\mathrm{N}=417$ that had assigned GIS attributes. From landslides with attributes, failures are predominately slides, ranging from shallow to deep-seated (Figure 3.10). Falls are additionally present in areas of steeper slopes. The majority of slopes within the window area generally fall between $0-10^{\circ}$ and $30-50^{\circ}$, with the highest percentage falling into the $0-10^{\circ}$ category at $26.2 \%$ (Figure 3.9). Landslides were preferentially triggered on slopes between $30-60^{\circ}$. Clustering of landslides is observed along the Papatea fault trace, consistent with (Massey, Townsend, Rathje, et al., 2018). Two large failures dominate the area, first being the Seafront landslide located near the coastline and secondly the Limestone Hills Landslide sampled in this study (Figure 3.10 . 

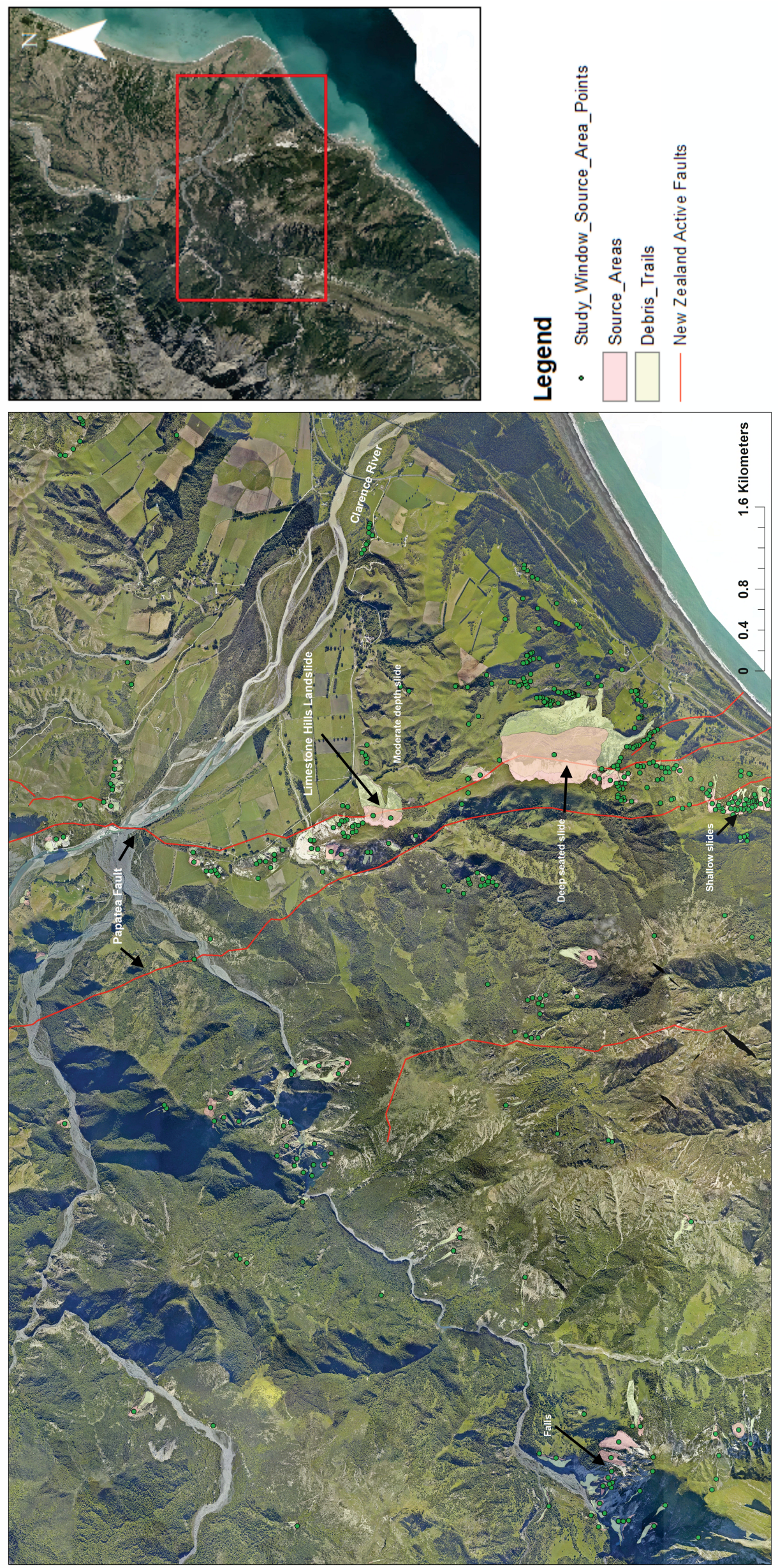

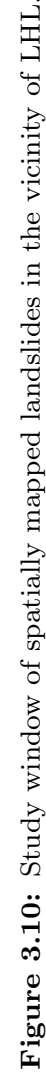




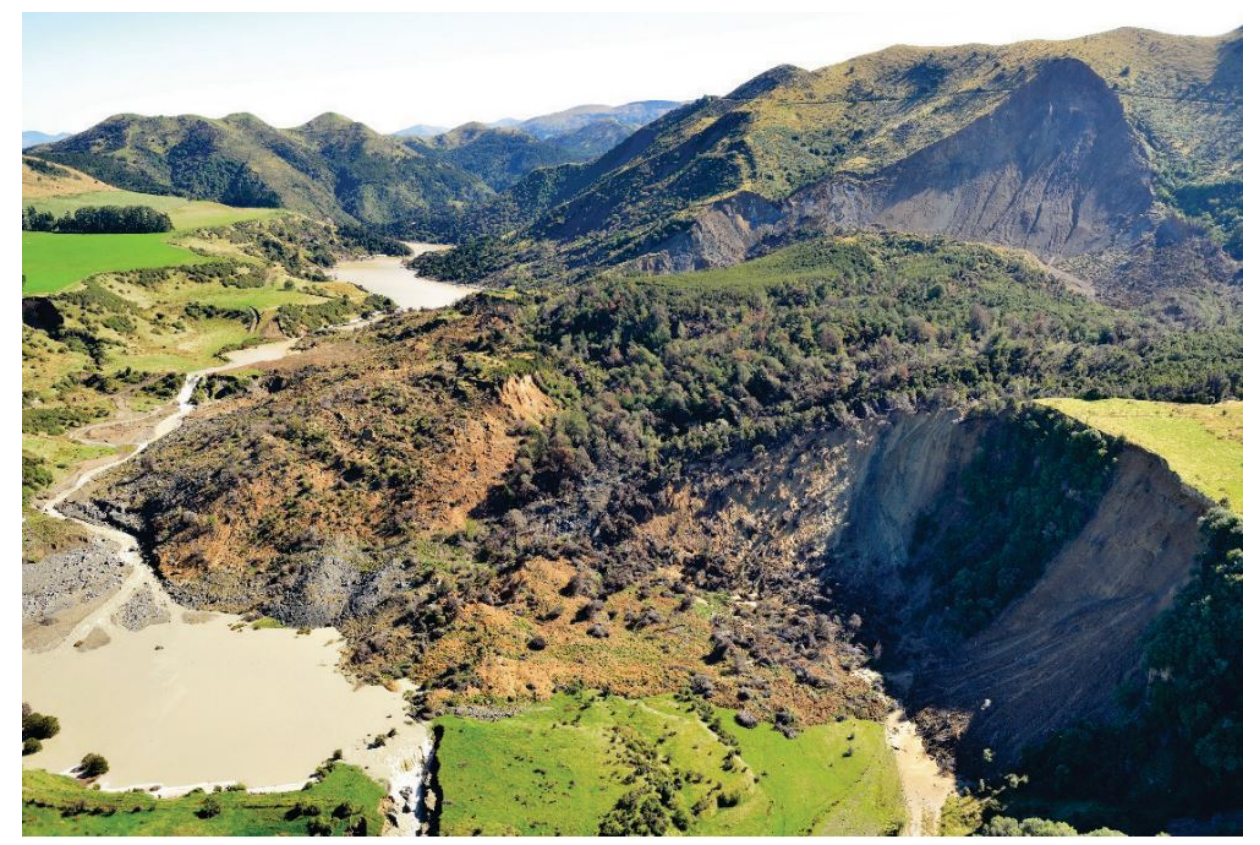

Figure 3.11: Aerial photograph of Leader Dam Landslide taken April 2017. Source: (Massey, Townsend, Dellow, et al., 2018).

\subsubsection{Leader Dam Landslide}

The Leader Dam Landslide is located approximately $10 \mathrm{~km}$ west from SH1 at Ferniehurst, on the edge of the Leader River. The landslide itself is a rock slide/slump, that failed within Late Miocene to Pliocene siltstone (Figure 3.11). As mentioned above, LDL has also been updated to Quaternary sediments as a landslide deposit but failed within Late Miocene to Pliocene siltstone (Neogene age). LDL is the largest landslide within the study window, with other large slides located to the south west. Landslides with the study window totalled $N=572$, with only $N=103$ that had assigned attributes. Based on this small sample size, landslides with attributes demonstrate failures are predominately falls closely followed by slides (Figure 3.12). However, upon inspection of aerial imagery, a large amount of slides are present that have not been classified. Slopes within the window generally fall within $0-40^{\circ}$, with the highest percentage of area falling within $20-30^{\circ}$ at $28.8 \%$. Landslides preferentially failed across slopes between $20-50^{\circ}$, with showing a wide range of slopes that failed. 

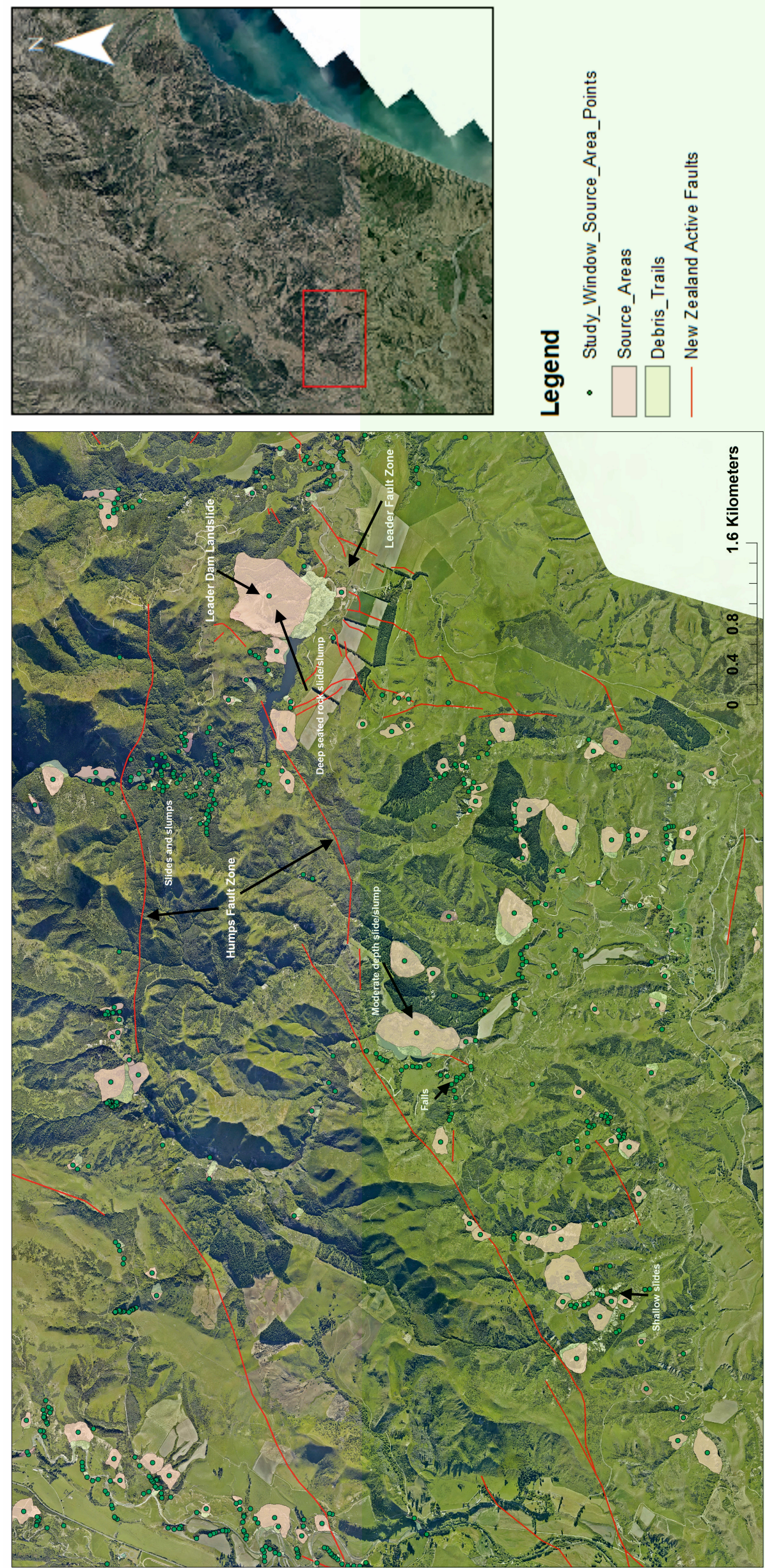

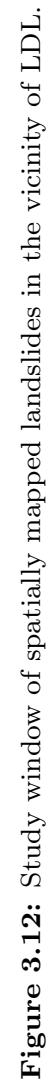




\section{Chapter 4}

\section{Methods}

\subsection{Sample collection}

Landslides triggered directly from the 2016 Kaikōura earthquake were targeted, and their failed debris was sampled. As failed material on catchment slopes i.e. landslide deposits are the focus of this study, two representative medium-sized landslides as discussed in section 3.2 were chosen to sample. Both block samples (intact) and bulk bag samples were excavated from the main landslide bodies from Leader Dam and Limestone Hills landslides to ensure a representative sample. Block samples provide suitable materials to measure in-situ properties (e.g. soil moisture and compaction), which ensure accurate replication of these properties for laboratory testing. Bag samples provide additional material to reconstitute samples if required. Block samples were stored in airtight containers and wrapped in cling film to ensure moisture content was retained. Both samples were transported and stored in at GNS Science, Lower Hutt in a humidity-controlled room to maintain the samples' natural moisture content until sample testing was undertaken.

\subsection{Physical properties}

A suite of standard physical properties tests was undertaken on each sample to determine their particle size, calcium carbonate content, moisture content, bulk density, dry density and Atterberg limits before testing. 


\subsubsection{Particle size}

Sub-samples were taken from each intact block for each material for particle size analysis. Sediment less than $2 \mathrm{~mm}$ in diameter had the organic content removed through a hydrogen peroxide $\left(\mathrm{H}_{2} \mathrm{O}_{2}\right)$ digestion process. To complete the reaction it was heated in a water bath for approximately two hours. To rinse each sample of $\left(\mathrm{H}_{2} \mathrm{O}_{2}\right)$, samples were centrifuged and diluted untill a $\mathrm{pH}$ of 7 was achieved. Following this, each sample was freeze dried and split into three sub-samples using a sample splitter into approximately ${ }^{1 / 8}$ of a teaspoon portions to obtain a true particle size distribution. A calgon solution $(0.5 \mathrm{~g} / \mathrm{L})$ was added to each subsample in a beaker, which was then placed into an ultrasonic bath for 40 minutes prior to being run through the Laser Diffraction Particle Size Analyser (LDPSA). Fully disaggregated samples were run through the LDPSA, averaged across three particle distributions and converted into a percentage passing graph.

\subsubsection{Calcium carbonate content}

Small sub-samples were taken from leftover material from LDL and LHL. As LHL material was only 355 microns, to make a valid comparison, LHL was sieved down to 355 microns. Two crubiles were labelled, one corresponding to each sample and put into an oven at $105^{\circ} \mathrm{C}$ for approximately $18-24$ hours to ensure each crucible was completely dry. Crucibles were taken out and allowed to cool within a desiccator, once cooled each crucible was weighed three times and the average was taken. Following this, $5 \mathrm{~g}$ of "wet" soil was added into each crucible and placed into the oven again at $105^{\circ} \mathrm{C}$ for 24 hours. Crucibles were again cooled and weighed. Next, to determine the amount of organic matter, samples were left in a furnace with lids on at $550^{\circ} \mathrm{C}$ for four hours, then cooled and weighed. Finally, to determine the carbonate content, samples were again placed in the furnace for $950^{\circ} \mathrm{C}$ for two hours, then cooled and weighed. The following equations were used to determine organic and carbonate contents:

$$
\text { Organic matter }(\mathrm{LOI} 550)=((D W 105-D W 550) / D W 105)) * 100
$$




$$
\text { Carbonate content }(\text { LOI950) }=((D W 550-D W 950) / D W 105)) * 100
$$

Where DW105 = dry weight for loss on ignition at $105^{\circ} \mathrm{C}$, DW550 = loss on ignition for $550^{\circ} \mathrm{C}$ and $\mathrm{DW} 950=$ loss on ignition at $950^{\circ} \mathrm{C}$.

Upon removal of the crucibles following the $950^{\circ} \mathrm{C}$ stage, lids were stuck on, likely from the high temperature. The lids were carefully removed, however small shards of the crucible rims broke off. As the initial crucible weights are important in LOI calculations, the shards were removed from the soil within the crucibles and included on the scale when each was weighed to ensure an accurate weight was recorded.

\subsubsection{Moisture content}

Moisture content for each lithology was undertaken by taking sub-samples from the main sample block and finding the difference between the weight before drying $(\mathrm{Wm})$ and after drying $(\mathrm{Wd})$ in an oven for 24 hours at $105^{\circ} \mathrm{C}$. Moisture content was calculated as a percentage using the following equation: (mass loss/Wd)*100. Three sub-samples of each lithology were completed and the average was taken.

\subsubsection{Bulk density and dry density}

A known volume $(50 \mathrm{~mm} * 50 \mathrm{~mm} * 20 \mathrm{~mm})$ was taken from each lithology using a square cutter and was weighed before (Wm) and after being dried (Wd) in an oven for 24 hours at $105^{\circ} \mathrm{C}$. Using the following equation the bulk density was calculated: Bulk density $=(\mathrm{Wm} / \mathrm{V})$. The same equation was used for dry density, but instead of $(\mathrm{Wm}),(\mathrm{Wd})$ was used.

\subsubsection{Atterberg limits}

To determine plastic and liquid limits standard procedures e.g. (Head \& Epps, 1980) and ASTM D4318-17 standard were followed using the thread rolling and drop cone penetrometer methods.

To determine the plastic limit, each sample was disaggregated and slowly mixed with water until it could be combined into a ball and split into three equal parts. The 
material was then rolled into a thread using fingertips until $3 \mathrm{~mm}$ in diameter was achieved using a glass rod $(3 \mathrm{~mm})$ as a guide. To achieve plastic limit, threads must be rolled until cracks develop (Figure 4.13). From this, the moisture content was determined for each thread. This was completed three times, and the average was taken.

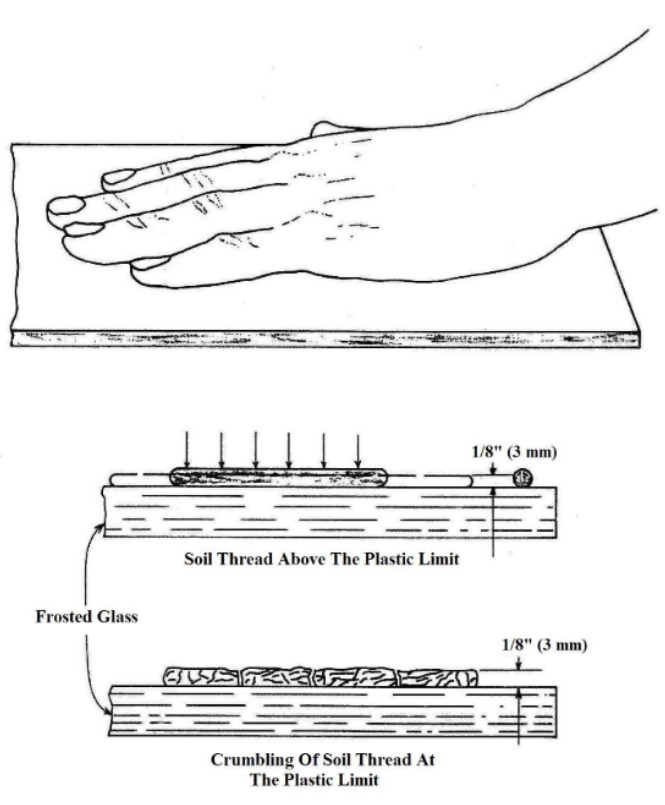

(a)

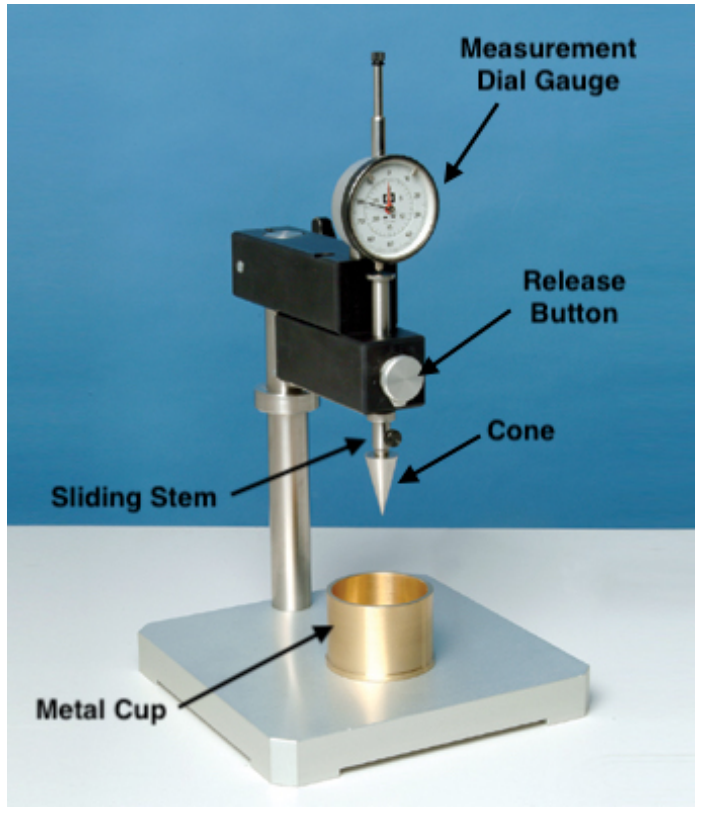

(b)

Figure 4.1: Methods used for determining plastic and liquid limits for a soil. a) schematic of the soil thread rolling method from State of New York Department of Transport Geotechnical Engineering Bureau (2015) b) annotated diagram of a drop cone penetrometer. Modified after: Inopave Group PTE Ltd (2003).

For liquid limit, the material was wet further from the plastic limit until a paste was formed. The paste was transferred into an metal cup (55m diameter x 40mm deep), filled to the top and leveled with the cup rim. The cup was tapped on a flat surface during filling to ensure no air bubbles were present. Then the cup is placed under the cone with the point adjusted to be positioned in the centre and a few millimetres above the soil in the cup (Figure $4.1 \mathrm{~b}$ ). The exposed sliding stem length was measured using calipers and was recorded. As a note, calipers were used to measure the exposed sliding stem as the dial gauge was reading incorrectly when undertaking this laboratory work. Following this, the cone is dropped by pushing and holding the release button for five seconds. The exposed sliding stem was remeasured. Additional wet material is added in and mixed, and then previous steps are repeated a two more times. After three drops, a representative moisture content sample is taken from the 
drop cone penetration area. By definition, 20mm of cone penetration measured from the sliding stem is the baseline liquid limit (BS1377: Part 2: 1990: 4.3). Using this as a guide, multiple tests were undertaken at varying moisture contents at, above and below the liquid limits. Moisture contents and corresponding penetration depths are then plotted as points on a graph, and a trendline is drawn. The liquid limit is read from $20 \mathrm{~mm}$ penetration across to the intersection with the trend line (Appendix A.1 and A.2)

\section{Liquid and plasticity index}

Using equations outlined in (Head \& Epps, 1980) and (Selby, 1982) the liquid and plasticity index was calculated as show:

Plasticity index (PI) is given by the difference between the liquid limit (LL) and plastic limit $(\mathrm{PL})$ :

$$
\mathrm{PI}=L L-P L
$$

Liquidity index (LI) is the ratio of the difference between natural water content (NWC), plastic limit and plasticity index:

$$
\mathrm{LI}=(N W C-P L) /(P I)
$$

If $\mathrm{LI}=1$ the natural soil is at its liquid limit and if $\mathrm{LI}=0$ the soil is at plastic limit. 


\subsection{Triaxial cell testing}

A triaxial cell test is one of the most widely preformed and versatile geotechnical laboratory test, that allows for the stiffness and shear strength of soil and rock to be determined for application in geotechnical design (Reese, 2013). Triaxial cell tests involve confining a soil or rock specimen (with a height, Äì to , Äì diameter ratio of 2:1) within a pressurised cell to simulate stress conditions at burial depth and then shearing to failure, while measuring pore pressure. The device used has been developed by Global Digital Systems (GDS) instruments, (Figure 4.2) and consist of five key components: triaxial cell, load frame (50 KN), volume controller, $\ddot{A}$ ôs, a data acquisition unit and the GDSLAB software platform. This device provides a unique way to replicate landslides in laboratory conditions through the influence of pore pressure. For this research conventional failure envelopes (CFE) were calculated by conducting a conventional isotropically consolidated undrained (ICU) experiments and then plotting its corresponding Mohr circle. Once each CFE was determined, Pore Pressure Reflation testing (PPR) then was undertaken for each sample (Table $4.1)$

\subsubsection{Sample preparation and set up}

A remoulded sample was produced with material $<500$ microns. To achieve this, the sample block was dried for five days at $50^{\circ} \mathrm{C}$, then crushed using a crushing block and rolling cylinder ensuring no new particles were created. Following this, it was sieved to $<500$ microns. As required cylindrical samples have a known diameter and width $(80 \mathrm{~mm} \times 160 \mathrm{~mm})$, the volume of material and water content required was calculated. The necessary water to bring the sample up to the intact moisture content was combined in a tray with the sieved sample, ensuring it was thoroughly mixed and clumps broken down. The wet sample was compacted into the remoulding cylinder in small layers progressively until no sample was left, ensuring adequate and even compaction for each layer. Brass splits were taken apart and the weight along with length and width measurements recorded. During preparation multiple samples were found to not be fully compacted or had defects upon removal of brass splits. As a result these samples were rejected and new ones were produced to maintain a 

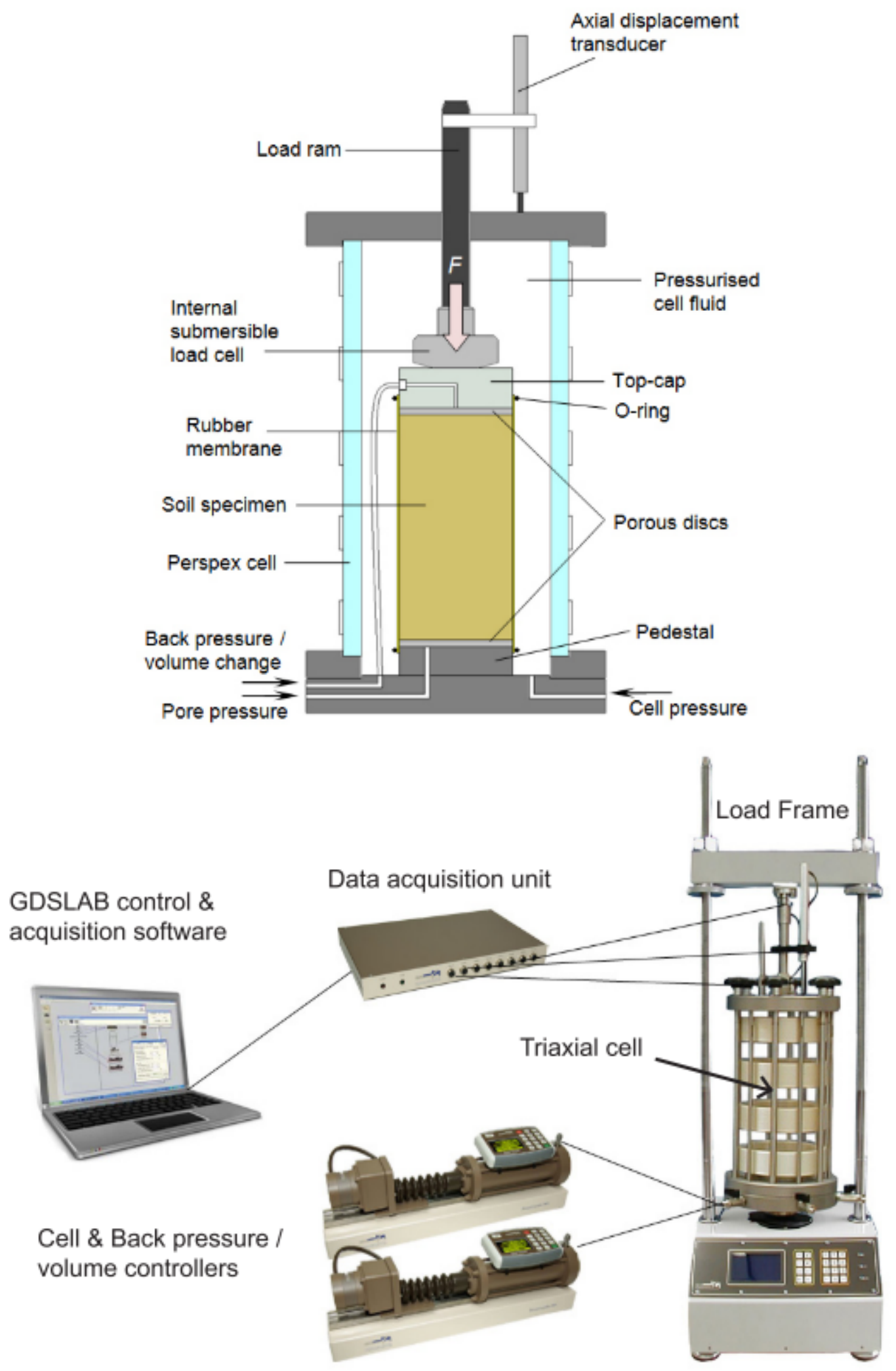

Figure 4.2: Diagram demonstrating the key components of a triaxial cell (top) and the associated equipment (bottom). Modified after Reese (2013) 
consistent sample standard.

Following this filter paper and a porous disk are placed under the sample that is then placed on the pedestal (Figure 4.2). A second porous disk and filter paper are then placed on top of the sample. A rubber membrane and top cap are fitted, allowing the perspex cell to be locked down and load ram guided into place. Ensuring all water lines are free of air bubbles, the cell can be filled with de-airrated water. It was found during initial testing, issues were experienced with rubber membranes leaking due to old age or over usage, resulting in the abortion of multiple tests. To address this problem, membranes were checked full of water before each subsequent test and additionally, new membranes were ordered and utilised, which had successful results.

\subsubsection{Sample saturation and consolidation phases}

The sample was fully saturated to ensure all voids within the sample were filled with water. This was completed by increasing the cell and back pressures/pore pressures, while maintaining a constant effective stress (cell , ̈̈ì back/pore pressure). An equivalent increase in cell and pore pressure should be observed. To ensure the sample was fully saturated a Skempton, Â̂o B-value check was completed, where the drain to the cell was closed while cell pressure was raised by $50 \mathrm{kPa}$. The following equation was used by comparing the ratio of pore pressure $(\mu)$ and cell pressure $\left(\sigma^{3}\right)$

$$
\mathrm{B} \text {-value }=\mu / \sigma^{3}
$$

When $\mathrm{B} \leq 0.95$ the sample is considered to be fully saturated and if $\mathrm{B}<0.95$ another saturation phase was conducted until an appropriate B value was reached. On occasions, multiple saturation phases were required to achieve the target $\mathrm{B}$ value. Following this, isotropic consolidation takes place to bring the sample to the required burial stress for shearing. Samples are brought to different effective stresses (Table 4.1) by initial stress-controlled shear to representative field stress conditions. This is achieved by increasing the cell pressure while maintaining a constant back pressure. Three different pressures are used as this gives a basis for the CFE construction. Successful consolidation is achieved when the sample shows no volume/displacement 
Table 4.1: Summary of the ICU and PPR testing programme conducted in this study

\begin{tabular}{|c|c|c|c|c|c|c|c|}
\hline Test Type & Sample & $\begin{array}{l}\text { Sample } \\
\text { Condition }\end{array}$ & B-Value & $\begin{array}{l}\text { Effective } \\
\text { Stress } \\
(\mathrm{kPa})\end{array}$ & $\begin{array}{l}\text { Strain } \\
\text { Rate } \\
(\mathrm{mm} / \mathrm{min})\end{array}$ & $\begin{array}{l}\text { Stress } \\
\text { Path } \\
(\mathrm{kPa})\end{array}$ & PPR Rate $(\mathrm{kPa} / \mathrm{h})$ \\
\hline ICU & LHL ICU1 & Remoulded & 0.95 & 250 & 0.04 & $\mathrm{~N} / \mathrm{A}$ & N/A \\
\hline ICU & LHL ICU2 & Remoulded & 0.97 & 500 & 0.04 & $\mathrm{~N} / \mathrm{A}$ & $\mathrm{N} / \mathrm{A}$ \\
\hline $\mathrm{ICU}$ & LDL ICU1 & Remoulded & 0.98 & 200 & 0.04 & $\mathrm{~N} / \mathrm{A}$ & $\mathrm{N} / \mathrm{A}$ \\
\hline ICU & LDL ICU2 & Remoulded & 0.96 & 500 & 0.04 & $\mathrm{~N} / \mathrm{A}$ & $\mathrm{N} / \mathrm{A}$ \\
\hline ICU & LDL ICU3 & Remoulded & 0.99 & 750 & 0.04 & $\mathrm{~N} / \mathrm{A}$ & $\mathrm{N} / \mathrm{A}$ \\
\hline PPR & LHL PPR3 & Remoulded & 0.96 & 500 & 0.04 & 300 & Stepped variable sequence $(10,15,20,15,10,5)$ \\
\hline PPR & LDL PPR1 & Remoulded & 0.95 & 500 & 0.04 & 300 & Linear 5 \\
\hline PPR & LDL PPR2 & Remoulded & 0.97 & 500 & 0.04 & 300 & Stepped 5 \\
\hline PPR & LDL PPR3 & Remoulded & 0.95 & 500 & 0.04 & 300 & Stepped variable sequence $(10,15,20,15,10,5)$ \\
\hline PPR & LDL PPR4 & Remoulded & 0.95 & 500 & 0.04 & 300 & Fluctuating 5 inc and dec \\
\hline
\end{tabular}

change once brought up to the required effective stress. If both cell and back pressure track each other, this indicates a leak in the system and the test must be aborted and re-run.

\subsubsection{Conventional isotropically consolidated undrained (ICU) shearing experiments}

To obtain a CFE for each sample, ICU experiments were undertaken at different effective stresses summarised in (Table 4.1). This involved applying axial strain (shear stress) to the sample until failure occurs, achieved by lowering the loading ram at a rate of $0.04 \mathrm{~mm} / \mathrm{min}$ while measuring the development of pore pressure and other variables. A maximum displacement of $10 \mathrm{~mm}$ could take place which signaled the end of the test.

\subsubsection{Pore pressure reinflation (PPR) testing}

To replicate pore pressures within the landslide a series of specialist pore pressure reinflation experiments were performed to simulate different increases and rate of increases in pore pressure similar to work undertaken by (Ng \& Petley, 2009). Each sample underwent saturation and isotropic consolidation as described in (stage one, Figure 4.3a) to replicate field stress conditions. Next (stage two), an initial shear phase "loads" the slope. During the PPR phase (stage three, Figure 4.3a), failure is initiated by increasing sample pore water pressure whilst holding the deviator (shear) and normal stress applied to the sample constant. This, in turn, results in a decrease in effective normal stress and ultimately leads to failure (Figure $4.3 \mathrm{a}$ ). During this stage, the sample displacement and pore pressure response is measured to understand 


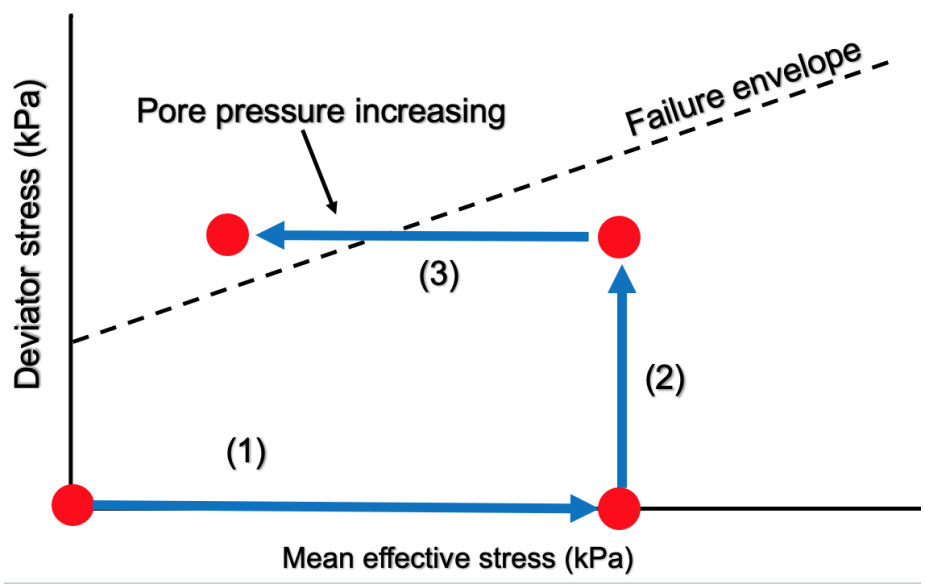

Figure 4.3: Schematic diagram demonstrating the stress history of a sample (Red circle) in relation to deviator stress, mean effective stress and the conventional failure envelope. Stage (1) consolidation phase - increasing mean effective stress to set the burial depth. Stage (2) increasing deviator stress (shear stress), applying load to the "slope". Stage (3) decreasing mean effective stress by increasing pore pressure to slope failure.

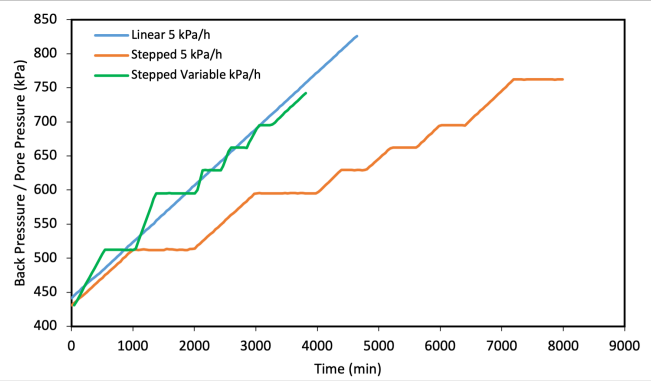

(a)

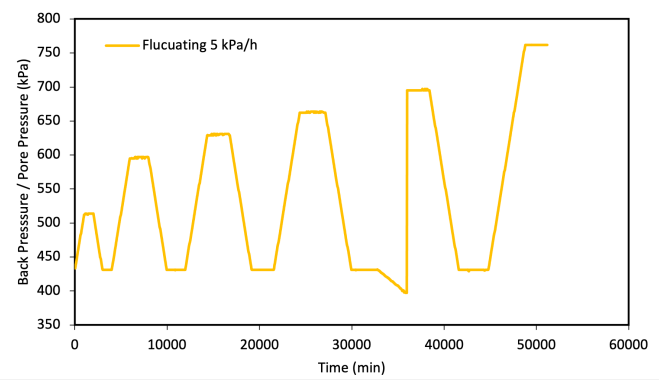

(b)

Figure 4.4: Diagrams demonstrating PPR increases against real time a) for all linear and stepped tests b) LDL fluctuating $5 \mathrm{kPa}$ test.

how the sample behaves. Three different increases in pore pressure were completed for both LDL and LHL in the following experiments with an additional test completed for LDL (Figure 4.4 and b) and (Table 4.1):

1. Linear $5 \mathrm{kPa} / \mathrm{h}$ increase - representing one large rainfall event

2. Stepped $5 \mathrm{kPa} / \mathrm{h}$ increase - representing rainfall events of the same magnitude over time

3. Variable stepped $\mathbf{k P a} / \mathbf{h}$ increase - different rainfall events of different magnitude over time

4. Flucutating $\mathbf{5} \mathbf{k P a} / \mathbf{h}$ - Only LDL - representing fluctuating rainfall increases and decreases over time 
The selection of the above testing regime is to simulate a range of pore pressure conditions. Simulating different patterns and magnitudes of increases allows for the replication of pore pressure and groundwater conditions for a landslide. Ranging from linear increases to stepped variables provides a continuum of rainfall events that may occur. The addition of the fluctuating test enables to investigation of the influence decreases in pore pressure may have on deformation behavior, as this replicates groundwater conditions in between events that decreases to a base level. It must be noted as observed in figure 4.4 following cycle four, applied pore pressure decreases instead of increasing at $5 \mathrm{kPa} / \mathrm{h}$. This was an user error, despite this the sample had experienced a complex enough stress history to examine the impact on final failure and no concerning volume and density changes were caused. 


\section{Chapter 5}

\section{Results}

\subsection{Physical Properties}

The physical properties of the landslide debris samples are summarised in Table 5.1 and were shown to have broadly similar characteristics. LHL is fine grained silt

Table 5.1: Summary of physical properties for Limestone Hills Landslide (LHL) and Leader Dam Landslide (LDL) debris samples.

\begin{tabular}{c|cc}
\hline Physical property & \multicolumn{3}{|c}{ Sample number } \\
\cline { 2 - 3 } & LHL & LDL \\
\hline Lithology & Silt & Silt \\
Sand content (\%) & 13 & 15 \\
Silt content (\%) & 84.1 & 80.9 \\
Clay content (\%) & 2.9 & 4.1 \\
CaC0 $_{3}$ content (\%) & 11.2 & 1.4 \\
Moisture Content (\%) & 16.2 & 17.4 \\
Bulk density $\left(\mathrm{g} / \mathrm{cm}^{3}\right)$ & 2.06 & 2.07 \\
Dry density $\left(\mathrm{g} / \mathrm{cm}^{3}\right)$ & 1.76 & 1.75 \\
Liquid limit & 31.5 & 31.3 \\
Plastic limit & 20.3 & 20.9 \\
Plasticity index & 11.5 & 12.2 \\
Liquidity index & -0.3 & -0.3 \\
Class & CL & CL \\
\hline
\end{tabular}

(84.1\%) with some sand (13\%) and clay contents (2.9\%) (Figure 5.1). LDL is similar (80.9\% silt) but has slightly more sand (15\%) and clay $(4.1 \%)$ content. The natural moisture content for LHL was measured slightly higher at $17.4 \%$, compared to $16.2 \%$ for LDL. Bulk densities were similar, calculated at $2.06 \mathrm{~g} / \mathrm{cm}^{3}$ for LHL and LDL at 


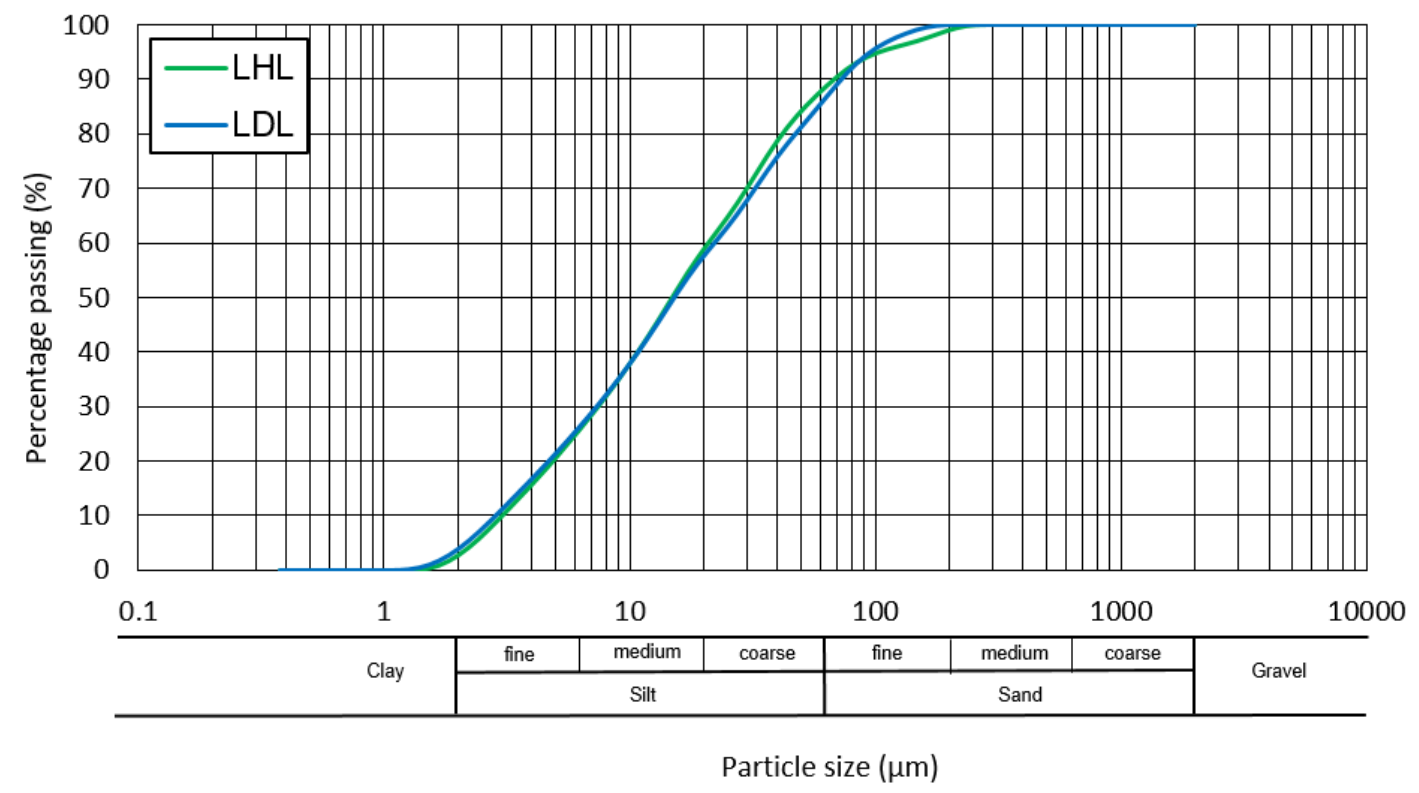

Figure 5.1: Passing percentage graph of particle size obtained from LDPSA results for LDL and LHL.

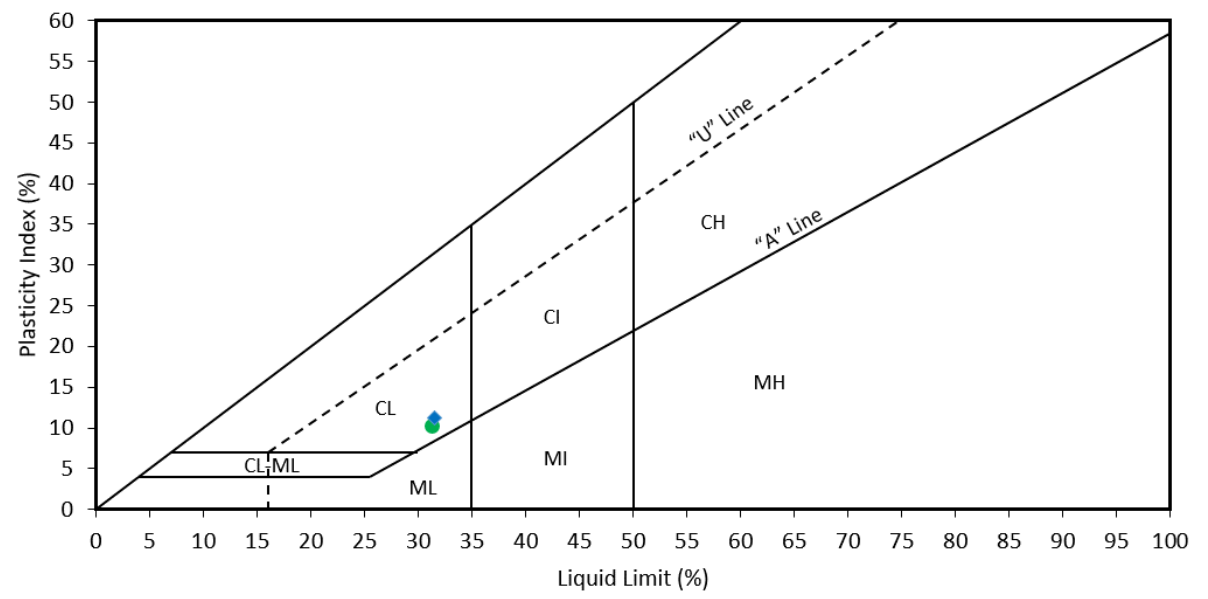

Figure 5.2: Casagrande plasticity chart for LHL and LDL samples. Note: $\mathrm{C}=$ clay, $\mathrm{M}=$ silt, $\mathrm{L}=$ low plasticity, $\mathrm{I}=$ intermediate plasticity, $\mathrm{H}$ = high plasticity, "A" line separates clays from silts, "U" line represents the upper boundary for general soils.

$2.07 \mathrm{~g} / \mathrm{cm}^{3}$. Both samples had slightly different liquid limits (31.5 and 31.3 respectively) and similar plastic limits (20.3\% and 20.3\% respectively) As a result, both LDL and LDL are classified as low plasticity clay (Figure 5.2). Additionally calcium carbonate contents show to be higher within LHL with $11.2 \%$ compared to $1.4 \%$ within LDL. 


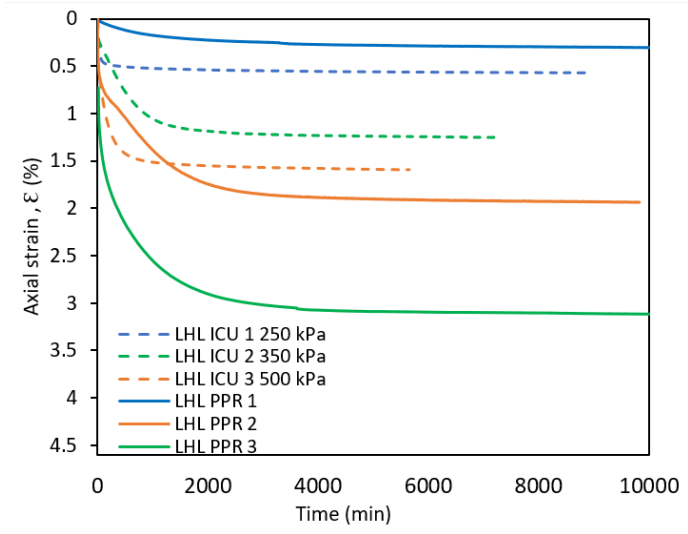

(a)

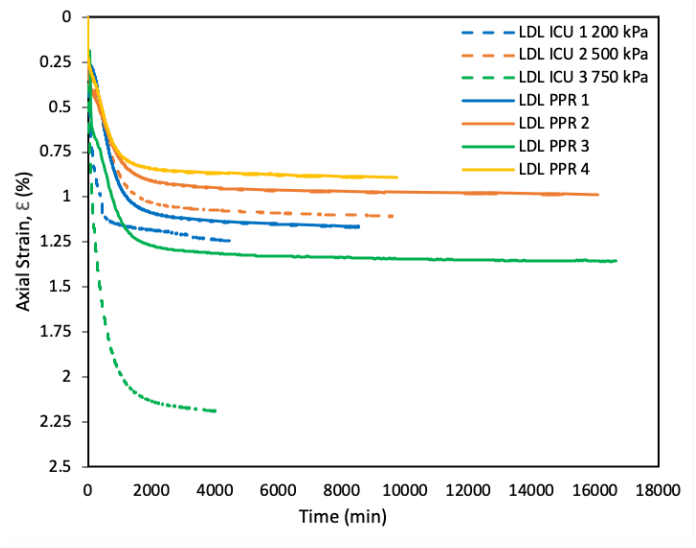

(b)

Figure 5.3: Consolidation histories demonstrating axial strain vs time for all a) LHL tests b) LDL tests.

\subsection{Triaxial cell testing}

To achieve the proposed research objectives and questions, a series of Isotropic Consolidated Undrained (ICU) tests and Pore Pressure Reinflation (PPR) tests were conducted using a GDS triaxial cell.

\subsubsection{Consolidation behaviour}

To generate a conventional failure envelope (CFE), samples were subject to ICU tests. Samples were fully saturated to achieve a B-Value of $\geq 0.95$ prior to consolidation (Table 4.1). During ICU tests, samples were consolidated to different mean effective stresses of 250, 350 and $500 \mathrm{kPa}$ for LHL and 200, 500 and $750 \mathrm{kPa}$ for LDL respectively (Table 4.1).

LHL consolidation histories for both ICU and PPR tests show increasing axial strain in the early stages of consolidation and then slowly decreases to $\sim 0 \%$ change (constant), indicating the samples are fully consolidated (Figure 5.3a). Intuitively, the highest mean effective stress e.g. $500 \mathrm{kPa}$ ICU and PPR tests underwent greater axial strain, therefore consolidated the most. However, some sample variability in time and amount of consolidation exists, e.g. LHL PPR1 underwent the least axial strain $(0.25 \%)$ even though it was consolidated at $500 \mathrm{kPa}$. Despite this each sample was consolidated until no further change in axial strain could be measured. LDL samples all show similar patterns of consolidation as observed for LHL. Again some variability in time to reach constant axial strain is observed (Figure 5.3b), each 


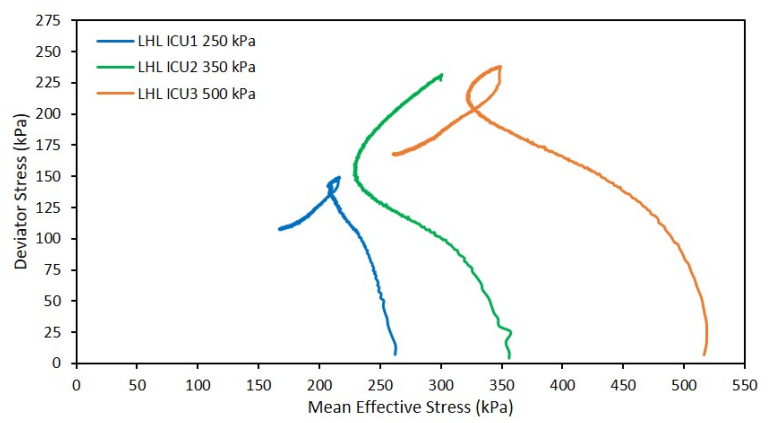

(a)

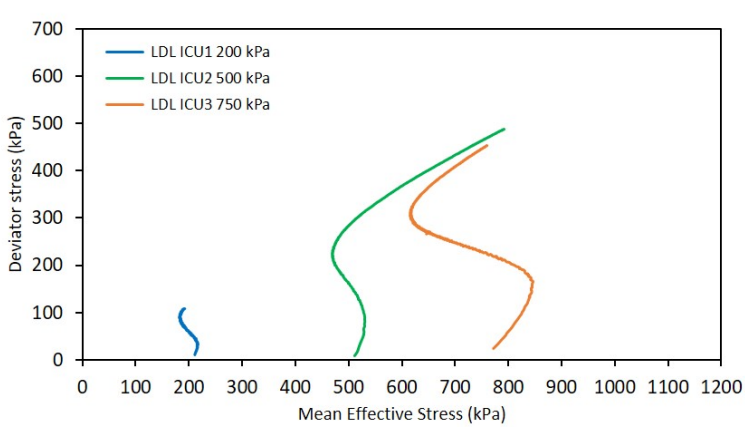

(b)

Figure 5.4: Stress path plots of deviator stress vs mean effective stress from ICU tests for a) LHL and b) LDL.

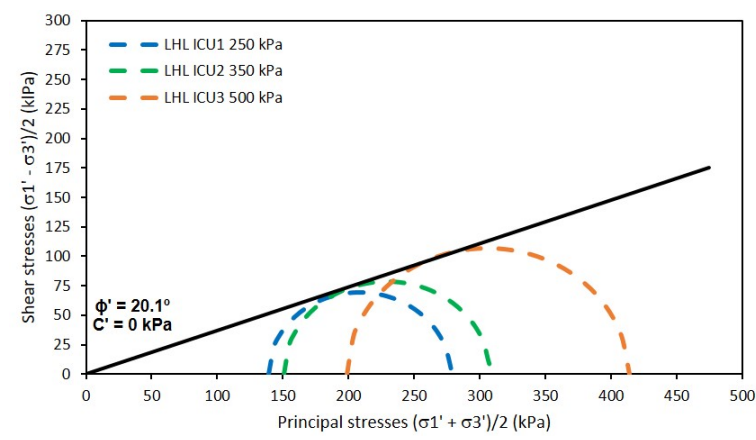

(a)

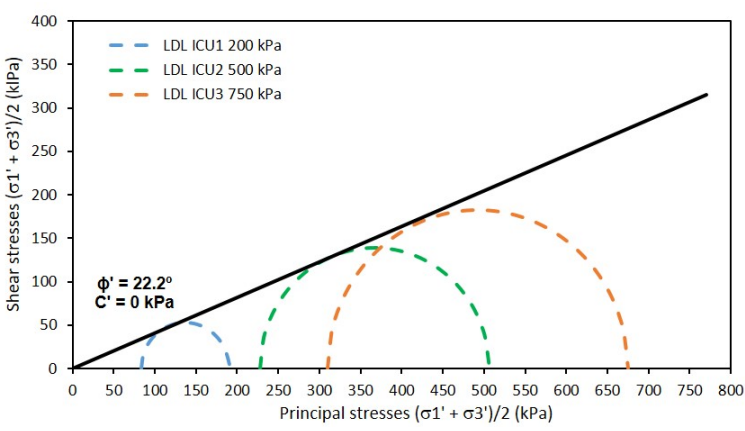

(b)

Figure 5.5: Mohr Circles constructed from ICU tests for a) LHL and b) LDL. 
sample was consolidated until no further change in axial strain could be measured.

\subsubsection{ICU shear strength characteristics}

Both materials followed a conventional isotropically consolidated undrained stress path during shear (Figures 5.4 with decreasing mean effective stress towards the CFE. Post failure behavior for LHL, demonstrates mean effective and deviator stresses decreasing, apart from LHL $350 \mathrm{kPa}$ which increases (Figures 5.4 a). Post failure behavior for LDL, also demonstrates mean effective and deviator stresses increasing for the chosen "middle" mean effective stress test (500 kPa) (Figures 5.4b). It is important to note LHL $350 \mathrm{kPa}$ and LDL $500 \mathrm{kPa}$ stress paths increase significantly above the CFE line. This is likely associated with sample failure altering the area and pore pressure dispersion causing an increase in deviator and mean effective stresses. These results were used to generate Mohr Circles using the methodology after Head et al. (1998).

Calculated Mohr Circle failure envelopes (Figures 5.5 a and b) suggests that LDL has a slightly higher effective friction angle $(\phi)=,22.2^{\circ}$ than LHL $(\phi)=,20.1^{\circ}$. Both samples have an effective cohesion $\left(\mathrm{C}^{\prime}\right)=0 \mathrm{kPa}$, as expected with remoulded samples. Despite the minor variability in the friction angles between LDL and LHL samples both materials display similar shear strength characteristics, consistent with their similar physical properties.

\subsubsection{Pore Pressure Reinflation (PPR) Testing}

Specialist PPR tests were undertaken to simulate pore pressure changes in LDL and LHL samples. Three different PPR tests were undertaken (Table 4.1). In these tests back pressure (applied pore pressure) is increased to simulate increasing pore pressures and reducing mean effective stress in the slope following periods of rainfall. Initial sample densities for each sample before each PPR test was undertaken are presented in Appendix A. All samples have an initial density representative of the each respective bulk density calculated in physical property testing (Table 5.1) . 


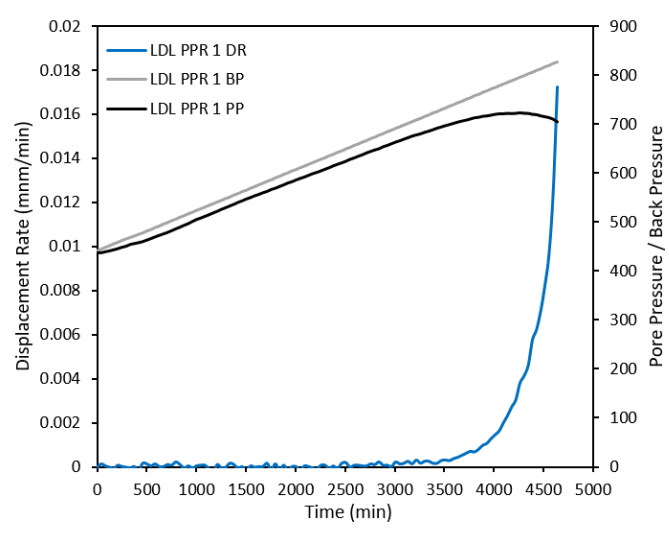

(a)

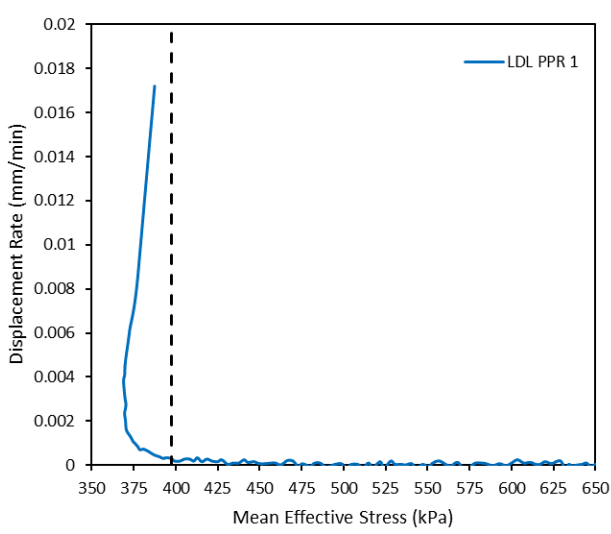

(c)

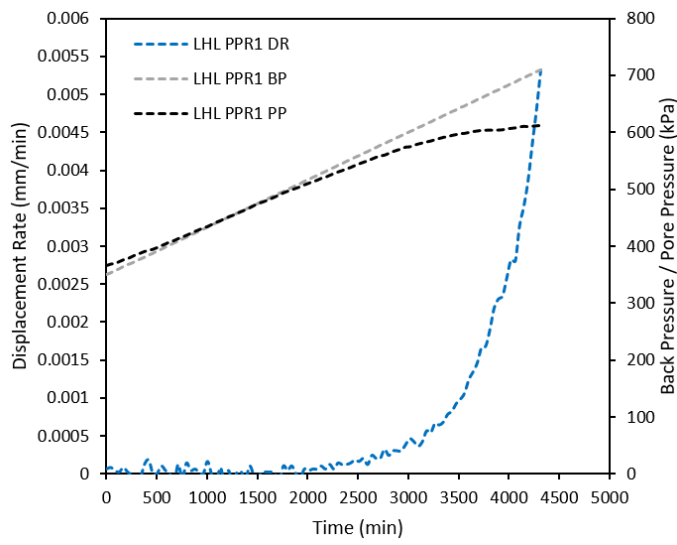

(b)

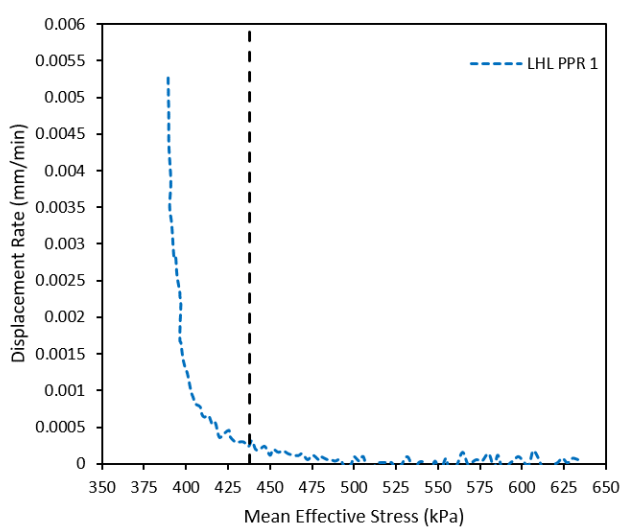

(d)

Figure 5.6: Deformation behavior of LDL and LHL during linear PPR $5 \mathrm{kPa} / \mathrm{h}$ tests. Plots a) LDL and b) LDL, demonstrating displacement rate and pore pressure back pressure vs time. Plots c) LDL and d) LHL demonstrating displacement rate vs mean effective stress. Note:increasing mean effective stress in fig a) for LDL at displacement rates above $0.006 \mathrm{~mm} / \mathrm{min}$ is a post failure (end of test) response where sample drainage results in increasing mean effective stress through decreasing pore pressures. Vertical dashed lines in a) and b) are the conventional failure envelope for each respective material.

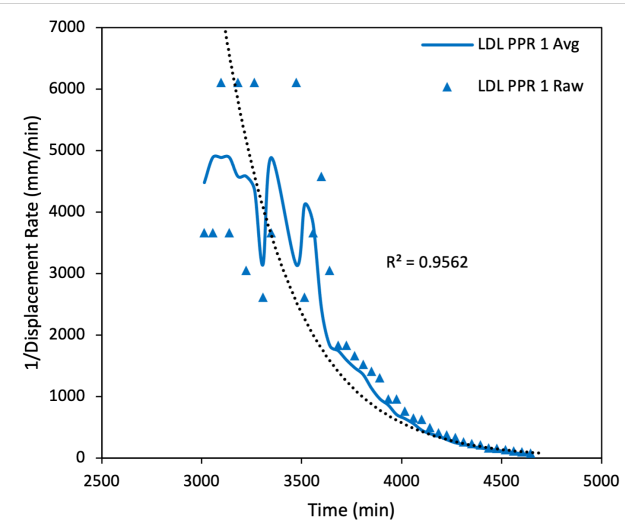

(a)

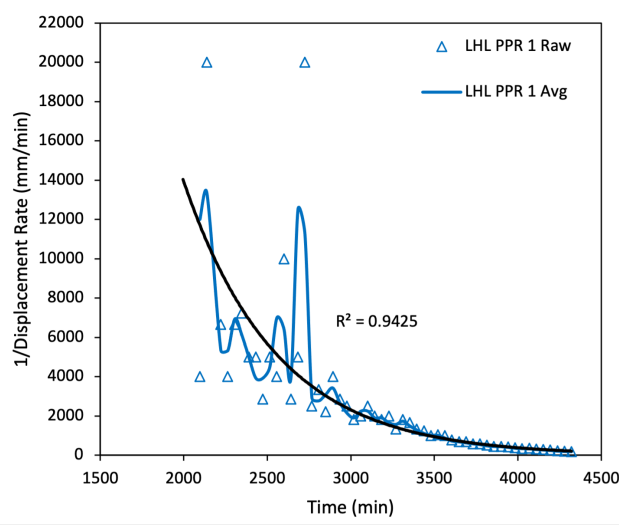

(b)

Figure 5.7: Inverse velocity $(1 / v)$ vs time and best fit trend line $R^{2}$ values for a) LDL and b) LHL. Note: $1 / v$ is equal to $1 /$ displacement rate 
Table 5.2: Coefficient fits for $1 / v$ analysis for LDL and LHL. Note: Bold numbers represent the best fit for each sample.

\begin{tabular}{ccccc}
\hline Sample Number & PPR Test & Linear Trend $\mathbf{R}^{2}$ & Exponential Trend $\mathbf{R}^{2}$ & Power Trend R $^{2}$ \\
\hline LDL PPR1 & Linear $5 \mathrm{kPa} / \mathrm{h}$ & 0.8843 & $\mathbf{0 . 9 5 6 2}$ & 0.9313 \\
LDL PPR2 & Stepped $5 \mathrm{kPa} / \mathrm{h}$ & 0.711 & $\mathbf{0 . 9 6 3}$ & 0.9585 \\
LDL PPR3 & Stepped Variable kPa/h & 0.682 & 0.9746 & $\mathbf{0 . 9 8 1 8}$ \\
LDL PPR4 & Fluctuating $5 \mathrm{kPa} / \mathrm{h}$ & 0.3418 & 0.7188 & $\mathbf{0 . 7 4 1}$ \\
& & & & 0.919 \\
LHL PPR1 & Linear $5 \mathrm{kPa} / \mathrm{h}$ & 0.6175 & $\mathbf{0 . 9 4 2 5}$ & 0.9013 \\
LHL PPR2 & Stepped $5 \mathrm{kPa} / \mathrm{h}$ & 0.4665 & $\mathbf{0 . 9 2}$ & $\mathbf{0 . 9 4 3 5}$ \\
LHL PPR3 & Stepped Variable kPa/h & 0.7433 & 0.9145 & \\
\hline
\end{tabular}

\section{Linear $5 \mathrm{kPa} / \mathrm{h}$ tests}

Both LDL and LHL PPR1 samples display three stages of behavior. Stage one demonstrates as back pressure (applied pore pressure) is increased, pore pressure (measured) also increases (generating pore pressure), therefore implying a decrease in mean effective stress (Figure $5.6 \mathrm{a}$ and b). Little to no displacement is observed until 2250 minutes for LDL and 1750 minutes for LHL. At these points a critical stress threshold (stage two) is reached, pore pressure begins to deviate from back pressure and very low displacement rates are observed of $0.00009 \mathrm{~mm} / \mathrm{min}$ and 0.0004 $\mathrm{mm} / \mathrm{min}$ respectively. Following this, the sample begins to deform as mean effective stress continues to decrease reaching the CFE (Figure 5.6c and d). Around 4000 minutes for LDL and 3000 minutes for LHL higher displacement rates begin to develop (exponential acceleration stage three) until complete failure by 0.001 $\mathrm{mm} / \mathrm{min}$ for both, reaching respective peak displacement rates of $0.017 \mathrm{~mm} / \mathrm{min}$ and $0.00530 \mathrm{~mm} / \mathrm{min}$. Both materials demonstrate asymptotic inverse velocity trends decreasing from $14000 \mathrm{~mm} / \mathrm{min}$ (LHL) and $6000 \mathrm{~mm} / \mathrm{min}$ (LDL)to $\sim 0 \mathrm{~mm} / \mathrm{min}$ (Figure 5.7). $\mathrm{R}^{2}$ fit values of 0.9562 for LDL and 0.9425 LHL (Table 5.2) suggest similar ductile behavior (Petley et al., 2002).

\section{Stepped $5 \mathrm{kPa}$ tests}

As stepped PPR tests provide more detail within individual stages/steps, each test is broken down into three stages of behavior. Stage one demonstrates the same behavior in pore pressure as back pressure, as it is increased and held constant during the early stages of the experiment, while mean effective stress begins to decrease (Figure $5.8 \mathrm{a}$ and b) and (Figure 5.9 a and b). Together displacement rates show little to no change from $0 \mathrm{~mm} / \mathrm{min}$. 


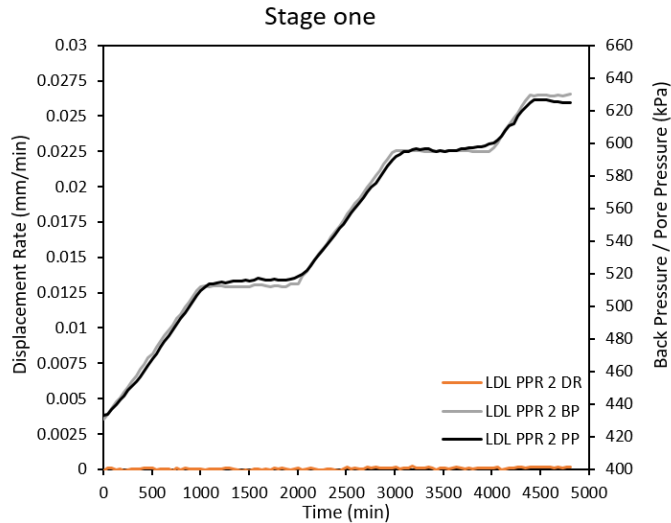

(a)

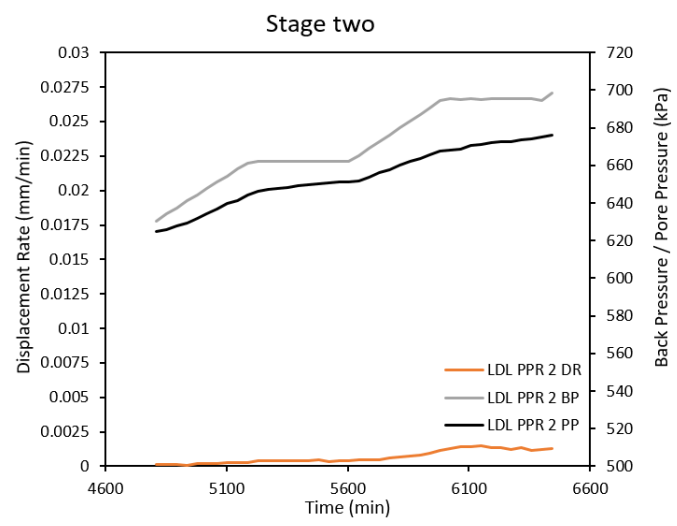

(c)

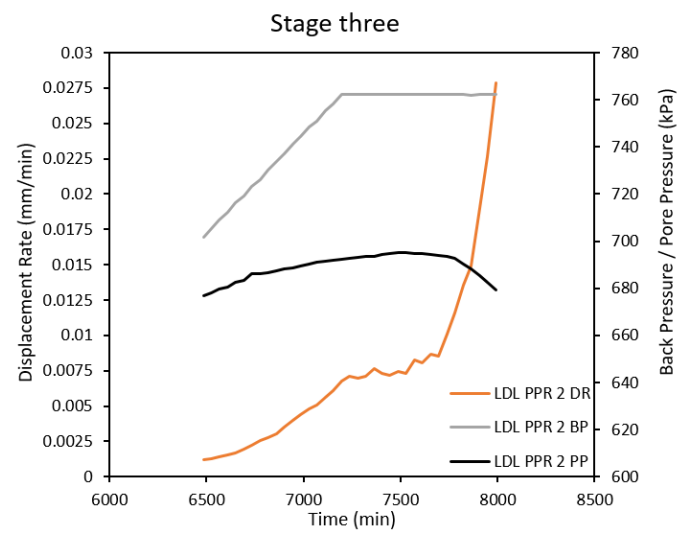

(e)

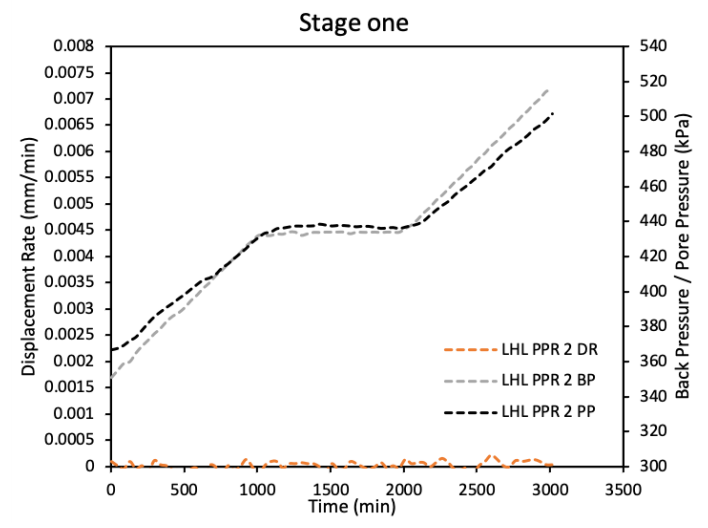

(b)

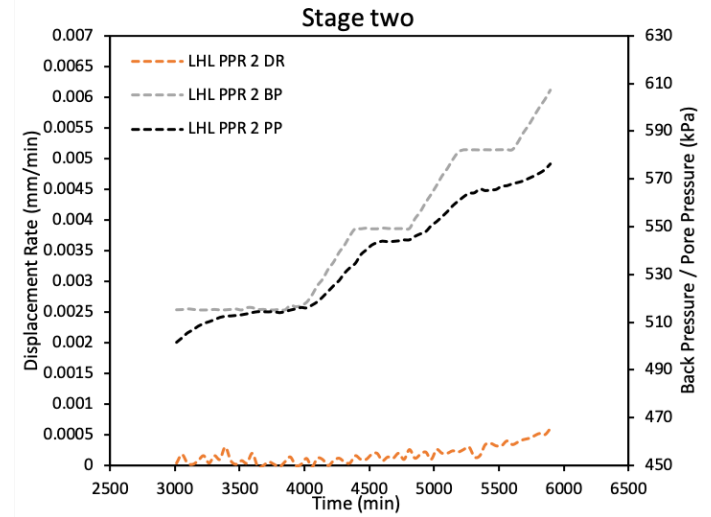

(d)

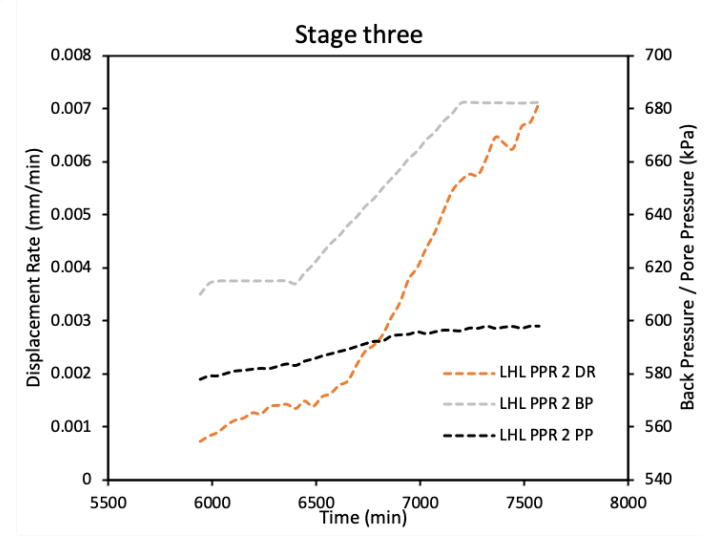

(f)

Figure 5.8: Split test plots for stepped $5 \mathrm{kPa} / \mathrm{h}$ tests of displacement rate and back pressure / pore pressure vs time for LDL a) Stage one, c) Stage two and e) Stage three. LHL b) Stage one, d) Stage two and f) Stage three. 


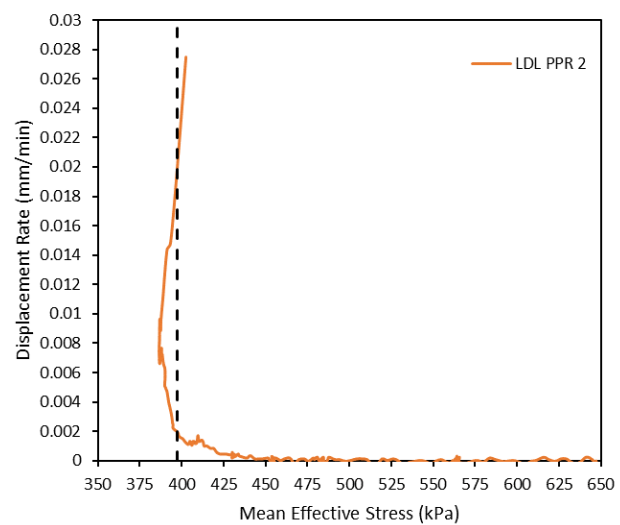

(a)

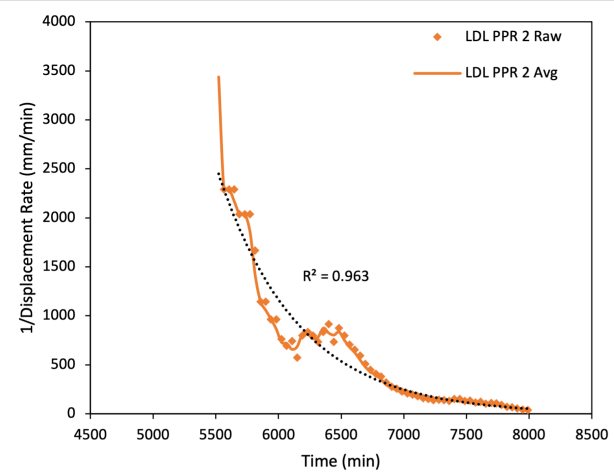

(c)

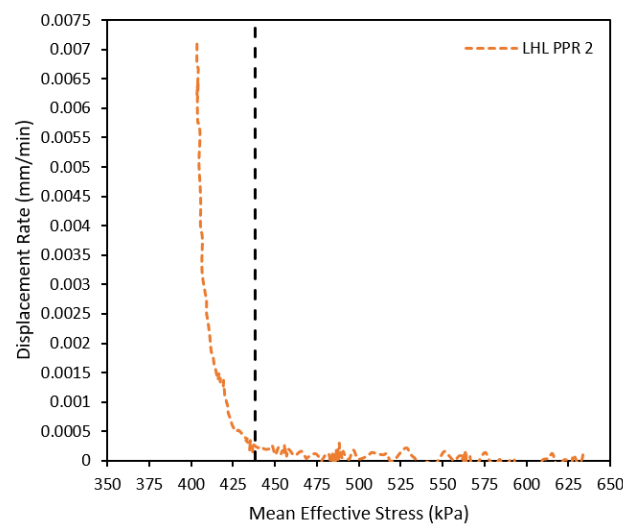

(b)

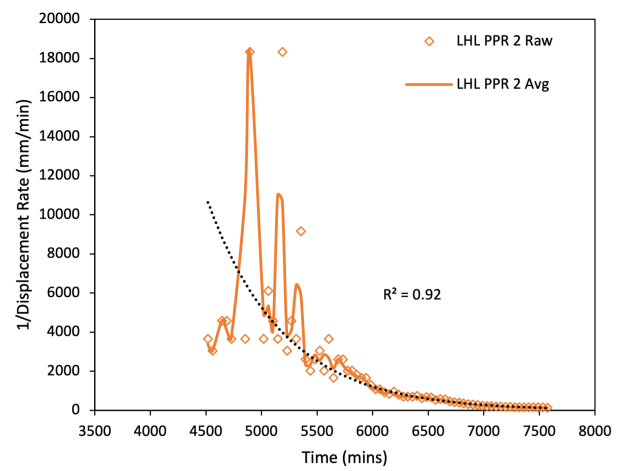

(d)

Figure 5.9: Stepped $5 \mathrm{kPa} / \mathrm{h}$ test plots for a) LDL and b) LHL demonstrating displacement rate vs mean effective stress. Plots c) LDL and d) showing 1/v vs time. Note:increasing mean effective stress in fig c) for LDL at displacement rates above $0.004 \mathrm{~mm} / \mathrm{min}$ is a post failure (end of test) response where sample drainage results in increasing mean effective stress through decreasing pore pressures. Vertical dashed lines in a) and b) are the conventional failure envelope for each respective material.

LDL shows a critical stress threshold is reached by 4852 minutes (stage two) and the sample begins to deform at a very low displacement rate of $0.0001 \mathrm{~mm} / \mathrm{min}$, until 6150 minutes where it becomes roughly constant at $0.0013 \mathrm{~mm} / \mathrm{min}$. Simultaneously pore pressure increases whilst back pressure is held constant from 5180-5600 minutes and 5980-6400 minutes. Mean effective stress continues to decrease (Figure 5.9.). LHL shows similar behavior where a critical stress threshold is reached by 4700 minutes (stage two) and initiating sample deformation as displacement rate begins to increase from $0.00014 \mathrm{~mm} / \mathrm{min}$ (Figure 5.8c), while pore pressure deviates from back pressure, increasing under constant back pressure from 4470-4800 minutes and 5200-5600 minutes. During stage two mean effective stress continues to decrease reaching the CFE (Figure 5.8d and 5.9p).

In stage three both samples begin to develop higher displacement rates overall. LDL 
undergoes a period of reduced displacement rate from 7200-7600 minutes also observed at $412.5 \mathrm{kPa}$ MES (Figure 5.8p and 5.9p), before final exponential acceleration to a peak rate of $0.0270 \mathrm{~mm} / \mathrm{min}$ under constant back pressure. Concurrently pore pressure stops increasing and begins decreasing under constant back pressure, indicating sample dilation. The CFE is reached prior to final exponential acceleration. LHL similarly shows higher displacement rates (stage three) with a period of reduced displacement from 6270-6480 minutes (Figure 5.8 ), before final exponential acceleration to a peak displacement rate of $0.0067 \mathrm{~mm} / \mathrm{min}$, occurring under constant back pressure. It is key to note final exponential acceleration for LHL occurs after the CFE (Figure $5.9 \mathrm{~b}$ ).

Both materials display exponential decreases in inverse velocity from $3500 \mathrm{~mm} / \mathrm{min}$ for LDL and $1800 \mathrm{~mm} / \mathrm{min}$ for LHL to $\sim 0 \mathrm{~mm} / \mathrm{min}$ (Figure 5.9c and d). $\mathrm{R}^{2}$ values of 0.92 and 0.963 (Table 5.2) suggest best fits for both materials as exponential trend lines, therefore suggesting ductile behavior consistent with the asymptotic pattern by Petley et al. (2002).

\section{Stepped variable tests}

Similar to stepped $5 \mathrm{kPa} / \mathrm{h}$ experiments, stepped variable $\mathrm{kPa} / \mathrm{h}$ tests demonstrate three stages of behavior. In stage one for both materials both back pressure and pore pressure increases, while mean effective stress decreases. (Figure 5.10 a and b) and (Figure 5.11 a and b). Together displacement rates show little to no change from 0 $\mathrm{mm} / \mathrm{min}$. Notably, for LHL pore pressure increases under constant back pressure early in the test from 500-1000 minutes (Figure 5.10b).

LDL demonstrates a critical threshold is reached (stage two) by 1080 minutes, (Figure 5.10 c) where pore pressure deviates from back pressure and sample deformation begins at initially a displacement rate from $0.00016 \mathrm{~mm} / \mathrm{min}$. Pore pressure increases under periods of constant back pressure from 1290-1960 minutes and 2130-2380 minutes. Concurrently, mean effective stress continues to decreases towards the CFE as the sample is deforming (Figure 5.11 a). LHL demonstrates similar behavior except reaching the critical stress threshold at 1300 minutes, with displacement rate increasing initially at $0.00018 \mathrm{~mm} / \mathrm{min}$ (Figure 5.10d). Pore pressure is also increasing under constant back pressures from 1300-1800 and 2130-2340 minutes, 


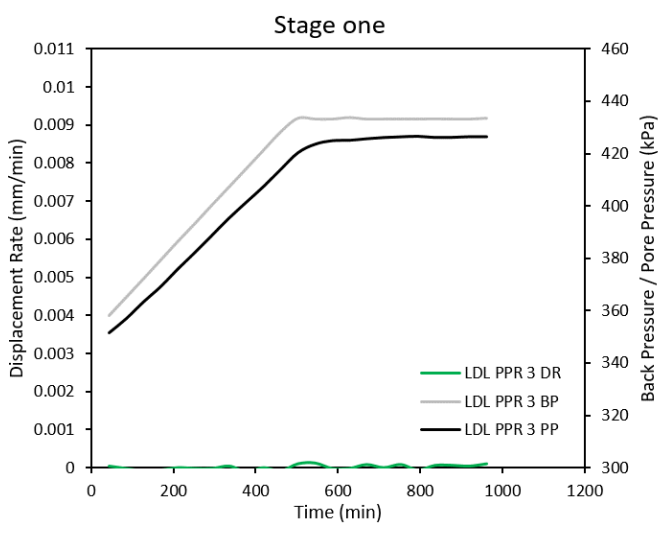

(a)

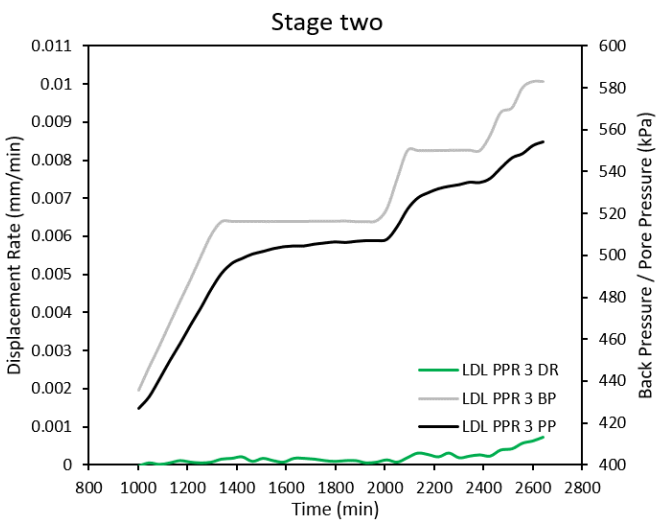

(c)

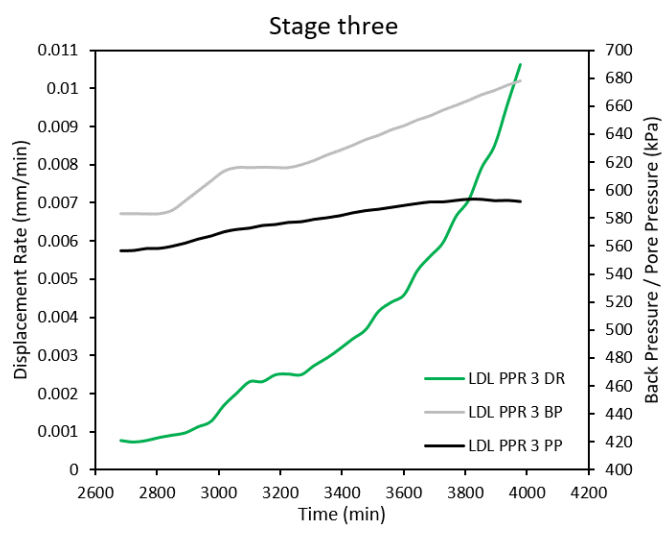

(e)

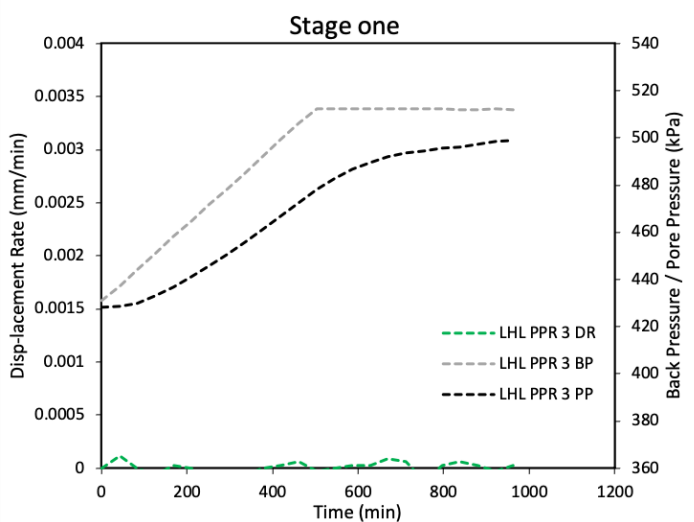

(b)

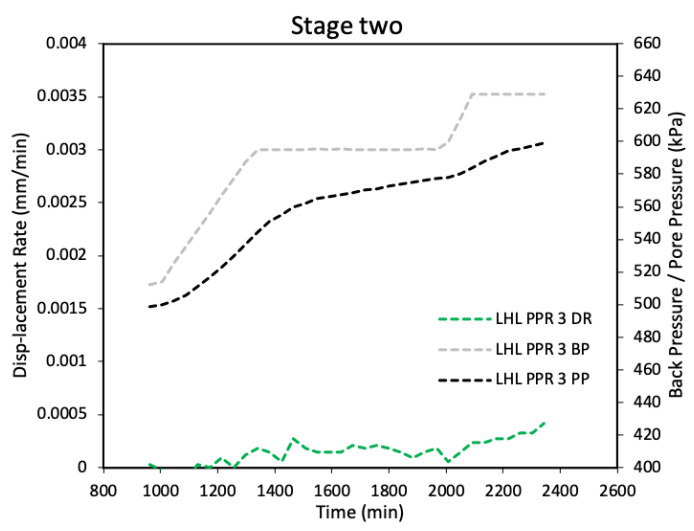

(d)

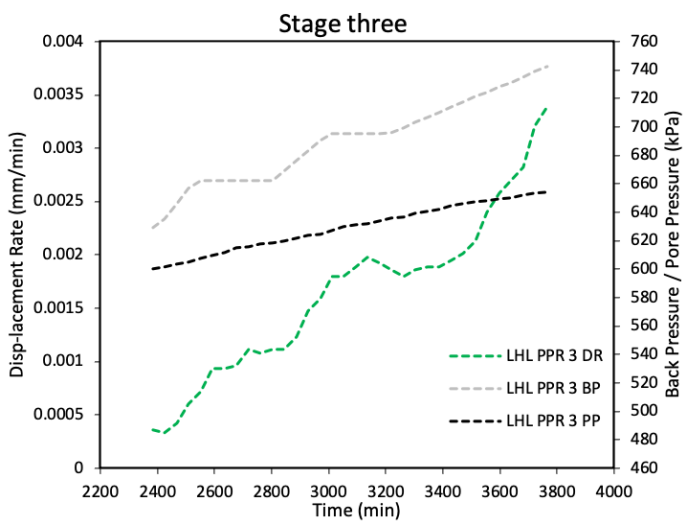

(f)

Figure 5.10: Split test plots for stepped variable $\mathrm{kPa} / \mathrm{h}$ tests demonstrating displacement rate and back pressure/pore pressure vs time for LDL a) Stage one, c) Stage two and e) Stage three. LHL b) Stage one, d) Stage two and f) Stage three. 
while mean effective stress decreases through stage two (Figure $5.11 \mathrm{~b}$ ).

In stage three, LDL continues to deform as higher displacement rate develops until a decrease in displacement rate from 3000 minutes until 3260 minutes, before final exponential acceleration to a peak displacement rate of $0.01060 \mathrm{~mm} / \mathrm{min}$ (Figure 5.10). Simultaneously, pore pressure continues to increase, but at a slower rate, again under back pressure increases and constant pressures. LHL differently is punctuated with steps in displacement rate from 2400-3700 minutes with exponential acceleration to failure after 3260 minutes (Figure 5.10f). Pore pressures continued to increase under constant back pressures from 2550-2800 and 3000-3200 minutes. For both LDL and LHL, mean effective stresses decreased as the test progressed, however LDL PRP3 did not exceed the CFE, failing at mean effective stress of 428. LHL did not exceed the CFE until near the end of the test at a displacement rate of 0.001875 $\mathrm{mm} / \mathrm{min} 5.11 \mathrm{a}$ and $\mathrm{b})$.

Similar to linear and stepped experiments, both materials display asymptotic decreases in $1 / \mathrm{v}$ with time (Figure 5.11) c and d). Best fit $\mathrm{R}^{2}$ values of 0.9618 for LDL and (Table 5.2) for LHL 0.9458 under power trends are consistent with asymptotic patterns and thus ductile behavior (Petley et al., 2002).

\section{LDL fluctuating $5 \mathrm{kPa}$ test}

An additional experiment was conducted on LDL material to simulate fluctuations in pore pressure over time. LDL PPR4 demonstrate two main stages of behavior. Firstly, (Stage one) back pressure and pore pressure both increase and decrease through cycles 1-5 until 44700 minutes. Pore pressure increases slightly in periods of constant back pressures before decreasing (Figure 5.12a). During this period, displacement rate fluctuates with concurrently with back and pore pressure increases and decrease, not reaching above rates of $0.00015 \mathrm{~mm} / \mathrm{min}$. Displacement plots demonstrate decreases in displacement (i.e dilation) upon each back pressure increase, then increasing displacements (contraction) under constant and decreasing pore pressures (Figure 5.12 c). Mean effective stress decreases towards the CFE (Figure 5.12 ). By 47900 minutes a critical stress threshold is reached (Stage two) (Figure 5.12 b) and displacement rates develop rapidly, initially from $0.00148 \mathrm{~mm} / \mathrm{min}$ to $0.002048 \mathrm{~mm} / \mathrm{min}$ until 49990 minutes. Pore pressures begins to slightly deviate 


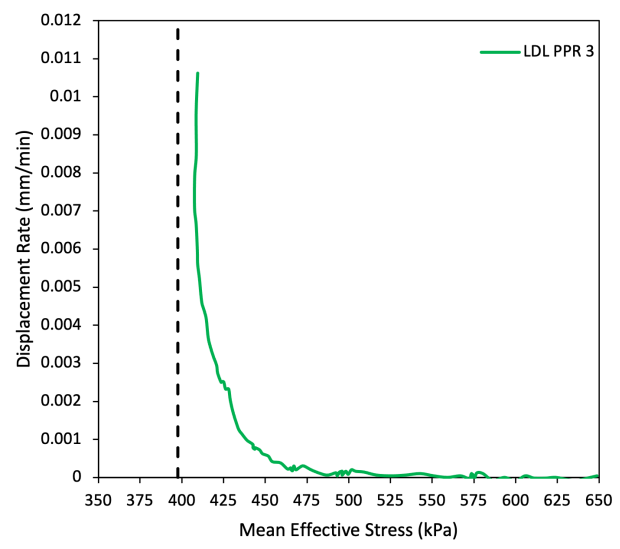

(a)

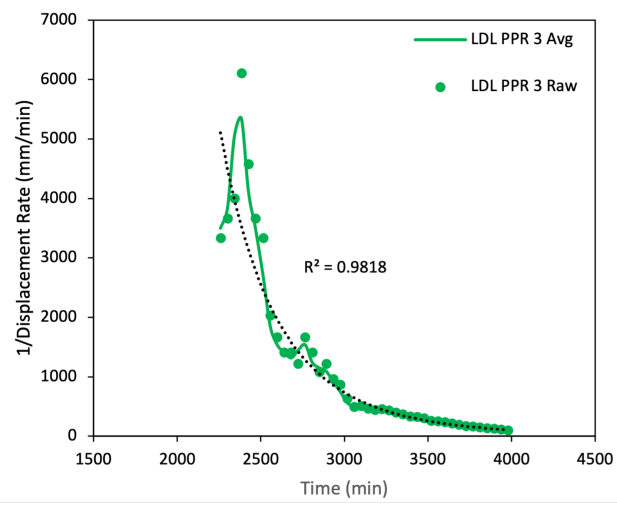

(c)

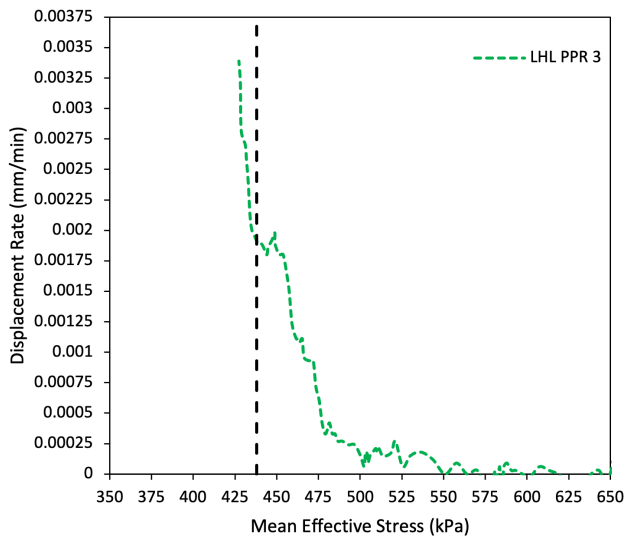

(b)

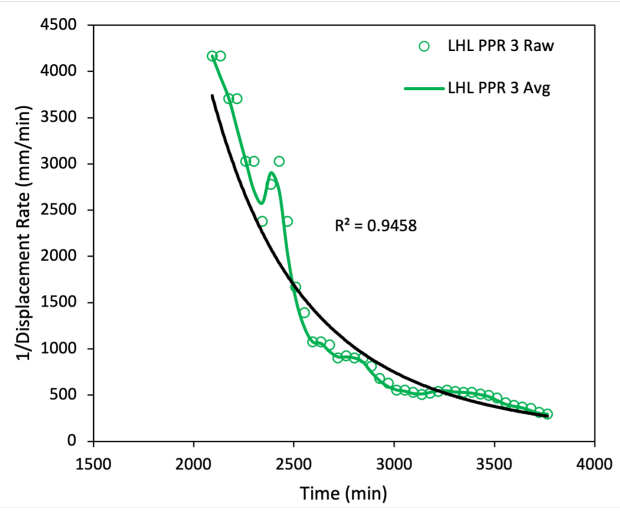

(d)

Figure 5.11: Stepped variable $\mathrm{kPa} / \mathrm{h}$ test plots for a) LDL and b) LHL demonstrating displacement rate vs mean effective stress. Plots c) LDL and d) showing $1 / \mathrm{v}$ vs time. Note: vertical dashed lines in a) and b) are the conventional failure envelopes for each respective material. 
away from back pressure. This is followed by a decrease in displacement rate and exponential acceleration to a peak displacement rate of $0.00426 \mathrm{~mm} / \mathrm{min}$, under constant back pressure. Mean effective stresses continues to decrease, exceeding the CFE with continual sample deformation taking place (Figure 5.12 ) failing at a mean effective stress of $359 \mathrm{kPa}$. LDL PPR4 shows a decrease in 1/v from around 8000 $\mathrm{mm} / \mathrm{min}$ to $\sim 0 \mathrm{~mm} / \mathrm{min}$. $\mathrm{R}^{2}$ best fit of 0.7241 (Figure $5.12 \mathrm{f}$ for a power function is again consistent with ductile behavior (Petley et al., 2002) however is a lower $\mathrm{R}^{2}$ than all other tests best fits $\mathrm{R}^{2}$. 


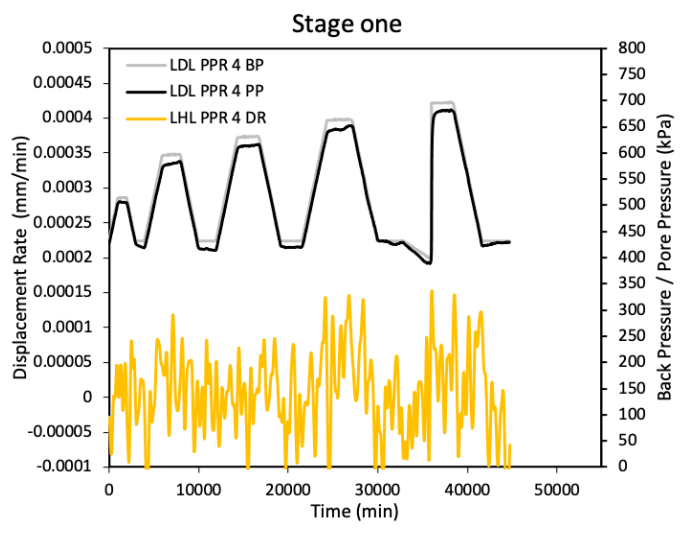

(a)

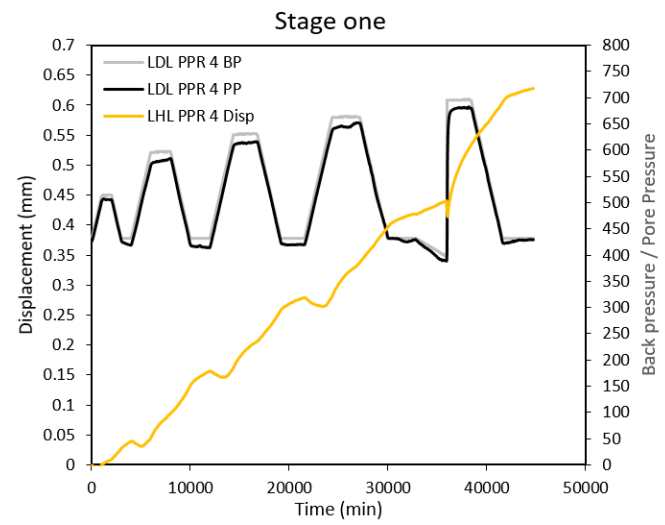

(c)

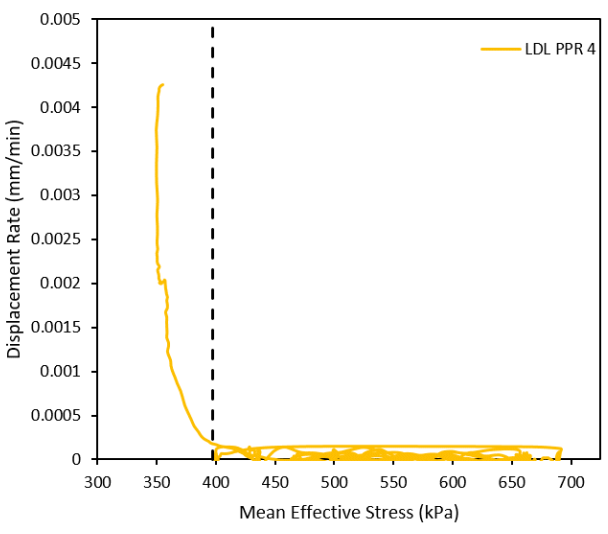

(e)

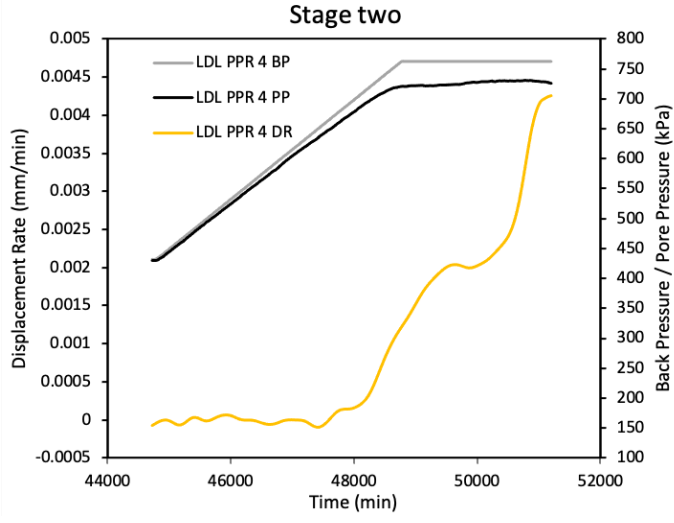

(b)

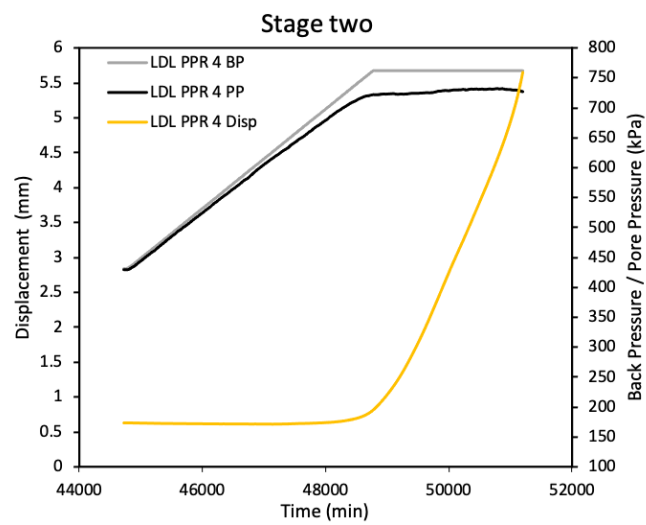

(d)

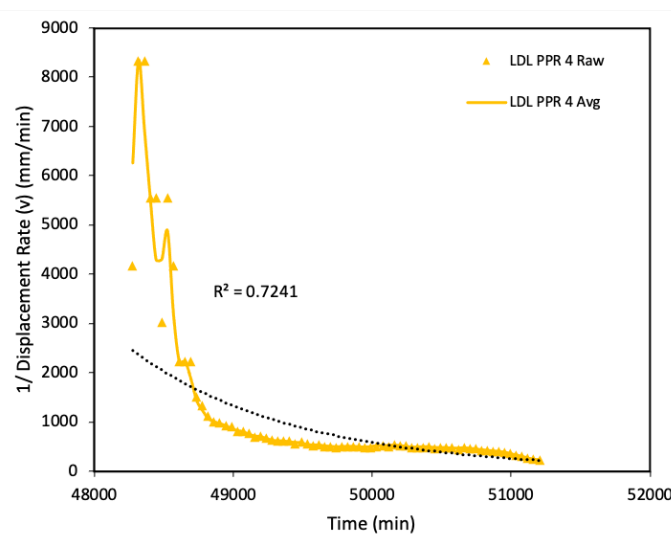

(f)

Figure 5.12: Fluctuating $5 \mathrm{kPa} / \mathrm{h}$ test plots for LDL of a) displacement rate and back pressure / pore pressure vs time for stage one and b) stage two. Displacement and pore pressure /back pressure vs time for a) stage one and b) stage two. Plot c) displacement rate vs mean effective stress. Plot d) $1 / v$ vs time. Note: vertical dashed line is the conventional failure envelope. 


\section{Chapter 6}

\section{Discussion}

This chapter combines specialist laboratory testing and geomorphic mapping for the Limestone Hill Landslide and Leader Dam Landslide study sites to explore how failed and partially failed slopes composed of primarily silt behave during rainstorms following major earthquakes. This will be organised under five main research questions.

1. Can laboratory experiments explain the behaviour of failed landslide material?

2. Given similarity between materials, is the behaviour similar?

3. Do changes in pore pressure influence landslide behaviour?

4. Is there a rate effect observed within pore pressure and displacement trends?

5. Do fluctuating pore pressures influence landslide failure behaviour?

\subsection{Can laboratory experiments explain the behaviour of failed landslide material?}

Linear $5 \mathrm{kPa} / \mathrm{h}$ experiments conducted on both materials displayed three stages of behaviour as discussed in section 5.2.3. During the first stage (stage one, Figure 6.1) an initial increase in pore pressure generated a reduction in mean effective stress but does not result in any measurable displacement / strain response. Behavior is consistent with plastic behavior observed in other laboratory and field studies where minor changes in effective stress are not sufficient to reach the materials yield state 


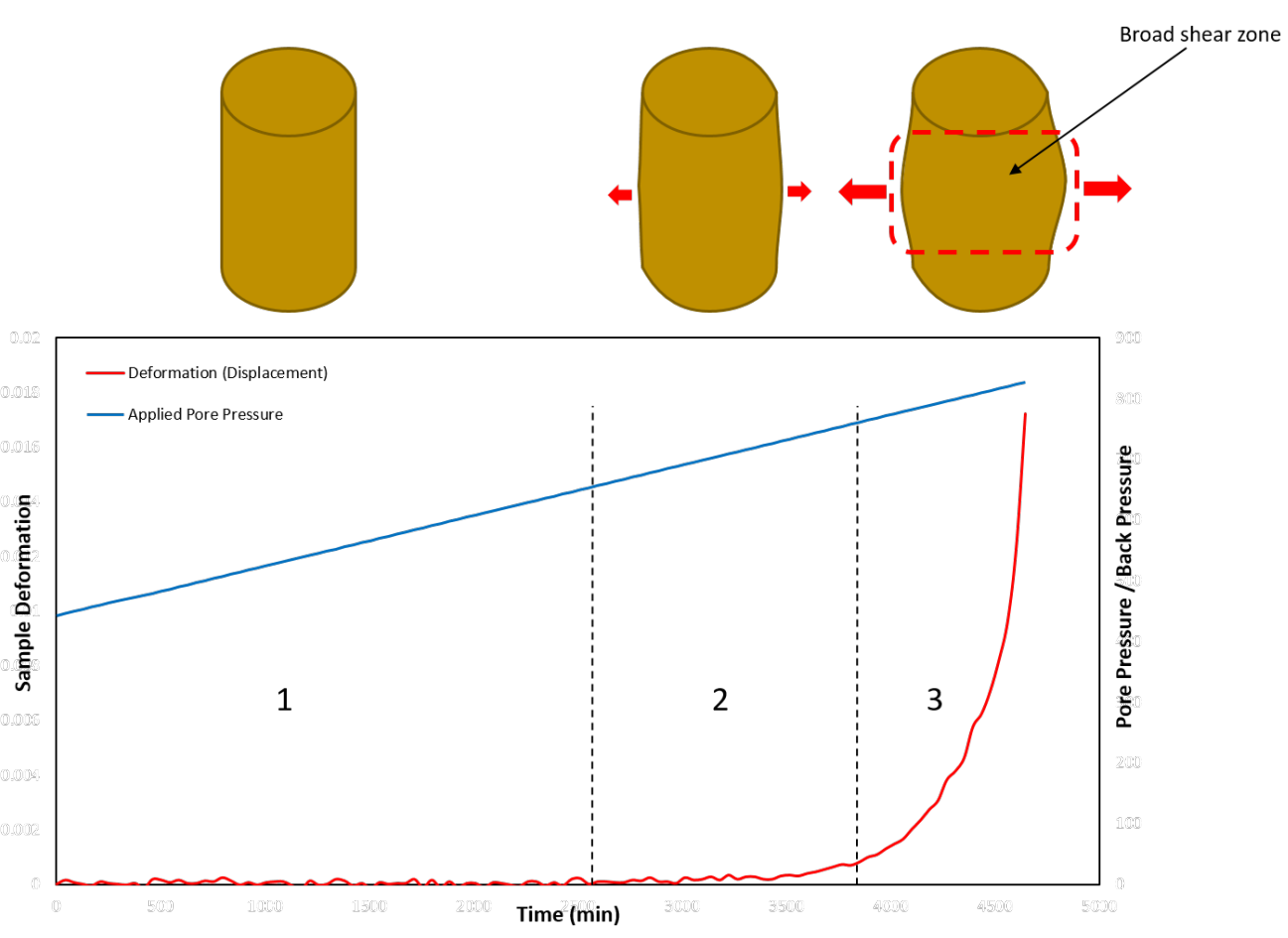

Figure 6.1: Conceptual diagram demonstrating stages of sample behaviour for linear PPR tests. Note: differing size arrows are indicative of the amount of deformation.

and therefore no irreversible deformation can occur (Cosgrove, 2018; Ng \& Petley, 2009; Anderson \& Sitar, 1995; Selby, 1982) Once pore pressure is sufficiently increased to reach the yield stress for each material, ductile deformation occurs (stage two, Figure 6.1). This suggests a critical pore pressure state must be reached to enable a reduction of shear strength to overcome the inter-particle contacts within the sample (Selby, 1982). Observed behavior is reflected by sample dilation and increasing permeability (Figures 6.2 through increasing sample volume and decreasing density, along with asymptotic (power law or exponential) 1/v-t trends, (Petley et al., 2002), consistent with existing observations e.g. (Cosgrove, 2018; Ng \& Petley, 2009).

Deformation past the yield state i.e stage three (Figure 6.1) is characterised by an asymptotic trend in 1/v-t space, towards a steady-state movement e.g. (Figure 6.3b). As materials are remoulded to represent failed / partially failed slope sediments strain localisation along a distinct shear surface was not observed. Instead both materials displayed deformation through a broader shear zone (stages two and three figure 6.1) and (Appendix A.3), supported by existing laboratory studies within both remoulded cohesive materials (Carey \& Petley, 2014) and non-cohesive materials (Ng \& Petley, 2009: Petley et al., 2002). This behaviour style has also been observed in landslide 


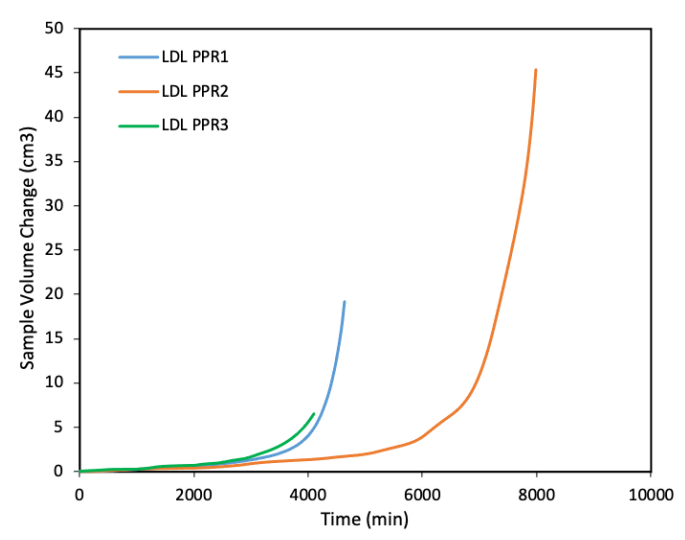

(a)

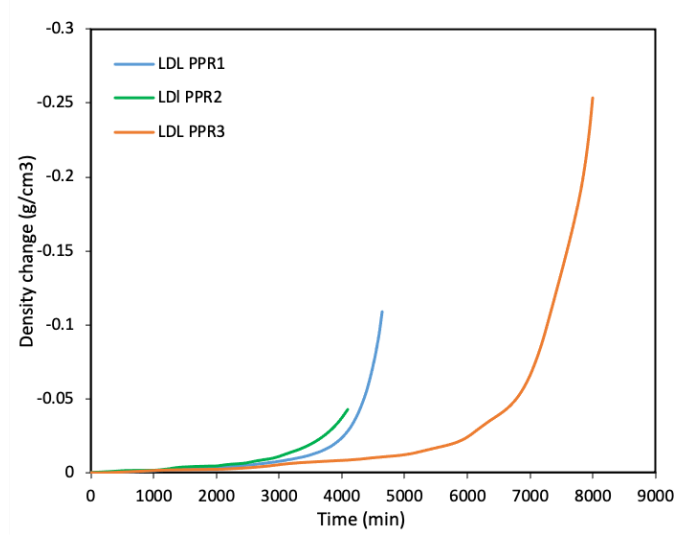

(c)

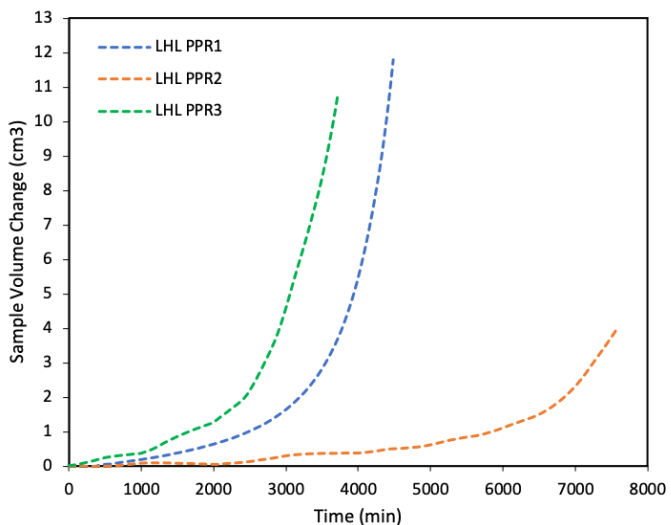

(b)

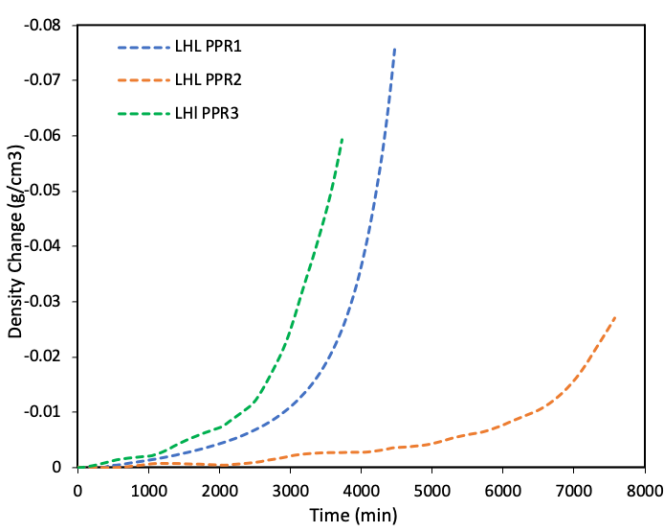

(d)

Figure 6.2: Comparison plots of sample volume change vs time for all PPR tests for a) LDL and b) LHL. Plots c) LDL and d) LHL demonstrate density change vs time

field studies. Allison and Brunsden (1990) measured graded slip movement, where movement develops and becomes increasingly continuous in response to a rise in pore pressure, continuing while pore pressures decline; occurring over shorter time periods.

\subsection{Given similarity between materials, is the behaviour similar?}

Given that LDL and LHL materials have broadly similar physical and geotechnical properties it could be expected that they would display similar movement behavior. PPR testing (Table 4.1) demonstrated whilst both materials demonstrated the same three stages of deformation to failure (Figure 6.1), a notable difference was observed in the final rate of failure. For instance, peak displacement rates for LDL stepped $\mathrm{kPa} / \mathrm{h}$ tests is $0.0275 \mathrm{~mm} / \mathrm{min}$ compared to $0.0067 \mathrm{~mm} / \mathrm{min}$ for the same LHL test. 


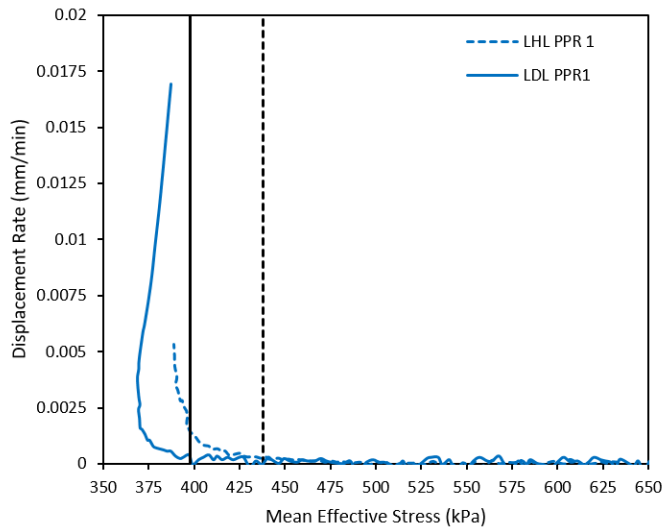

(a)

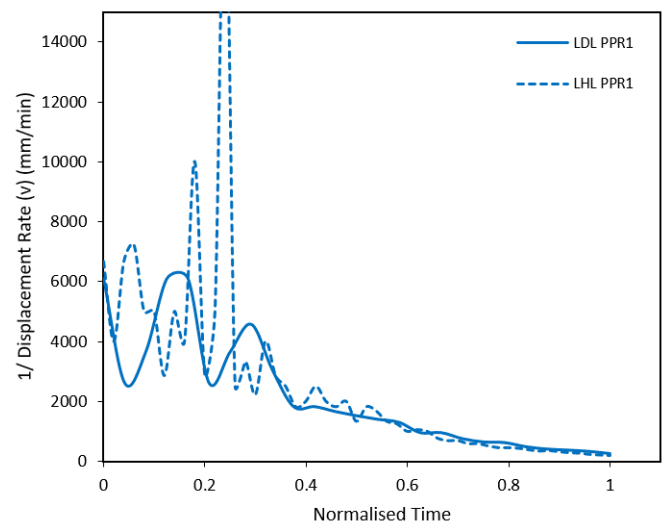

(b)

Figure 6.3: Comparison plots for linear $5 \mathrm{kPa} / \mathrm{h}$ LDL and LHL tests demonstrating a) displacement rate vs mean effective stress. Plot b) demonstrates $1 / \mathrm{v}$ vs normalized time. Note: increasing mean effective stress in fig a) for LDL at displacement rates above $0.0025 \mathrm{~mm} / \mathrm{min}$ is a post failure (end of test) response where sample drainage results in increasing mean effective stress through decreasing pore pressures vertical lines are LDL (solid) and LHL (dashed) respective conventional failure envelope.

This difference could potentially be attributed to the slight contrast in calcium carbonate contents (LDL 1.4\% and LHL 11.2\%) (Table 5.1) which is the only variable identified to be different in this study between materials. Whilst previous studies have shown that increasing $\mathrm{CaCO}_{3}$ content corresponds with an increase in shear strength in marine soils (Fukue et al., 1999), its impact on remoulded or previously failed soil behaviour remains unknown. The grain shape characteristics of calcite indicate that it may be unable to align as effectively as platy clays. This would provide a mechanism to reduce movement in the LHL material and could explain why it does not reach the same displacement rates as LDL during experiments.

The identification of differences in displacement rates in broadly similar materials highlights possible implications for landslide behaviour and run-out distances. Small differences in materials have demonstrated relatively important behavioural differences can arise; not all materials across Kaikōura could behave predictably. LDL slopes have the potential to initiate failure at higher displacement rates as demonstrated, and as a consequence have the possibility to travel further distances down slope. This is critical as other landslide deposits of the same material to LDL may experience this upon failure. Geomorphic mapping in section 3.2 demonstrates overall larger landslide source areas in first time failures compared to LHL, with some extended deposits indicating longer run-out. There is insufficient evidence to identify if LDL has overall further run-out distances. Further mapping and analysis is 
required to verify this phenomenon; this may be reflected differently if more landslides were examined which initiated on steeper slopes.

\subsection{Do changes in the pattern of pore pressure increase influence landslide behaviour?}

Subjecting materials to complex stress histories e.g. stepped tests such as PPR2 \& PPR3 (Table 4.1) produces pronounced pre-failure deformation and progressive weakening/damage accumulation i.e (Petley et al., 2002), absent in linear tests. Once the yield stress is reached during the stepped tests, displacement in response to pore pressure is reflected by pulses in displacement rate (Figure 6.4a and b) with accompanying increases in sample volume (dilation) and decreases in density (Figure $6.2 \mathrm{~b} \& \mathrm{~d}$ ). The significance of these pulses is they occur early in the experiment when mean effective stress is still relatively high and before the conventional failure envelope (CFE) is reached. Subsequently, samples experience notable deformation before the $\mathrm{CFE}$ is reached which in cases such as the stepped variable tests allows them to fail at higher mean effective stresses prior to the respective CFE.

Existing laboratory observations within cohesive material, e.g. stage two (Ng \& Petley, 2009), and the long term creep test by Carey and Petley (2014) reflect similar trends in punctuated movements in response to increasing pore pressures, prior to final failure, characterised as "stick-slip or creep-decay" mechanism identified by Allison and Brunsden (1990). During "stick-slip or creep-decay" behavior, sample displacement occurs in pulses in response to sharp increasing pore pressures, which then reduces as pore pressures dissipate.

Whilst movement in stepped tests reflects accelerated sample displacement in response to increasing pore pressures, observations do not completely align with decreases in movement and with decreasing pore pressures. Following pulses of movement pore pressures continue to increase e.g. (Figures $5.8 \mathrm{c}$ and d), indicating samples are continuing to respond to the initial pore pressure increases. $\mathrm{Ng}$ and Petley (2009) suggest that upon pore pressure cessation (constant pressures), it is the change in pore pressure that generates such slip, not solely the absolute pore pressure. 


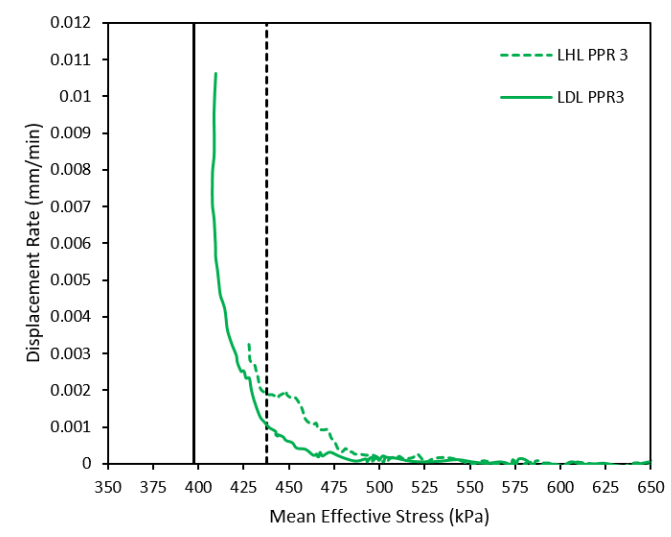

(a)

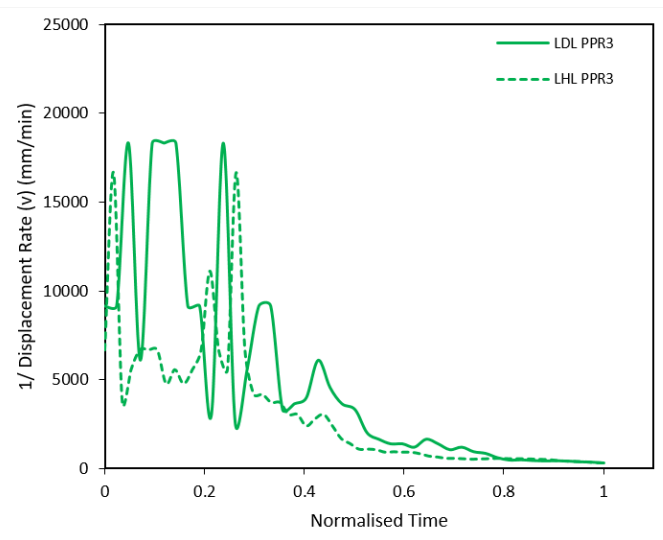

(c)

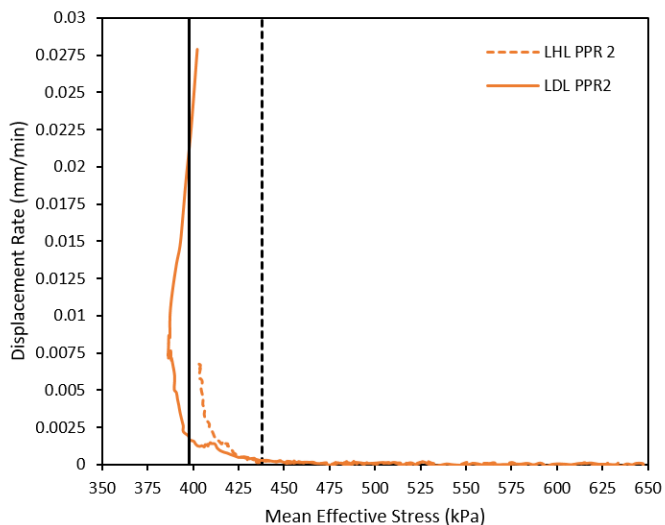

(b)

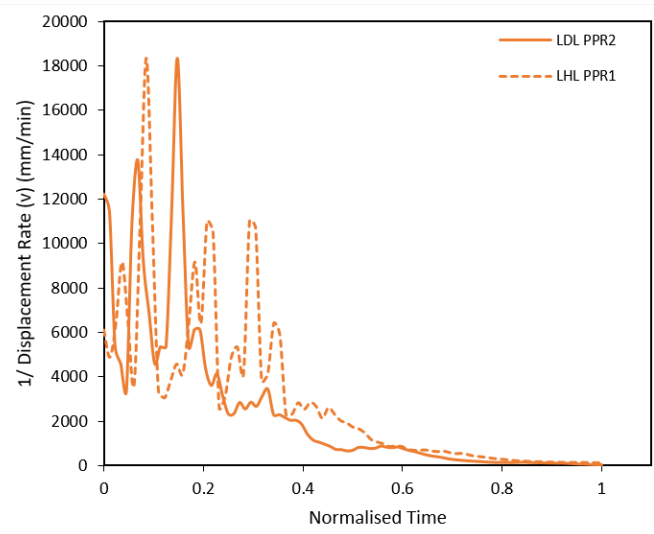

(d)

Figure 6.4: Comparison plots of LDL and LHL stepped tests demonstrating, displacement rate vs mean effective stress for a) Stepped $5 \mathrm{kPa} / \mathrm{h} \mathrm{b}$ ) Stepped variable $\mathrm{kPa} / \mathrm{h}$. Plots c) for stepped $5 \mathrm{kPa} / \mathrm{h}$ and c) Stepped variable $\mathrm{kPa} / \mathrm{h}$ demonstrates $1 / \mathrm{v}$ vs normalized time. Note: vertical lines are LDL (solid) and LHL (dashed) respective conventional failure envelopes.

This interpretation is consistent with observations in this study, suggesting a rate effect is present, and is explored further in section 6.4. While more complex pore pressure histories (stepped tests) may influence the timing and stress state of the failing material it doesn't impact on the failure style. Behaviour is consistent with asymptotic trends yielded in $1 / \mathrm{v}$-t space suggesting ductile behaviour (Figure 6.4 c \& d), agreeing with observations by Petley et al. (2002) and existing laboratory studies in both intact (Ng \& Petley, 2009) and remoulded materials (Carey \& Petley, 2014).

Pre-failure deformation observed in materials has implications for the timing and amount of rainfall required for slope failure. The change (reduction) in effective stress in a material results in progressive weakening and pre-failure deformation of material through a complex stress history. This process implies slopes that don't fail in first significant rainfall event, could experience pre-failure deformation that may reduce 
the rainfall threshold required to induce failure during future storm events. This provides a credible mechanism to explain why different slopes fail at different times, reflecting the temporal variation in failure.

A further important observation as a result of pre-failure deformation is the ability for samples to creep and fail under constant applied pore pressures e.g. stepped 5 $\mathrm{kPa}$ tests (Figure 5.8). Sample failure under constant applied pore pressures suggest either 1) there is a time dependency component for failure, or 2) the sample is still responding to pore pressure increases. Carey and Petley (2014) and Ng and Petley (2009), both demonstrate a time dependent component where the required stress state has been achieved for failure, but damage accumulation and internal restructuring for failure has not e.g. Petley et al. (2002). It is likely observations are the result of pore pressures continuing to increase rather than a time dependency component as time scales under which constant stress is held in this study is much too small (e.g. Carey and Petley (2014) who kept a constant mean effective stress for 81 days prior to failure).

\subsection{Is there a rate effect observed within pore pressure and displacement?}

As demonstrated in section 6, a complex non-linear relationship exists between displacement and pore pressure, commonly observed within landslides Corominas et al. (2005) and Massey et al. (2013). Evidence suggests a rate effect with deformation and pore pressure is responsible for observations in this study. Firstly, in stepped variable tests (PPR2 and PPR3, Table 4.1), displacement rate (thus deformation) is complex and punctuated than linear tests e.g. (Figure 6.5b), across both periods of constant and increasing applied pore pressures. Variable increase rates in pore pressure (e.g LDL PPR3, compared to consistent $5 \mathrm{kPa} / \mathrm{h}$ increases and holds e.g. LDL PPR1 and LDL PPR2) reflect earlier sample deformation, reaching the required yield stress state earlier and thus commencing pre-failure deformation and ultimately failing at a higher mean effective stress (Figure 6.5c and d). This behaviour corroborates rate effects observed within existing landslides by Carey et al. (2019), Massey et al. (2013), Ng and Petley (2009), and Corominas et al. (2005) 


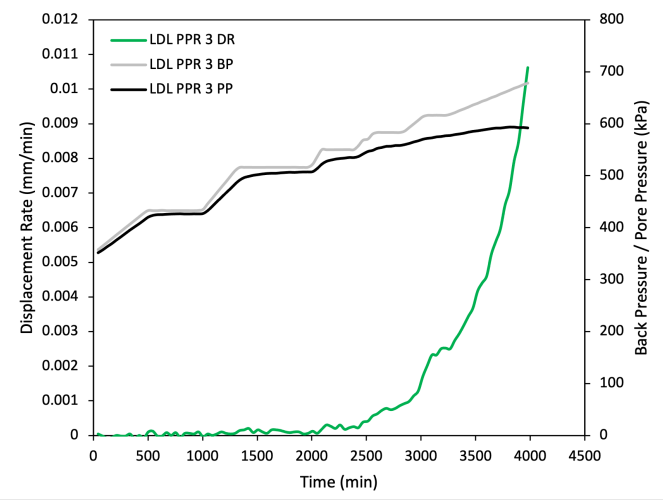

(a)

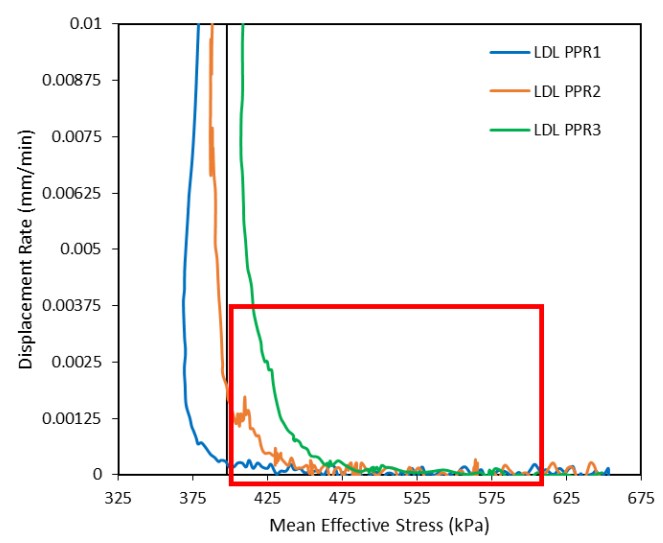

(c)

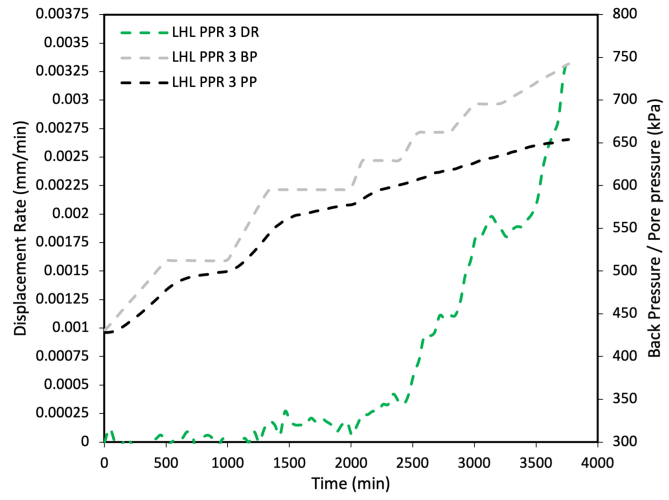

(b)

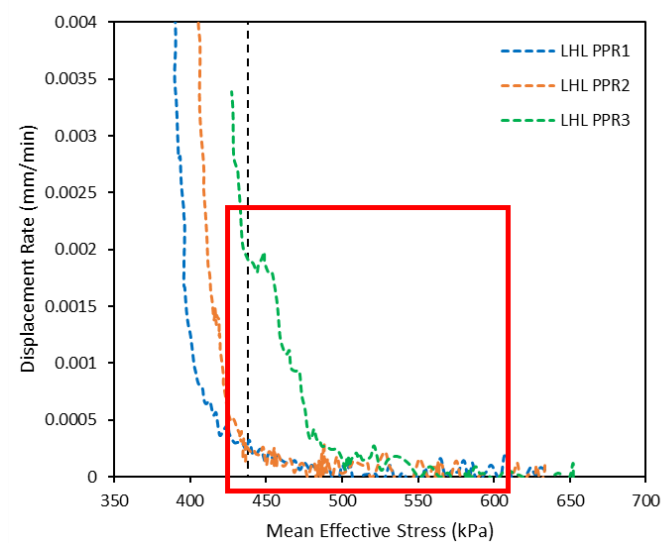

(d)

Figure 6.5: Displacement rate and back pressure / pore pressure vs time for a) LDL and b) LHL. Displacement rate vs mean effective stress for c) LDL and d) LHL. Note: increasing mean effective stress in e.g. fig c) for LDL PPR1 at displacement rates above $0.00375 \mathrm{~mm} / \mathrm{min}$ is a post failure (end of test) response where sample drainage results in increasing mean effective stress through decreasing pore pressures. Red rectangles are areas of interest referred to in the text.

whereby displacement is proposed to be controlled by the absolute pore pressure (mean effective stress) and the rate of change of pore pressure (rate of change of mean effective stress).

This finding suggests that both the amount and intensity of rainfall received on a slope influences its failure susceptibility. For instance, high intensity rainfall storm cells may have the potential to cause greater deformation to materials, as the rate of change in pore pressure from an initial state is likely to be larger, compared to a small consistent rainfall. Therefore this influences the CFE of a material (changing the point of failure with respect to the $\mathrm{CFE}$ ), as greater progressive weakening can take place thus, allowing the material to fail at higher mean effective stresses.

Furthermore, this may also allow settings with low ground water levels (low pore pressures) to experience deformation earlier on in the slopes deformation history than 


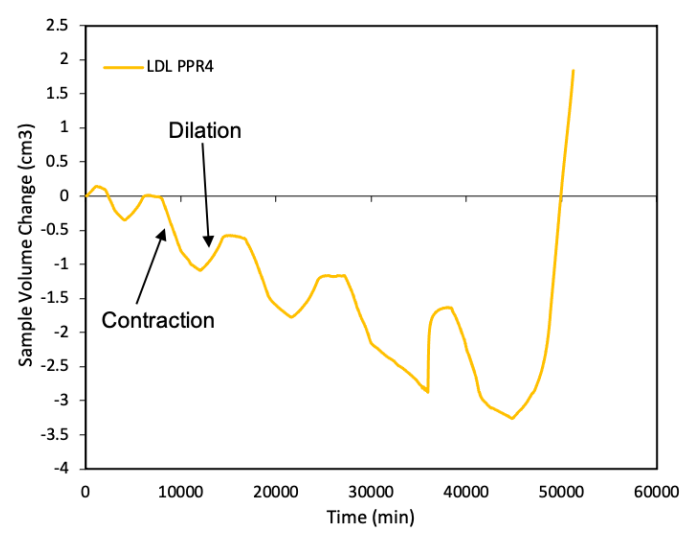

(a)

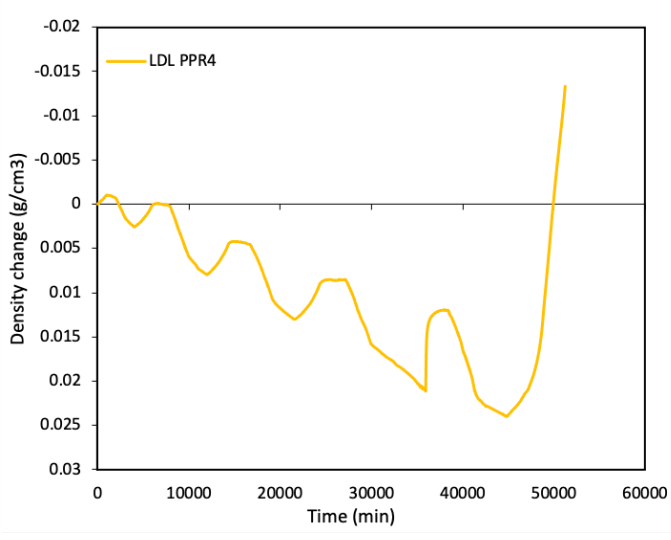

(b)

Figure 6.6: Comparison plots for LDL PPR4, for a) volume change vs time. b) density change with time. Note: increasingly negative density change is equal to density decreasing.

if it was subject to slow inputs of rainfall over time in certain conditions e.g. (Figure $6.5 \mathrm{a}$ and b). The combination of these factors ultimately suggests why different slopes may fail during different storm events at different times.

\subsection{Do fluctuating pore pressures influence landslide failure behaviour?}

Behaviour from the LDL PPR4 test demonstrates remarkably different initial sample behaviour with respect to linear and stepped test, through dilating and contraction cycles. As initial back pressures and pore pressures increases, displacement rate fluctuates correspondingly, however, stress applied to the sample is insufficient to cause notable pre-failure deformation, instead cycles of sample dilation and contraction (Figure 6.6), persist until the yield stress threshold is reached and displacement rates becomes rapid exponential to failure. Deformation patterns yield an asymptotic trend in 1/v-t space indicating ductile failure (Petley et al., 2002). However, final failure after 50,000 minutes (Figure 5.12 1/v becomes increasingly linear, indicating the pre-failure stiffening observed, results in a more brittle material at failure compared to linear and stepped tests for both materials (Figure 6.7 and d).

The apparent sample densification (Figure 6.6a) is hypothesised to be the consequence of cyclic loading. The drawdown of pore pressures, effectively draining the material has resulted in progressive stiffening prior to a critical stress threshold 


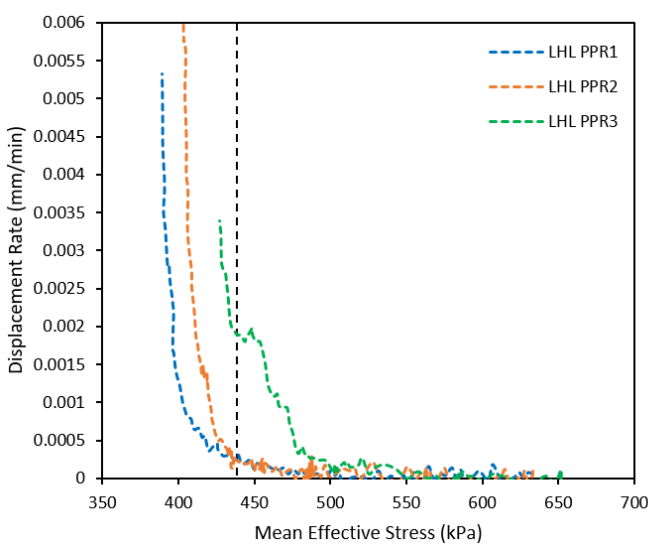

(a)

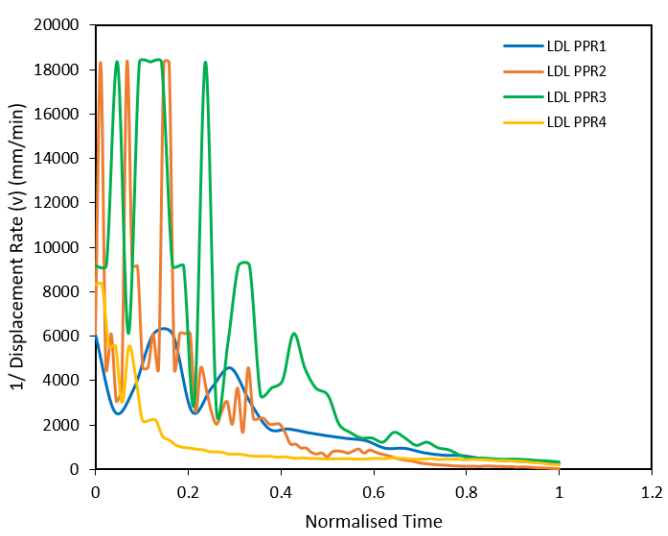

(c)

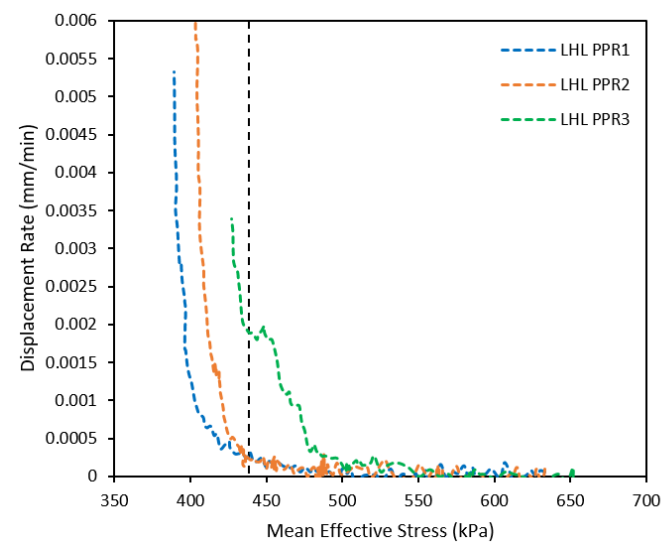

(b)

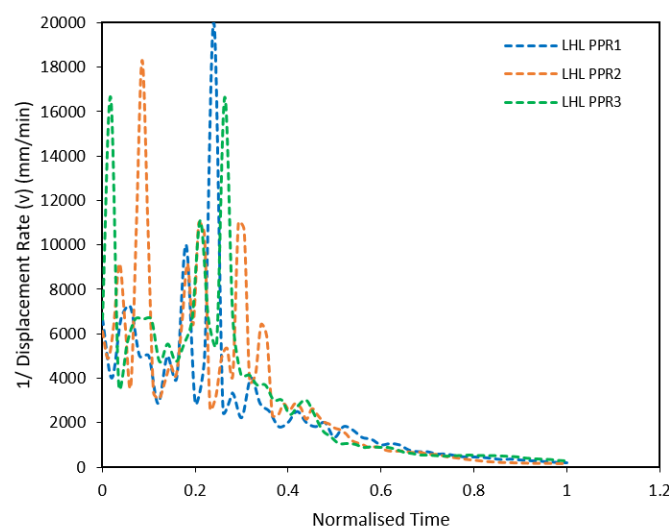

(d)

Figure 6.7: Summary plots for each material demonstrating displacement rate vs mean effective stress for a) LDL and b) LHL. Plots c) for LDL and d) LHL demonstrate 1/v vs normalized time. Note dashed vertical lines represent each respective conventional failure envelope.

being reached for significant deformation. This observation suggests a large decrease in mean effective stress is required for failure to occur. This is consistent with $1 / \mathrm{v}$ observations, becoming near linear i.e. stiffening/brittle failure.

This densificaiton and strengthening behavior has been observed in previous studies within normally consolidated materials e.g. (Carey et al., 2021, Brain et al., 2017 and Take et al., 2004) demonstrating sample strengthening through dynamic stress inputs (e.g. earthquake simulations). In these earlier studies sample densification resulted from dynamic loading cycles was argued to increase inter-participle friction.

Observations in this study indicate the same behavior can be observed during cycles of elevated and and decreasing pore pressure. The implications of this behaviour, suggests that LDL materials in certain geomorphic settings, where groundwater tables have the ability to drain, may be prolonged on the landscape. For the 
reasoning that progressive densification and could allow materials to persist on hillslopes through rainfall events resisting pre-failure deformation and progressive weakening, ultimately requiring a larger rainfall event to cause failure, contrasting observations from stepped tests.

\subsection{Conceptual landslide model}

Making a connection between material failure mechanics and the landscape response is crucial to help explain behavior we observe. The results from this laboratory based study together with observations from the field sites have been used to propose a conceptual model (Figure 6.8 to explain the behaviour of failed and partially failed hillslopes in fine-grained sediments during rainstorms following large earthquakes. Four slopes are represented:

1. Blue - poorly draining steep hillslope

2. Orange - poorly draining slope, moderate angle slope

3. Green - poorly draining, moderate angle slope but deeper failure surface (higher normal stress)

4. Yellow - freely draining, shallow-moderate angle slope

It is known that landslide susceptibility increases following large earthquakes that result in widespread landsliding due to the amount of weakened and partially weakened sediment (e.g. Wenchuan and Kaikōura). As a consequence during the first major rainfall event (RE1) to impact an area after the earthquake can cause many reactivated landslides in a consistent and predictable manner. Therefore, enough deformation and reduction of mean effective stress is experienced to surpass the CFE, e.g. slope 1 (Figure 6.8a). This is in agreement with field observations by (Rosser et al., 2020) who quantified a drop in threshold from $60 \mathrm{~mm} / 24 \mathrm{hrs}$ to $9 \mathrm{~mm} / 24 \mathrm{hrs}$ and observed the highest slope failure rates in the first rainfall event (Cyclone Debbie). This has importance as a large number of new failures, and reactivation's are likely to occur, within the first rainfall event as slopes are in a critical state compared before the earthquake, as observed following the Chi-Chi and Wenchuan earthquakes (Hovius et al., 2011; Tang et al., 2011; Dadson et al., 2004). 

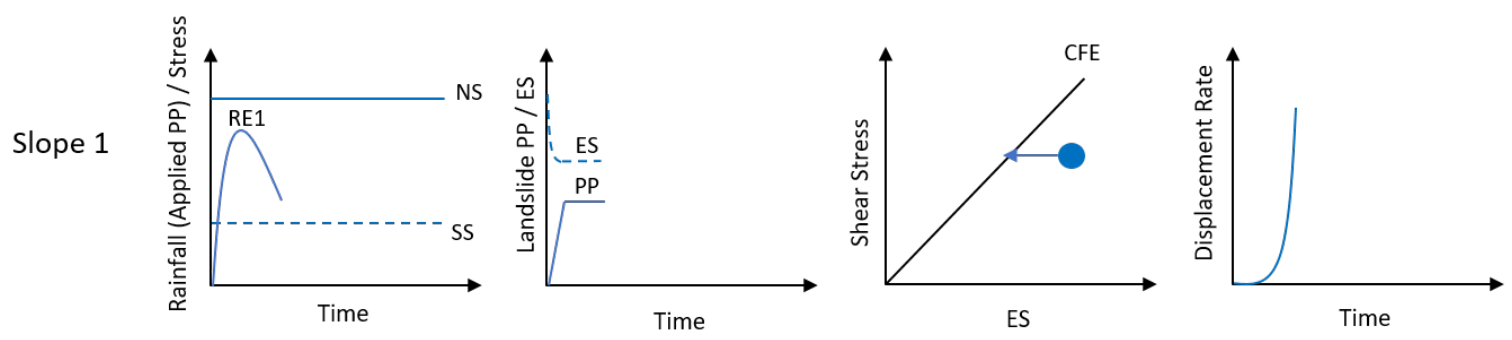

(a)
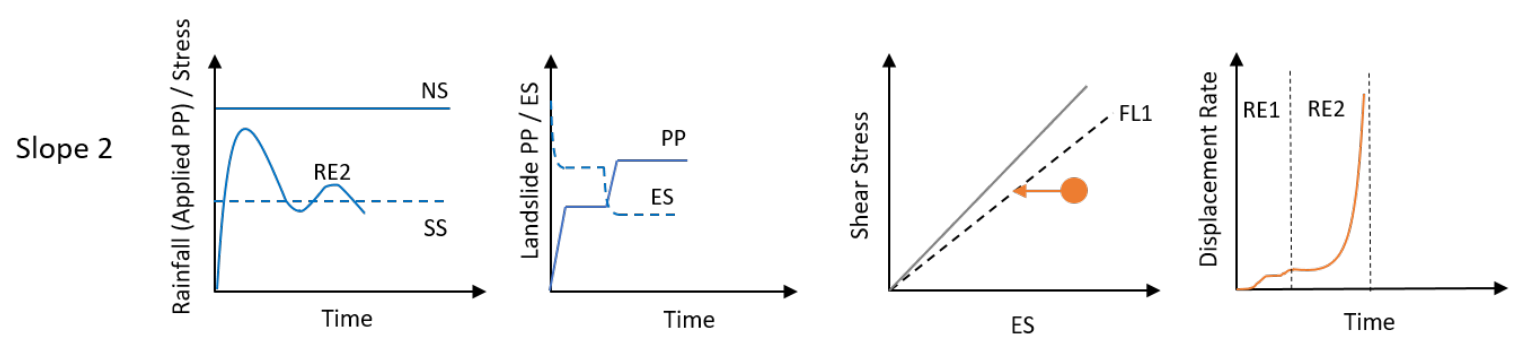

(b)
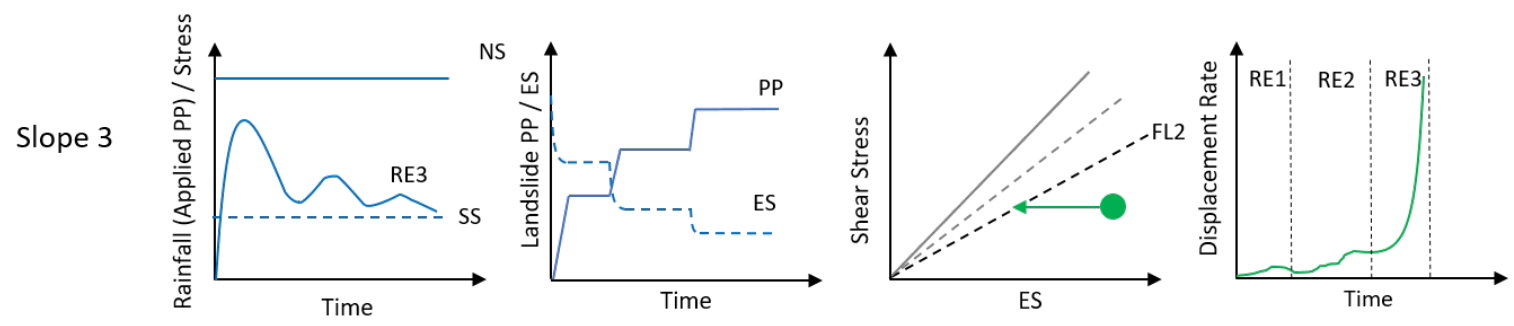

(c)
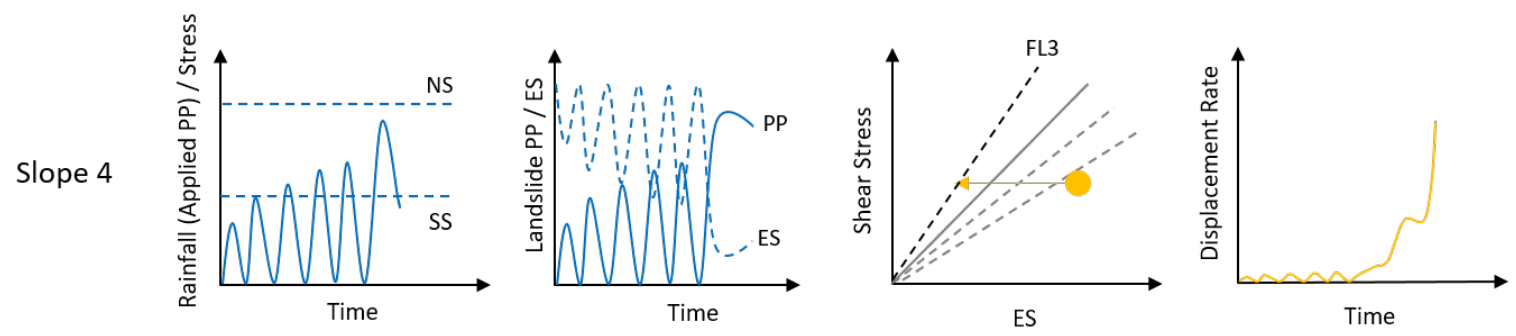

(d)

Figure 6.8: Conceptual landslide model demonstrating progressive deformation and slope failures overtime in rainfall events following a large earthquake. a) slope 1 b) slope 2 c) slope 3 and d) slope 4 . Note CFE = conventional failure envelope. $\mathrm{FL}=$ failure line. $\mathrm{RE}=$ rainfall event. $\mathrm{NS}=$ normal stress. $\mathrm{SS}=$ Shear stress. $\mathrm{ES}=$ effective stress. $\mathrm{PP}=$ pore pressure. 
Despite these observations, the significance is now put onto slopes that did not fail e.g. slopes two and three (Figure 6.8b). Rather than reaching a critical state during RE1 for failure, they instead underwent progressive pre-failure deformation in response to pore pressure increases. Subsequently the CFE shallows for both, therefore reducing the amount of rainfall and required thus a decrease in effective stress needed to reach failure. Following the next rainfall event (RE2), slope three undergoes increases in pore pressure and in response, the sample exhibits an exponential sample displacement to failure. This pore pressure increase is enough to decrease the effective stress and reach the shallow failure line (FL1).

Slope three undergoes deformation in response to RE 1 and 2 and their associated pore pressure increases (Figure 6.8c). Despite this, it is insufficient to cause failure, instead shifting the slope closer towards the new shallower failure line FL2 as the material strength weakens. With succeeding rainfall (RE3), a smaller amount of rainfall has the ability to increase pore pressures further and decrease the effective stress causing the slope to accelerate to failure, reaching FL3. It is essential to recognise that the progressive weakening through RE 1-3 has preconditioned this slope overtime to set up for failure, requiring less rainfall than materials before the storm series.

Slope four, (analogous to LDL PPR4) has a different stress history whereby it is subject to pore pressure fluctuations in a drained ground water system i.e. any excess pore pressure developed during storms can dissipate (Figure 6.8 d). As a consequence, displacement rate behaviour fluctuates concurrently at low rates with pore pressure increases and decrease, but does not experience significant pre-failure deformation, like slopes 1, 2 and 3. Instead, it is hypothesised that the dilating and contracting cycles results in material densification and strengthening, observed by FL3 steepening in comparison to the original CFE, thus causing the slope to fail at lower effective stresses. Therefore, a much larger rainfall event is required to cause sample failure. Slope deformation displays similar rapid exponential displacement to failure in which slopes one, two and three experience in their final phases. 


\subsection{Implications for Kaikōura}

The conceptual model proposed provides insight into why susceptibility is elevated following a large earthquake and may prevail for prolonged periods in landscapes that are subjected to regular high-intensity rainfall events. This observation has two principal implications for Kaikōura. First, the CFE for the tested materials is not fixed but can be considered to be a dynamic state that is dependent in part, on the stress history of a given slope. Therefore, landslide reactivation and rainfall failure thresholds are more complex than standard Mohr-Coulomb failure due to the materiel properties and drainage characteristics of slopes. Secondly, the concept of a dynamic CFE, highlights the impact progressive weakening has on the timing of reactivation and failure. The variability in a material's initial state e.g. normal stress and shear stress, suggests different slopes will fail at different points in time, but also different rain storms. Consequently different deposits could persist in the landscape for different periods of time subject to their stress history, thus prolonging the associated hazard.

The identification of different displacement rates in broadly similar materials impacts on potential landslide run-out characteristics. LDL slopes appear to be capable of moving at significantly higher displacement rates and therefore could run-out over longer distances potentially increasing their hazard and associated risk to people, property and infrastructure.

Similar observations have been made in other geological materials such as Mesozoic Basement Rocks (greywacke). For example, following the earthquake, rotational, translational failures and debris flows occurred impacting the Southern Kaikōura Transport Corridor (SKTC) in response to rainfall received from Cyclone Gita in 2018 (Stringer et al., 2020; Mason et al., 2018), which was not the first large rainfall event in the region succeeding the 2016 earthquake. Whilst no laboratory testing has been undertaken to date, evidence detailed by (Stringer et al., 2020; Mason et al., 2018) supports this inference.

Not only do reactivated landslides have a direct impact on the landscape, society and infrastructure, they also have an indirect impact through elevated sediment transport on hill slopes and into fluvial systems (Marchi, 2017; Davies \& Korup, 2007; Korup 
et al., 2004). For instance, in response to Cyclone Alison in 1975 (Bell, 1976), mass movements originating in fluvial catchments resulted in rapid river aggradation and erosion causing damage to railway and highway infrastructure along SH1. Inputs of increased material into fluvial systems from hillslope sediments in Kaikōura will no doubtfully occur; if the hill slope and river coupling allow, future aggradation events like this may occur.

\subsubsection{Limitations and recommendations for future research}

It is important to recognise that results presented here are produced in the laboratory setting. The key behind the methodology used in this study is simulating failure using an appropriate "field" stress path whereby the sample is subject to constant normal stress and shear stress. This is representative of field settings as rainfall-induced failure is regularly the result of increasing pore pressures within a slope, therefore reducing mean effective stress at constant deviator stress (Carey \& Petley, 2014). As deviator stress is constant, measuring the response of the sample e.g. in terms of displacement is not altering/influencing how the sample fails. Furthermore, triaxial cell tests do not force failure on a specific shear surface as dynamic back pressure shear boxes do, therefore triaxial cell samples can undergo various styles of deformation/failure in response to their physical properties.

Past laboratory observations have been validated with field data i.e. (Petley et al., 2017), demonstrating the ability to link the two which is crucial. The behaviour here is consistent with field observations after Rosser et al. (2020) in terms of the first landsliding events occurring and continued landsliding in successive events.

Continued spatial monitoring is currently being undertaken by Rosser et al. (2020) and laboratory results will help verify this behaviour in the years to come.

Past site-specific studies, e.g. (Carey et al., 2019; Carey \& Petley, 2014; Ng \& Petley, 2009) have incorporated piezometer and rain gauge measurements where available when deciding on pore pressure increase rates, which is desirable. In this study as we are concerned at a catchment scale and not a specific slope, selecting a general range of pore pressure increase rates (within values in the literature) is representative for this study, as rainfall and groundwater conditions are complex and likely to vary 
spatially across the region. However in the future, if site specific studies are required, piezometer data could be incorporated.

Pore pressure histories were focused on in this study, therefore the same stress state was simulated for both materials. Further research could explore different behavior in deep and shallow landslide deposits so see if the behavior is broadly similar.

Additionally, different materials could be tested e.g. sandy materials that have better drainage, or rock slopes that could be analogous for brittle failure rather than ductile landscapes.

Whilst, only one scenario with applied pore pressure increases have been incorporated into the testing rational, pore pressure simulations in this study are sufficient and representative for the study objectives as often pore pressure increases are responsible for slope failure. Future research should investigate the impact of decreases in pore pressure, as this will build on the interesting finding that the fluctuating pore pressure test in this study had in terms of material strengthening.

While no dynamic shaking was simulated, future studies could incorporate dynamic shaking prior to PPR increases. This will allow to determination of any influence of shaking on sample characteristics and behavior; which may be significance as the landslide reactivation hazard is already prominent, and a dynamic component may worsen or improve landslide likelihood. 


\section{Chapter 7}

\section{Conclusions}

This study has undertaken a specialist laboratory Pore Pressure Reinflation (PPR) testing program using a triaxial cell to investigate rainfall-induced landslide reactivation mechanisms, following the 2016 Kaikōura Earthquake. Results give crucial insight into the long-term landslide hazard which exists following large earthquakes. The following can be concluded:

- Results from this study demonstrate that the stress history the landslide debris is subject to fundamentally influences the behavior of Leader Dam Landslide (LDL) and Limestone Hills Landslide samples (LHL)

- Despite broadly similar materials, LDL demonstrates peak displacement rates two times that of LHL. The presence of higher calcium carbonate content in LHL is proposed to cause restriction in movement due to grain roughness.

- Linear tests are able to explain the behavior of failed landslide material. Three stages of movement are identified within all linear and stepped tests. Stepped tests demonstrate progressive weakening through pre-failure deformation, lacking in linear tests. Overall sample behavior yields an asymptotic relationship in $1 / \mathrm{v}$-t plots indicating ductile deformation.

- Fluctuating pore pressures demonstrate different behavior to linear and stepped tests. Initial behavior of dilating and contracting cycles, accompanied with overall increasing density is evident. Ultimately allowing the material to fail after the conventional failure envelope (CFE), in a more brittle manner 
reflected by $1 / \mathrm{v}$-t plots.

- Evidence of a rate effect is observed within stepped variable tests, suggesting the way rainfall is received may influence how deformation occurs under rainfall events.

- A conceptual model linking laboratory tests has been proposed illustrating different slopes and their behavior through successive rainfall events.

Particularly the concept that a material's CFE is a dynamic concept and changes by decreasing in angle in response to progressive weakening (stepped tests) or increases in angle in response to material strengthening (fluctuating test).This concept helps give insight into why different slopes fail at different times.

These findings give important insights into the current prolonged landslide hazard for Kaikoura following the 2016 earthquake, as it was previously unknown how materials and their mechanics will react under future rainfall events. Different slopes and failed materials will continue to progressively weaken or strengthening in response to rainfall events, failing at different points in time. Landslide reactivation will be a large concern and will continue until the landscape stabilizes and returns its to pre-earthquake state. 


\section{Bibliography}

Allison, R. J., \& Brunsden, D. (1990). Some mudslide movement patterns. Earth Surface Processes and Landforms, 15(4), 297-311.

Anderson, S. A., \& Sitar, N. (1995). Analysis of rainfall-induced debris flows. Journal of Geotechnical Engineering, 121(7), 544-552.

Bell, D. (1976). High intensity rainstorms and geological hazards: Cyclone Alison, march 1975, Kaikoura, New Zealand. Bulletin of the International Association of Engineering Geology-Bulletin de l'Association Internationale de Géologie de l'Ingénieur, 13(1), 189-200.

Bierman, P. R. (2014). Key concepts in geomorphology/paul r. bierman y david $r$. montgomery.

Brain, M. J., Rosser, N. J., \& Tunstall, N. (2017). The control of earthquake sequences on hillslope stability. Geophysical Research Letters, $44(2), 865-872$.

Caine, N. (1980). The rainfall intensity-duration control of shallow landslides and debris flows. Geografiska annaler: series A, physical geography, 62(1-2), 23-27.

Carey, J., \& Petley, D. (2014). Progressive shear-surface development in cohesive materials; implications for landslide behaviour. Engineering Geology, 177, 54-65. https://doi.org/https://doi.org/10.1016/j.enggeo.2014.05.009

Carey, J. M., Massey, C. I., Lyndsell, B., \& Petley, D. N. (2019). Displacement mechanisms of slow-moving landslides in response to changes in porewater pressure and dynamic stress. Earth Surface Dynamics, 7(3), 707-722.

Chen, X., Zhou, Q., Ran, H., \& Dong, R. (2012). Earthquake-triggered landslides in southwest China. Natural Hazards and Earth System Sciences, 12(2), 351-363. 
Corominas, J., Moya, J., Ledesma, A., Lloret, A., \& Gili, J. A. (2005). Prediction of ground displacements and velocities from groundwater level changes at the Vallcebre landslide (Eastern Pyrenees, Spain). Landslides, 2(2), 83-96.

Cosgrove, B. (2018). Mechanisms of rainfall-induced landsliding in Wellington fill slopes (Master's thesis). Victoria University of Wellington. Wellington.

Cowan, H. (1991). The north Canterbury earthquake of september 1, 1888. Journal of the Royal Society of New Zealand, 21(1), 1-12.

Craig, R. F. (2004). Craig's soil mechanics. CRC press.

Crosta, G. B., \& Frattini, P. (2001). Rainfall thresholds for triggering soil slips and debris flow. Proc. of the 2nd EGS Plinius Conference on Mediterranean Storms: Publication CNR GNDCI, 2547, 463-487.

Crozier, M. (2005). Multiple-occurrence regional landslide events in New Zealand: Hazard management issues. Landslides, 2(4), 247-256.

Crozier, M. (2018). Reprint of "a proposed cell model for multiple-occurrence regional landslide events: Implications for landslide susceptibility mapping". Geomorphology, 30\%, 3-11.

Cruden, D. M., \& Varnes, D. J. (1996). Landslides: Investigation and mitigation. chapter 3-landslide types and processes. Transportation research board special report, (247).

Dadson, S. J., Hovius, N., Chen, H., Dade, W. B., Lin, J.-C., Hsu, M.-L., Lin, C.-W., Horng, M.-J., Chen, T.-C., Milliman, J., et al. (2004). Earthquake-triggered increase in sediment delivery from an active mountain belt. Geology, 32(8), 733-736.

Davies, T. R., \& Korup, O. (2007). Persistent alluvial fanhead trenching resulting from large, infrequent sediment inputs. Earth Surface Processes and Landforms, 32(5), 725-742.

Dawson, R., Morgenstern, N., \& Stokes, A. (1998). Liquefaction flowslides in Rocky Mountain coal mine waste dumps. Canadian Geotechnical Journal, 35(2), 328343.

Dellow, S., Massey, C., Cox, S., Archibald, G., Begg, J., Bruce, Z., Carey, J., Davidson, J., Della Pasqua, F., Glassey, P., et al. (2017). Landslides caused by the mw7. 8 
Kaikōura earthquake and the immediate response. Bulletin of the New Zealand Society for Earthquake Engineering, 50(2), 106-116.

DeMets, C., Gordon, R. G., \& Argus, D. F. (2010). Geologically current plate motions. Geophysical Journal International, 181(1), 1-80.

Densmore, A. L., \& Hovius, N. (2017). Landslides and landscape evolution. AGU Fall Meeting Abstracts, 2017, EP52B-01.

Fan, R., Zhang, L. M., Wang, H., \& Fan, X. (2018). Evolution of debris flow activities in Gaojiagou Ravine during 2008-2016 after the Wenchuan earthquake. Engineering Geology, 235, 1-10.

Froude, M. J., \& Petley, D. N. (2018). Global fatal landslide occurrence from 2004 to 2016. Natural Hazards and Earth System Sciences, 18(8), 2161-2181.

Fukue, M., Nakamura, T., \& Kato, Y. (1999). Cementation of soils due to calcium carbonate. Soils and Foundations, 39(6), 55-64.

GeoNet. (2017). Niwa's offshore mapping adds more faults to the latest Kaikoura fault rupture map. https://www.geonet.org.nz/news/6JadI02Pi8YUAOiiKUOgO2

Glade, T. (1998). Establishing the frequency and magnitude of landslide-triggering rainstorm events in New Zealand. Environmental Geology, 35(2-3), 160-174.

Glade, T., Crozier, M., \& Smith, P. (2000). Applying probability determination to refine landslide-triggering rainfall thresholds using an empirical "antecedent daily rainfall model". Pure and Applied Geophysics, 157(6), 1059-1079.

Gorum, T., Fan, X., van Westen, C. J., Huang, R. Q., Xu, Q., Tang, C., \& Wang, G. (2011). Distribution pattern of earthquake-induced landslides triggered by the 12 may 2008 Wenchuan earthquake. Geomorphology, 133(3-4), 152-167.

Grapes, R., \& Downes, G. (1997). The 1855 Wairarapa, New Zealand, earthquake. Bulletin of the New Zealand Society for Earthquake Engineering, 30(4), 271368.

Grapes, R., Little, T., \& Downes, G. (1998). Rupturing of the Awatere Fault during the 1848 october 16 Marlborough earthquake, New Zealand: Historical and present day evidence. New Zealand Journal of Geology and Geophysics, 41(4), 387-399.

Hamling, I. J., Hreinsdóttir, S., Clark, K., Elliott, J., Liang, C., Fielding, E., Litchfield, N., Villamor, P., Wallace, L., Wright, T. J., et al. (2017). Complex multifault 
rupture during the $2016 \mathrm{mw} 7.8$ Kaikōura earthquake, New Zealand. Science, $356(6334)$.

Hancox, G. T. (2008). The 1979 Abbotsford Landslide, Dunedin, New Zealand: A retrospective look at its nature and causes. Landslides, 5(2), 177-188.

Head, K. H. et al. (1998). Manual of soil laboratory testing. volume 3: Effective stress tests. John Wiley \& Sons.

Head, K. H., \& Epps, R. (1980). Manual of soil laboratory testing (Vol. 1). Pentech Press London.

Helmstetter, A., Sornette, D., Grasso, J.-R., Andersen, J. V., Gluzman, S., \& Pisarenko, V. (2004). Slider block friction model for landslides: Application to Vaiont and La Clapiere landslides. Journal of Geophysical Research: Solid Earth, 109(B2).

Highland, L., Bobrowsky, P. T. et al. (2008). The landslide handbook: A guide to understanding landslides. US Geological Survey Reston.

Holden, C., Kaiser, A., Van Dissen, R., \& Jury, R. (2013). Sources, ground motion and structural response characteristics in Wellington of the 2013 Cook Strait earthquakes. Bulletin of the New Zealand Society for Earthquake Engineering, 46(4), 188-195.

Hovius, N., Meunier, P., Lin, C.-W., Chen, H., Chen, Y.-G., Dadson, S., Horng, M.-J., \& Lines, M. (2011). Prolonged seismically induced erosion and the mass balance of a large earthquake. Earth and Planetary Science Letters, 304(3-4), 347-355.

Hungr, O. (2007). Dynamics of rapid landslides. Progress in landslide science (pp. 4757). Springer.

Hungr, O., Leroueil, S., \& Picarelli, L. (2014). The varnes classification of landslide types, an update. Landslides, 11(2), 167-194.

Hutchinson, J. (1986). A sliding-consolidation model for flow slides. Canadian Geotechnical Journal, 23(2), 115-126.

Igwe, O., Sassa, K., \& Fukuoka, H. (2004). Liquefaction potential of granular materials using differently graded sandy soils. Disaster Prevention Research Institute Annuals.

Inopave Group PTE Ltd. (2003). Liquid Limit Testing. Retrieved December 1, 2020, from http://www.innopave.com/en/Products/SoilRock/lab_soil_details.asp? ProductID $=50$ 
Iverson, R. M. (2005). Regulation of landslide motion by dilatancy and pore pressure feedback. Journal of Geophysical Research: Earth Surface, 110(F2).

Iverson, R. M., Reid, M. E., \& LaHusen, R. G. (1997). Debris-flow mobilization from landslides. Annual Review of Earth and Planetary Sciences, 25(1), 85-138.

Jakob, M., Hungr, O., \& Jakob, D. M. (2005). Debris-flow hazards and related phenomena (Vol. 739). Springer.

Jones, F. O. (1973). Landslides of rio de janeiro and the serra das araras escarpment, brazil (tech. rep.). USGPO,

Kaiser, A., Balfour, N., Fry, B., Holden, C., Litchfield, N., Gerstenberger, M., D'anastasio, E., Horspool, N., McVerry, G., Ristau, J., et al. (2017). The 2016 Kaikōura, New Zealand, earthquake: Preliminary seismological report. Seismological Research Letters, 88(3), 727-739.

Khazai, B., \& Sitar, N. (2004). Evaluation of factors controlling earthquake-induced landslides caused by Chi-Chi earthquake and comparison with the Northridge and Loma Prieta events. Engineering geology, 71(1-2), 79-95.

Kilburn, C. R., \& Petley, D. N. (2003). Forecasting giant, catastrophic slope collapse: Lessons from Vajont, Northern Italy. Geomorphology, 54(1-2), 21-32.

Korup, O., McSaveney, M. J., \& Davies, T. R. (2004). Sediment generation and delivery from large historic landslides in the Southern Alps, New Zealand. Geomorphology, 61(1-2), 189-207.

Langridge, R., Campbell, J., Hill, N., Pere, V., Pope, J., Pettinga, J., Estrada, B., Berryman, K., et al. (2003). Paleoseismology and slip rate of the Conway Segment of the Hope Fault at Greenburn Stream, South Island, New Zealand. Annals of Geophysics.

Liao, Z., Hong, Y., Kirschbaum, D., \& Liu, C. (2012). Assessment of shallow landslides from Hurricane Mitch in central America using a physically based model. Environmental Earth Sciences, 66(6), 1697-1705.

Little, T., \& Jones, A. (1998). Seven million years of strike-slip and off-fault deformation on the Awatere Fault, South Island, New Zealand. Tectonics, 17(2), 285-302.

Macara, G. R. (2016). The climate and weather of Canterbury. NIWA, Taihoro Nukurangi. 
Marchi, L. (2017). Linking debris flows and landslides to large floods in gravel-bed rivers. Gravel-Bed Rivers: Processes and Disasters, 467-495.

Marden, M., \& Rowan, D. (1993). Protective value of vegetation on tertiary terrain before and during Cyclone Bola, East Coast, North Island, New Zealand. New Zealand Journal of Forestry Science, 23(3), 255-263.

Mason, D., Justice, R., \& Saul, G. (2018). Kaikōura earthquake slope hazards-risk mitigation and network resilience.

Mason, D. P., \& Little, T. A. (2006). Refined slip distribution and moment magnitude of the 1848 Marlborough earthquake, Awatere Fault, New Zealand. New Zealand Journal of Geology and Geophysics, 49(3), 375-382.

Massey, C., Townsend, D., Rathje, E., Allstadt, K. E., Lukovic, B., Kaneko, Y., Bradley, B., Wartman, J., Jibson, R. W., Petley, D., et al. (2018). Landslides triggered by the 14 november 2016 mw 7.8 Kaikōura earthquake, New Zealand. Bulletin of the Seismological Society of America, 108(3B), 1630-1648.

Massey, C. I., Petley, D. N., \& McSaveney, M. (2013). Patterns of movement in reactivated landslides. Engineering geology, 159, 1-19.

Massey, C., Della Pasqua, F., Taig, T., Lukovic, B., Ries, W., Heron, D., \& Archibald, G. (2014). Canterbury Earthquakes 2010/11 Port Hills slope stability: Risk assessment for redcliffs. GNS Science, Wellington, New Zealand, 123.

Massey, C., Taig, T., Della Pasqua, F., Lukovic, B., Ries, W., \& Archibald, G. (2014). Canterbury Earthquakes 2010/11 Port Hills slope stability: Debris avalanche risk assessment for richmond hill. GNS Science Consultancy Report, 34.

Massey, C., Townsend, D., Dellow, S., Lukovic, B., Rosser, B., Archibald, G., Villeneuve, M., Davidson, J., Jones, K., Morgenstern, R., et al. (2018). Kaikoura earthquake short term project: Landslide inventory and landslide dam assessments. GNS Science report, 19, 45.

Massey, C., Townsend, D., Lukovic, B., Morgenstern, R., Jones, K., Rosser, B., \& de Vilder, S. (2020). Landslides triggered by the mw7. 814 november 2016 Kaikōura earthquake: An update. Springer Nature, 17(10), 2401-2408.

McColl, S. T. (2015). Landslide causes and triggers. Landslide hazards, risks and disasters (pp. 17-42). Elsevier. 
Meunier, P., Hovius, N., \& Haines, J. A. (2008). Topographic site effects and the location of earthquake induced landslides. Earth and Planetary Science Letters, $275(3-4), 221-232$.

Nakamura, S., Wakai, A., Umemura, J., Sugimoto, H., \& Takeshi, T. (2014). Earthquakeinduced landslides: Distribution, motion and mechanisms. Soils and Foundations, 54(4), 544-559.

Nemcok, A. (1972). Classification of landslides and other mass movements. Rock mechanics, 4, 71-78.

Ng, K., \& Petley, D. (2009). The use of pore pressure reinflation testing in landslide management in Hong Kong. Quarterly Journal of Engineering Geology and Hydrogeology, 42. https://doi.org/10.1144/1470-9236/08-008

Page, M., Trustum, N., \& Gomez, B. (2000). Implications of a century of anthropogenic erosion for future land use in the Gisborne-East Coast Region of New Zealand. New Zealand Geographer, 56(2), 13-24.

Parker, R., Hancox, G., Petley, D., Massey, C., Densmore, A., \& Rosser, N. (2015). Spatial distributions of earthquake-induced landslides and hillslope preconditioning in northwest South Island, New Zealand. Earth surface dynamics., 3(4), 501525.

Petley, D. N., Bulmer, M. H., \& Murphy, W. (2002). Patterns of movement in rotational and translational landslides. Geology, 30(8), 719-722.

Petley, D., Carey, J., Ng, K., Massey, C., \& Froude, M. (2017). Understanding patterns of movement for slow moving landslides. 20th Symposium of the New Zealand Geotechnical Society, 24-26.

Quigley, M., Van Dissen, R., Litchfield, N., Villamor, P., Duffy, B., Barrell, D., Furlong, K., Stahl, T., Bilderback, E., \& Noble, D. (2012). Surface rupture during the 2010 mw 7.1 Darfield (Canterbury) earthquake: Implications for fault rupture dynamics and seismic-hazard analysis. Geology, 40(1), 55-58.

Rattenbury, M. S., Townsend, D., \& Johnston, M. R. (2006). Geology of the Kaikoura area (Vol. 1). Institute of Geological \& Nuclear Sciences.

Rattenbury, M., \& Isaac, M. (2012). The qmap 1: 250000 geological map of New Zealand project. New Zealand Journal of Geology and Geophysics, 55(4), 393405. 
Reese, S. (2013). Part one: Introduction to Triaxial Testing (tech. rep.). GDS Instruments. https://www.gdsinstruments.com/__assets_-_ pagepdf/000037/Part\% 201\%20Introduction\%20to\%20triaxial\%20testing.pdf

Rosser, B., Dellow, S., Haubrock, S., \& Glassey, P. (2017). New Zealand's national landslide database. Landslides, 14 (6), 1949-1959.

Rosser, B., Jones, K., Massey, C., Ashraf, S., Strawbridge, G., \& Morris, S. (2020). Quantifying the effects of the m7. 8 november 14, 2016 earthquake on rainfallinduced landslide triggering and reactivation, Kaikoura, New Zealand. EGU General Assembly Conference Abstracts, 12409.

Sassa, K. et al. (2000). Mechanism of flows in granular soils. ISRM international symposium.

Sassa, K., Fukuoka, H., Scarascia-Mugnozza, G., \& Evans, S. (1996). Earthquakeinduced-landslides: Distribution, motion and mechanisms. Soils and Foundations, 36, 53-64.

Sassa, K., Fukuoka, H., Wang, G., \& Ishikawa, N. (2004). Undrained dynamic-loading ring-shear apparatus and its application to landslide dynamics. Landslides, 1 (1), $7-19$.

Schulz, W. H., McKenna, J. P., Kibler, J. D., \& Biavati, G. (2009). Relations between hydrology and velocity of a continuously moving landslide - evidence of porepressure feedback regulating landslide motion? Landslides, 6(3), 181-190.

Schuster, R. L., \& Highland, L. (2001). Socioeconomic and environmental impacts of landslides in the western hemisphere. US Department of the Interior, US Geological Survey Denver (CO).

Selby, M. J. (1982). Hillslope materials and processes. Hillslope materials and processes.

Shieh, C.-L., Chen, Y., Tsai, Y., \& Wu, J. (2009). Variability in rainfall threshold for debris flow after the Chi-Chi earthquake in central Taiwan, China. International Journal of Sediment Research, 24(2), 177-188.

State of New York Department of Transport Geotechnical Engineering Bureau. (2015). Geotechnical test method: Test method for liquid limit, plastic limit, and plasticity index, GTM-7 Revision \#2 (tech. rep. EB 15-025). State of New York Department of Transport Geotechnical Engineering Bureau. New York. https: 
//www.dot.ny.gov/divisions/engineering/technical-services/technical-servicesrepository/GTM-7b.pdf

Stringer, J., Brook, M. S., \& Justice, R. (2020). Post-earthquake monitoring of landslides along the southern Kaikōura transport corridor, New Zealand. Landslides, $1-15$.

Tang, C., Zhu, J., Li, W., \& Liang, J. (2009). Rainfall-triggered debris flows following the Wenchuan earthquake. Bulletin of Engineering Geology and the Environment, 68(2), 187-194.

Tang, C., Zhu, J., Qi, X., \& Ding, J. (2011). Landslides induced by the Wenchuan earthquake and the subsequent strong rainfall event: A case study in the Beichuan area of China. Engineering Geology, 122(1-2), 22-33.

Terzaghi, K. v. (1936). The shearing resistance of saturated soils and the angle between the planes of shear. First international conference on soil Mechanics, 1936, 1, $54-59$.

Terzaghi, K. (1925). Erdbaumechanik auf bodenphysikalischer grundlage. F. Deuticke.

Tiranti, D., Crema, S., Cavalli, M., \& Deangeli, C. (2018). An integrated study to evaluate debris flow hazard in alpine environment. Frontiers in Earth Science, 6,60 .

Varnes, D. J. (1958). Landslide types and processes. Landslides and engineering practice, 24, 20-47.

Varnes, D. J. (1978). Slope movement types and processes. Special report, 176, 11-33.

Voight, B. (1988a). Materials science law applies to time forecasts of slope failure. Symposium international sur les glissements de terrain. 5, 1471-1472.

Voight, B. (1988b). A method for prediction of volcanic eruptions. Nature, 332(6160), 125-130.

Wang, F., Sassa, K., \& Wang, G. (2002). Mechanism of a long-runout landslide triggered by the august 1998 heavy rainfall in Fukushima Prefecture, Japan. Engineering Geology, 63(1-2), 169-185.

Wang, G., \& Sassa, K. (2002). Post-failure mobility of saturated sands in undrained load-controlled ring shear tests. Canadian Geotechnical Journal, 39(4), 821-837. 
Wang, G., \& Sassa, K. (2003). Pore-pressure generation and movement of rainfallinduced landslides: Effects of grain size and fine-particle content. Engineering geology, 69(1-2), 109-125.

Wang, G., Sassa, K., Fukuoka, H., \& Tada, T. (2007). Experimental study on the shearing behavior of saturated silty soils based on ring-shear tests. Journal of geotechnical and geoenvironmental engineering, 133(3), 319-333.

Xu, Q., Zhang, S., \& Li, W. (2011). Spatial distribution of large-scale landslides induced by the 5.12 Wenchuan earthquake. Journal of Mountain Science, 8(2), 246.

Yin, Y. (2011). Recent catastrophic landslides and mitigation in China. Journal of Rock Mechanics and Geotechnical Engineering, 3(1), 10-18.

Zachariasen, J., Berryman, K., Langridge, R., Prentice, C., Rymer, M., Stirling, M., \& Villamor, P. (2006). Timing of late holocene surface rupture of the Wairau Fault, Marlborough, New Zealand. New Zealand Journal of Geology and Geophysics, $49(1), 159-174$. 
Appendix A 


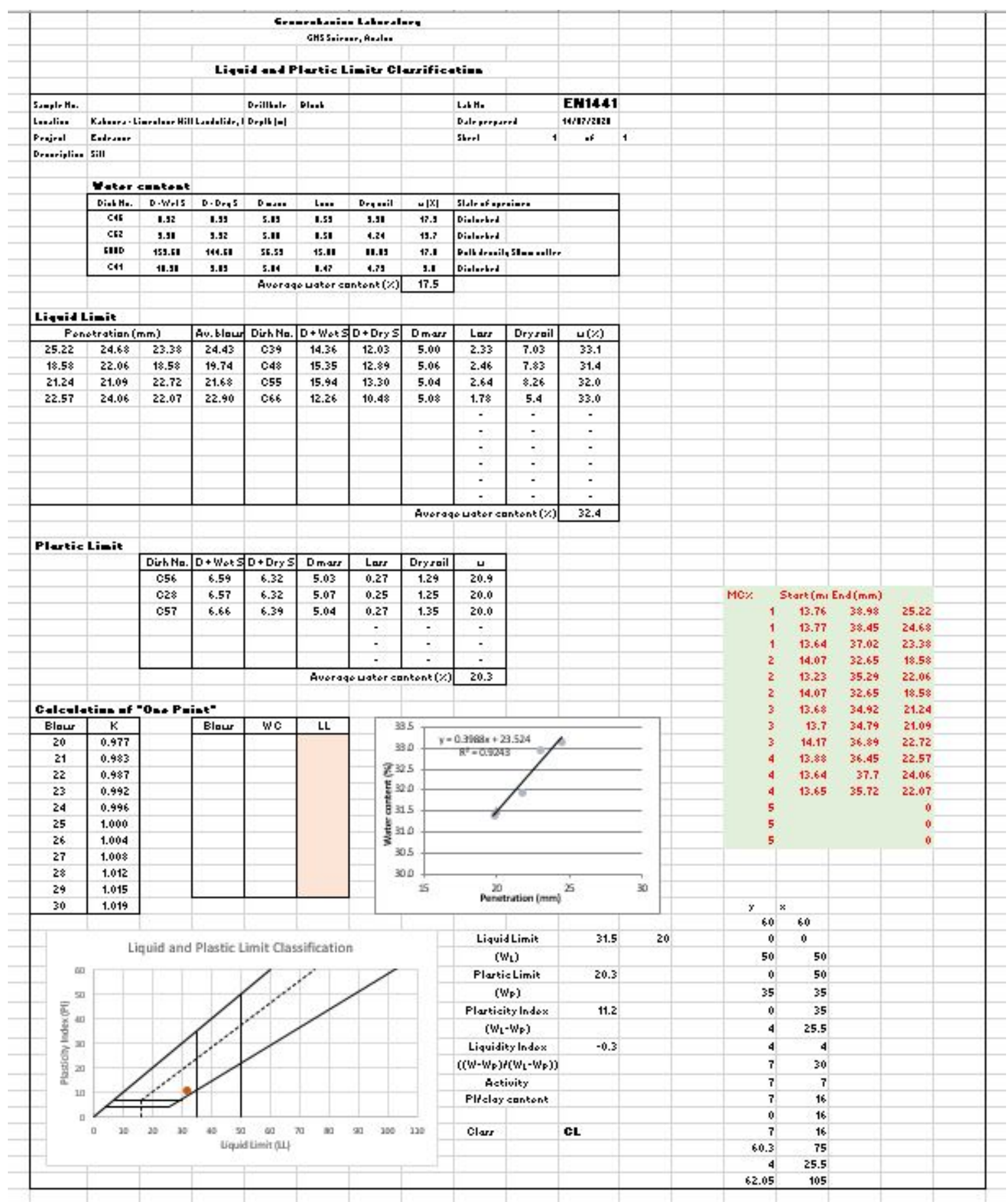

Figure A.1: Limestone Hills Landslide (LHL) liquid and plastic limit raw laboratory data 


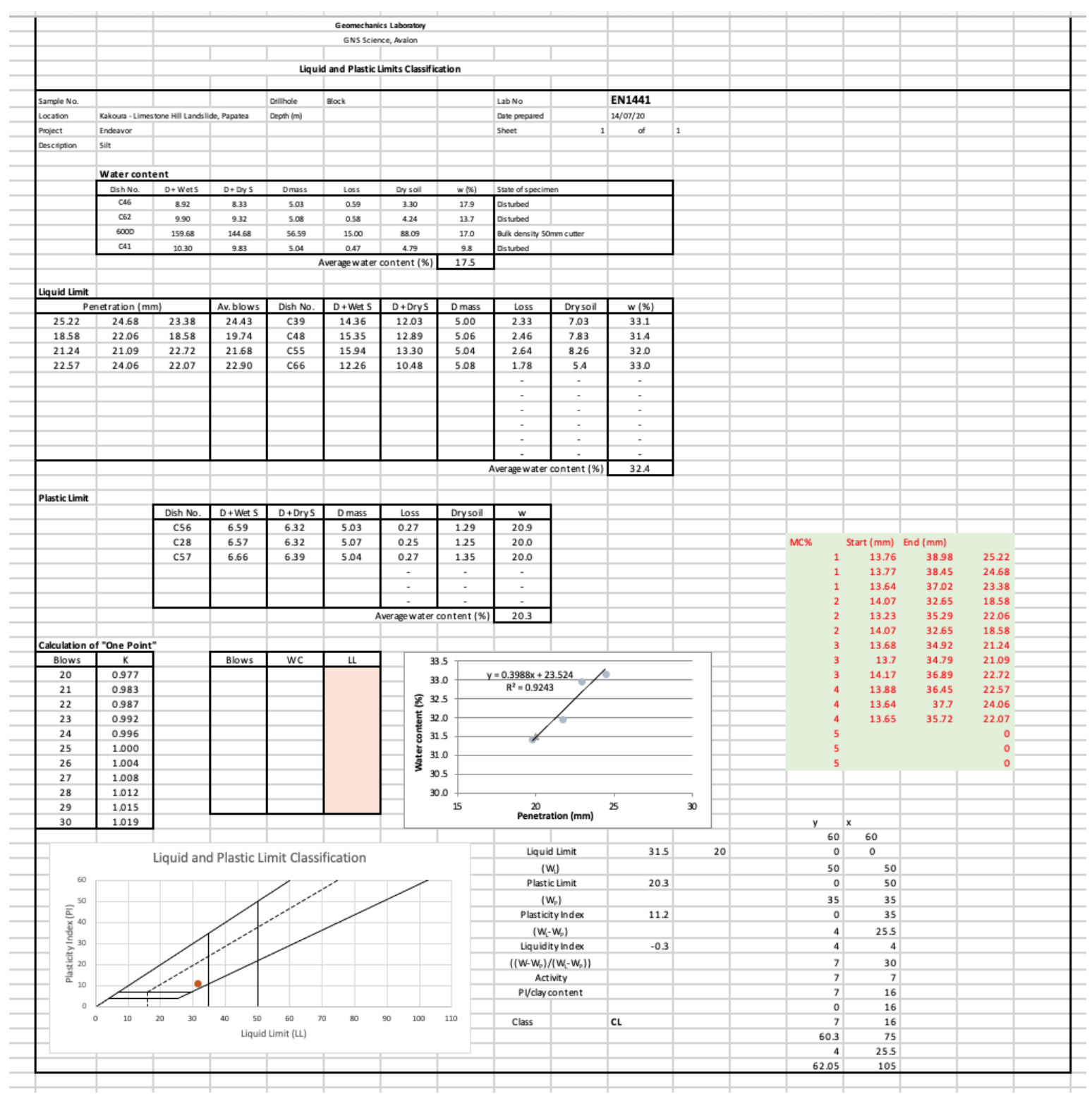

Figure A.2: Leader Dam Landslide (LDL) liquid and plastic limit raw laboratory data 


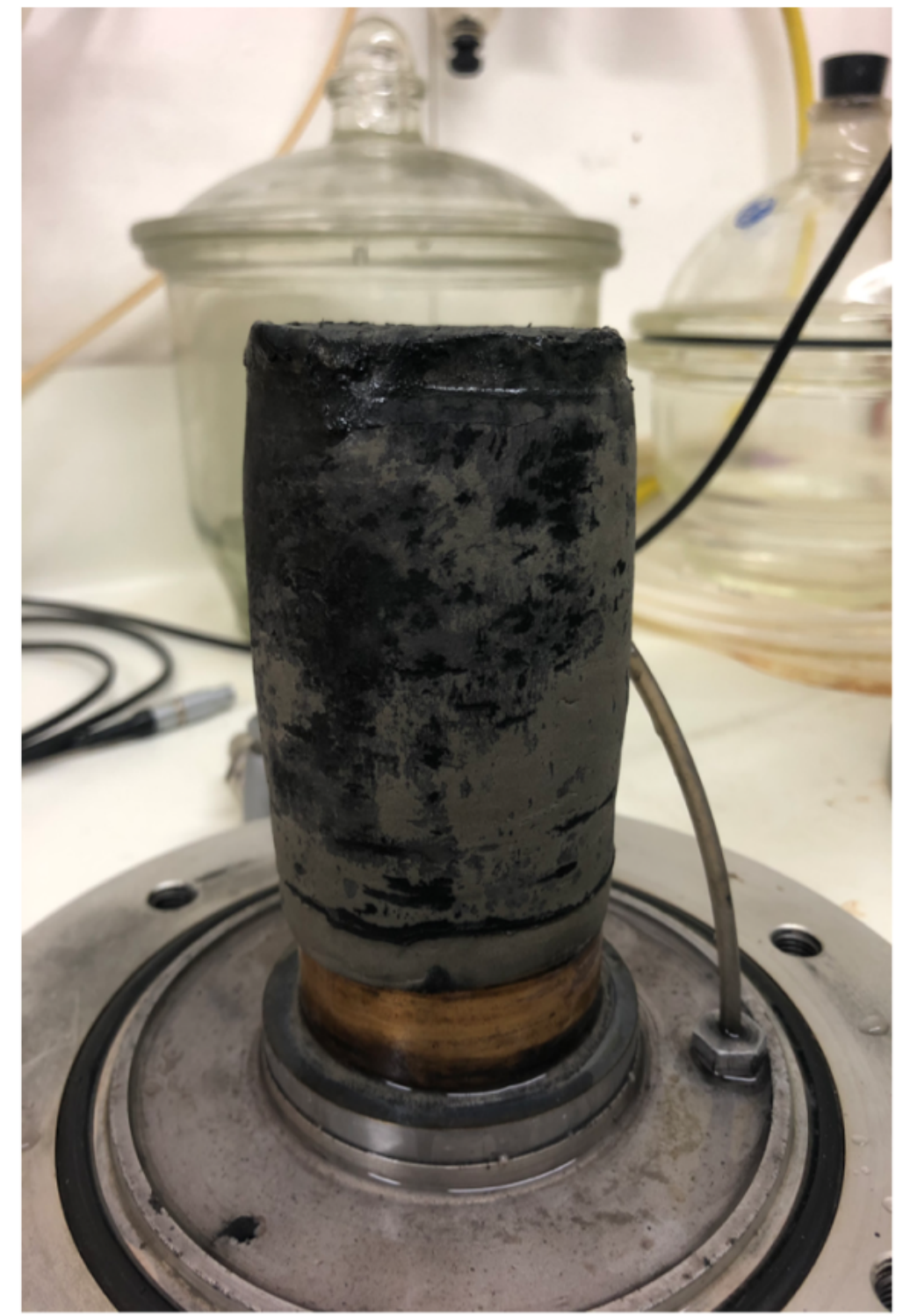

Figure A.3: Post test photograph of LDL PPR3 demonstrating sample barrelling 


\begin{tabular}{cc} 
Test Reference & Initial Sample Density $\left(\mathrm{g} / \mathrm{m}^{3}\right)$ \\
\hline LHL PPR1 & 2.09 \\
LHL PPR2 & 2.09 \\
LHL PPR3 & 2.10 \\
& \\
LDL PPR1 & 2.17 \\
LDL PPR2 & 2.07 \\
LDL PPR3 & 2.08 \\
LDL PPR4 & 2.07 \\
\hline
\end{tabular}

Table A.1: Table summarising initial test densities after producing a remoulded sample for each PPR test 
